

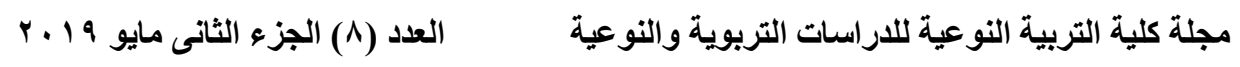

electronic content in the two types of graphic organizations (Fixed and mobile), and the research tools were prepared, which were the conceptual learning test and attitudes scale, and the treatments and tools were applied to a sample of the first stage students of basic education, divided into two equal groups, and the results revealed the effectiveness of using graphic organizations, and that the animated graphic organizations are more effective. From the static graphic organizations, and an effect of the interaction between the learning style (sequential and macro) was found, as the results showed that the students in each of the two designs to organize the electronic content (static - mobile) obtained a degree of mastery $(90 \%)$ of the total score of the achievement test. It was also found that there is a statistically significant difference between the mean scores in the test in favor of the sequential design. As well as the high size of the impact of the two designs (fixed and moving) on cognitive achievement and the trend towards it.

key words:E-learning environments - advanced graphic organizations learning style (sequential - macro) - concepts - geographical concepts trends

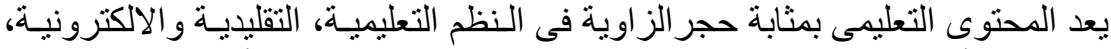

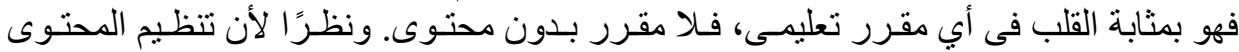

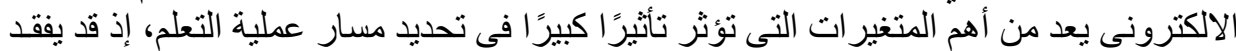

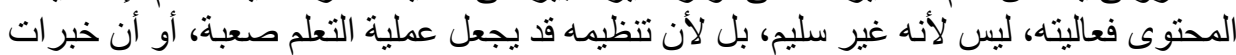

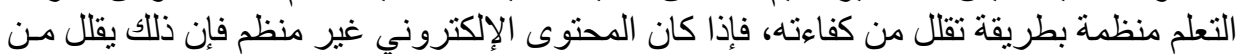

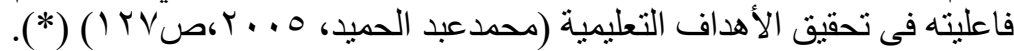

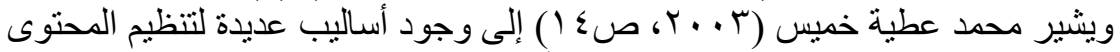

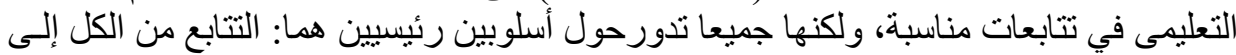

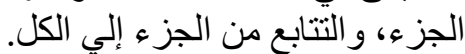

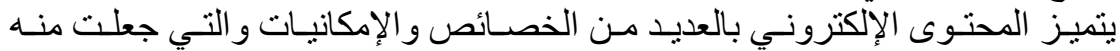

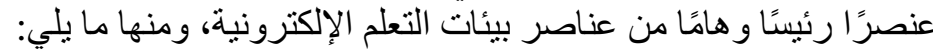

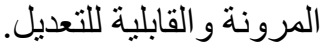

(*) تم الالنزام بقو اعد التوثيق وفق قو اعد الجمعية الامريكية لعلم النفس(6) APA الإصدار السادس، وبالنسبة

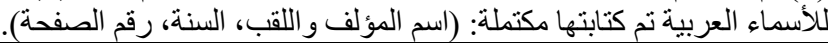




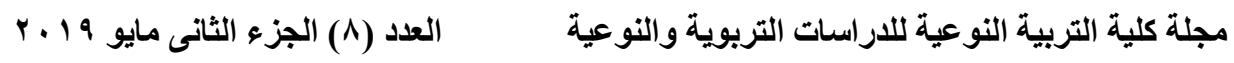

يتضمن وسائط متعددة (صوت مقادئا صورة -ـرسوم-فيديو -......) تدعم عملية التعلم.

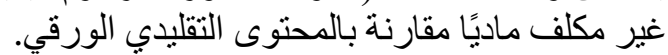

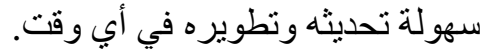

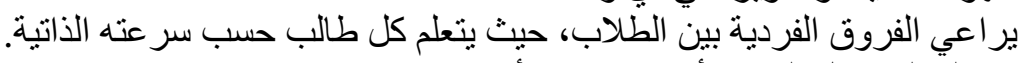
سهولة الوصول إليه في أي وقت ومن الطنابي أي مكان.

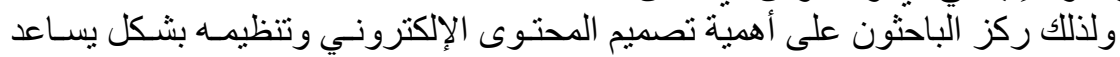

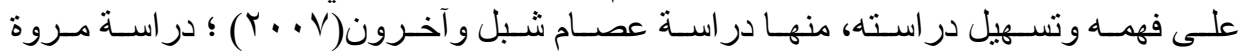

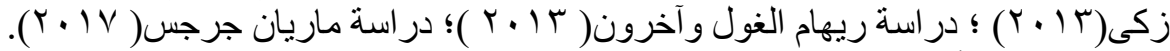

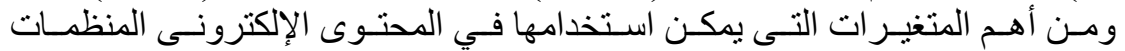

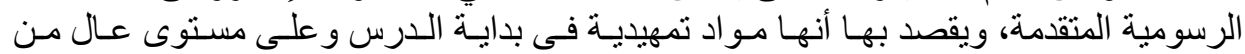

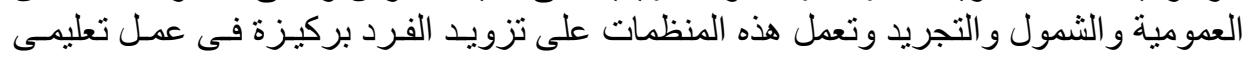

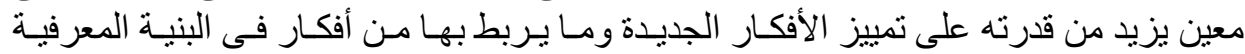

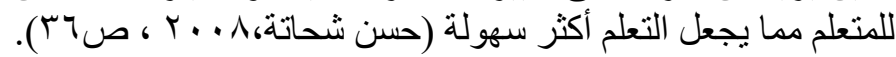

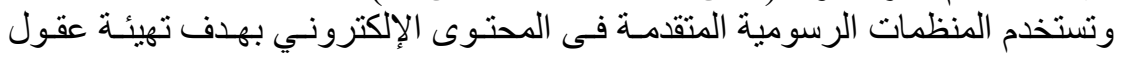

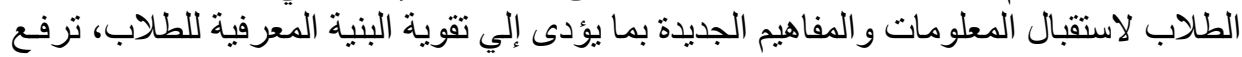

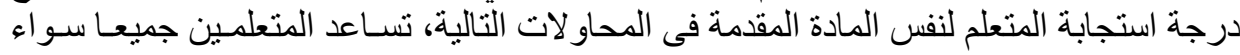

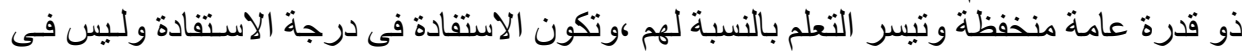

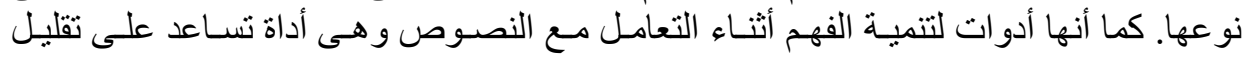

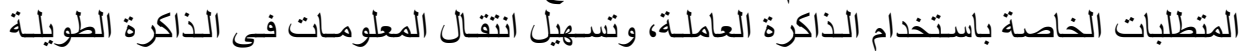

الددى (Singleton \& Filce,2015,p110)

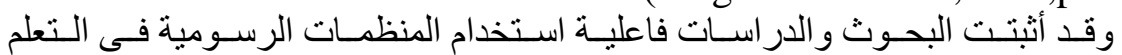

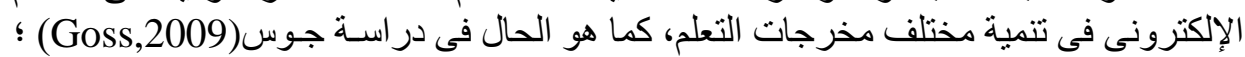

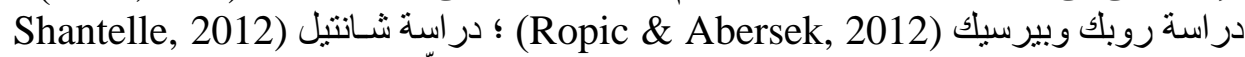

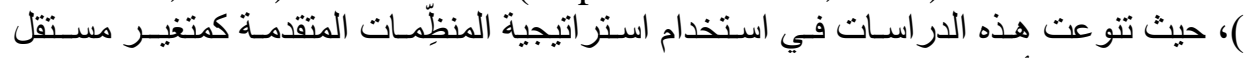

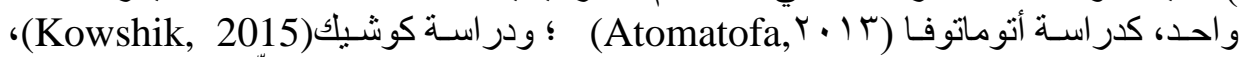

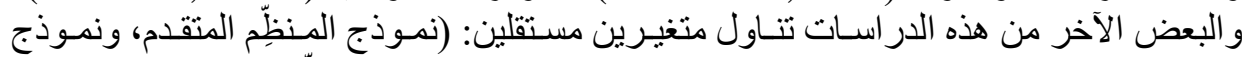

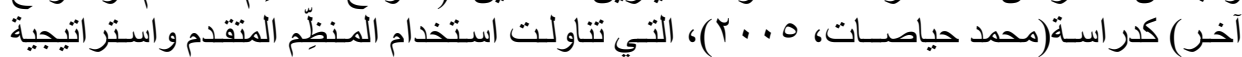

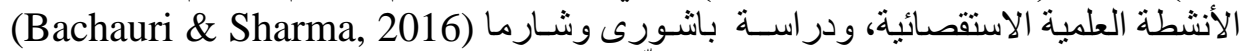

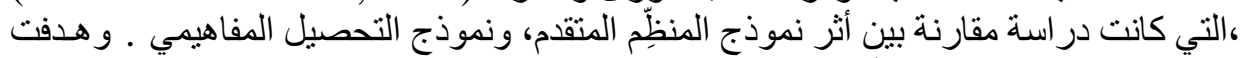

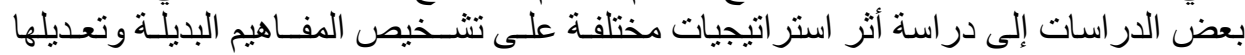

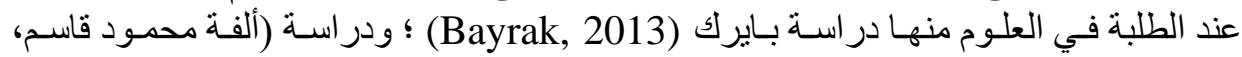

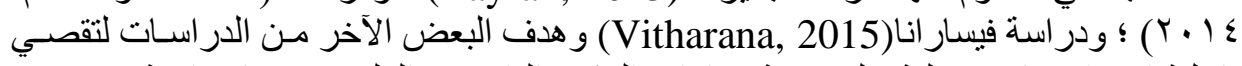

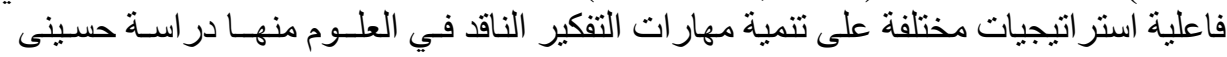

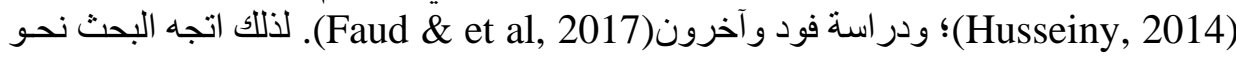

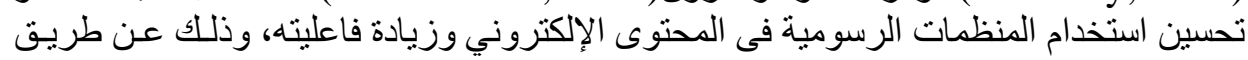




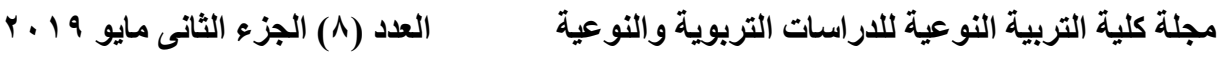

در اسة متغير ات تصميمها، ومن أهم هذه المتغير ات أنماط المنظمـات الثابتـة، وأنمـاط المنظمـات

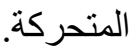

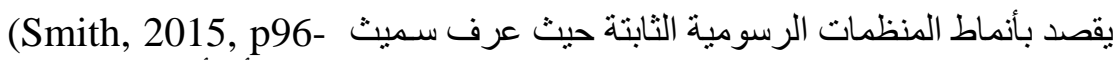

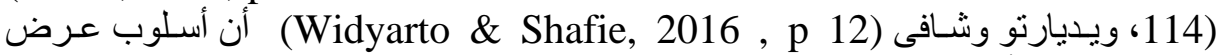

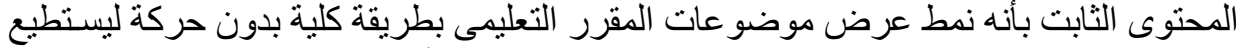

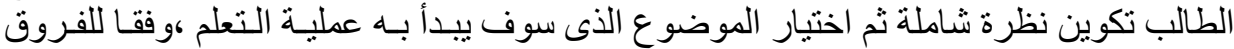

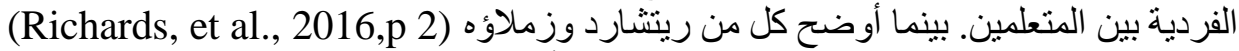

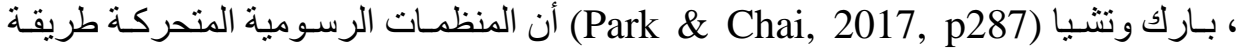

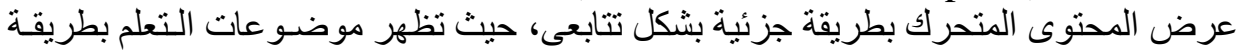

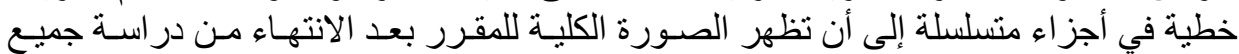

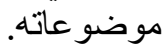

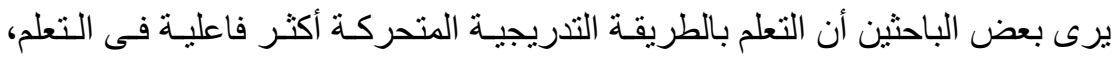

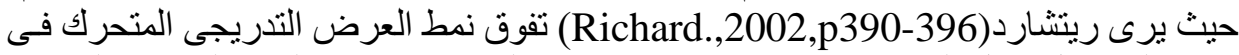

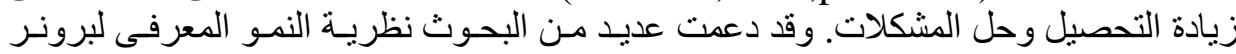

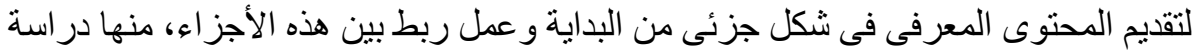
Taber\& Susan,2009,p148)؛(Kevin, Geraldi,2008,p.75

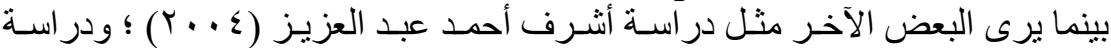

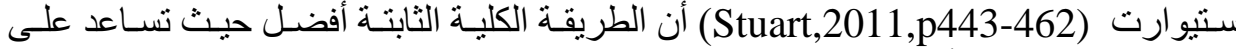

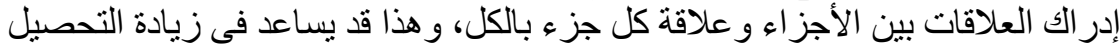

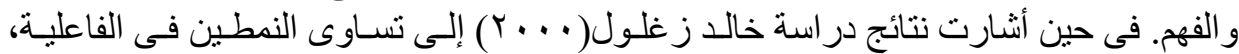

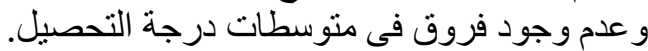

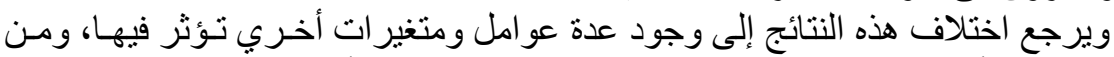

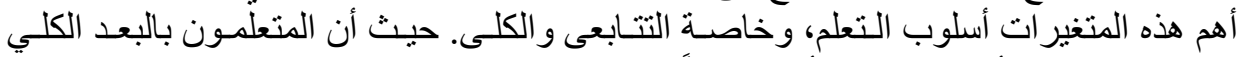

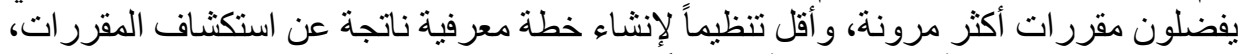

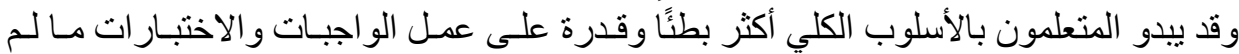

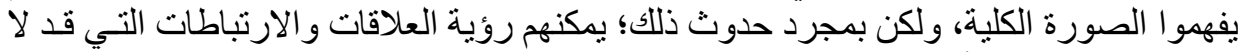
يدركها المتعلمون بالأسلوب التتابعي. (Nor \& Siti, 2006).

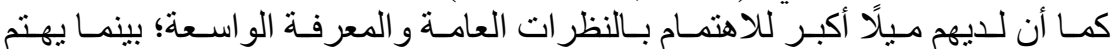

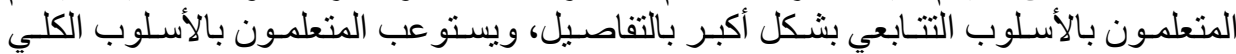

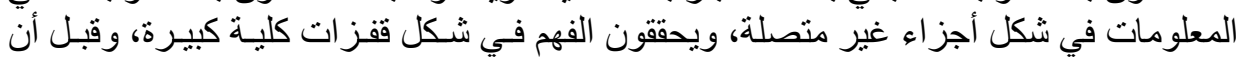

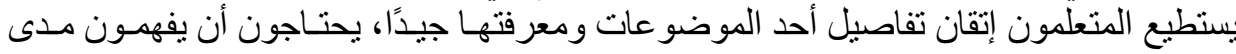

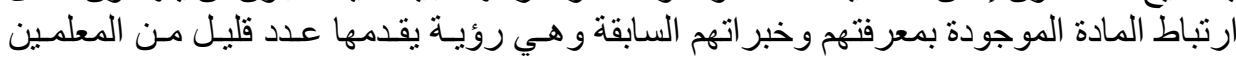

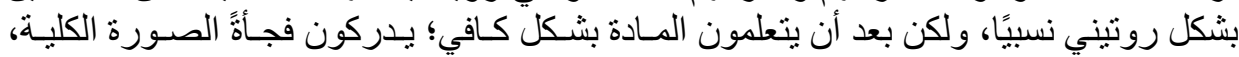

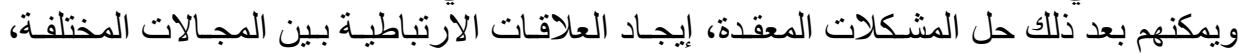




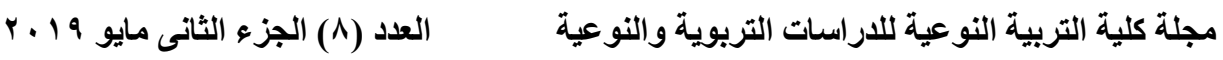

و الربط بين الأشياء بطرق ابتكارية، غير أنه قد تو اجههم بعض الصسعوبات في نوضيح كيفيـة فعل ذلك (Kinshuk, 2004) .

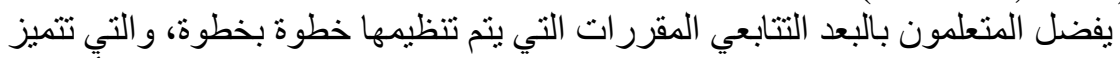

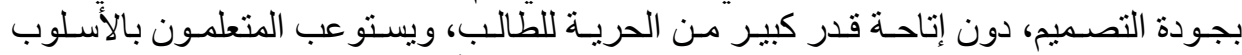

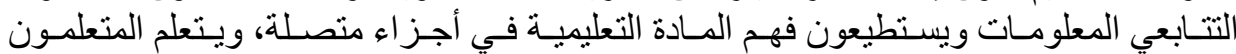
بالأسلوب التتابعي في خطوات تدريجية صغيرة، ولذلك يتميزون بالتقان التقام الخطي في التعلم، كمـا يتبعون مسار ات منطقية الخطوات في في إيجاد الحلول. وتناول كل جر اف وكينشوك وليو وليو (Graf, Kinshuk\& Liu, 2009) ؛ ومنبيدرو

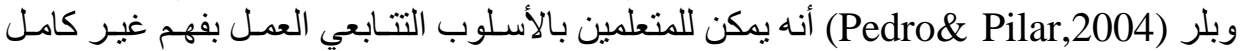

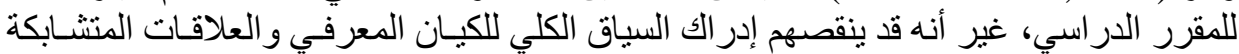
بين موضو عاته ونظمه المئ.

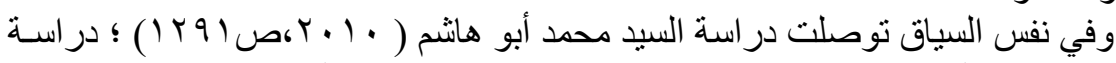

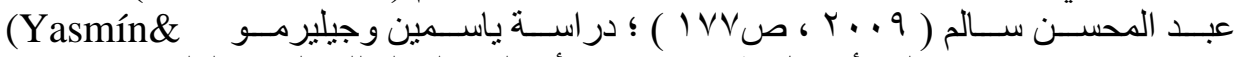

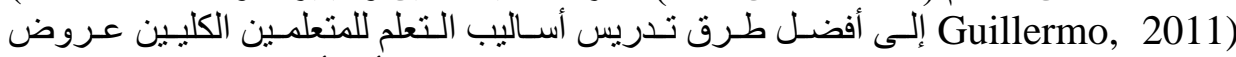

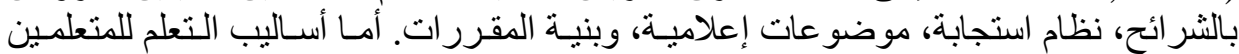

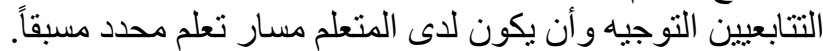

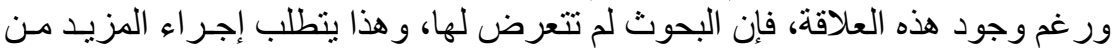

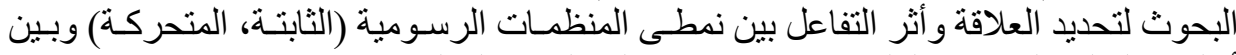

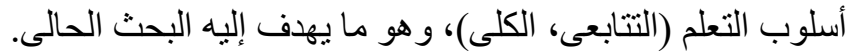

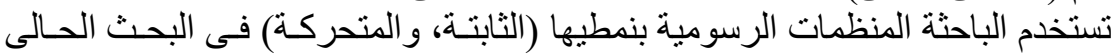

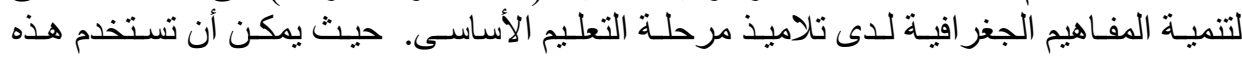

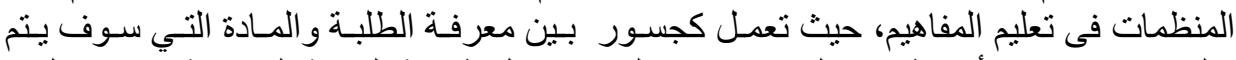

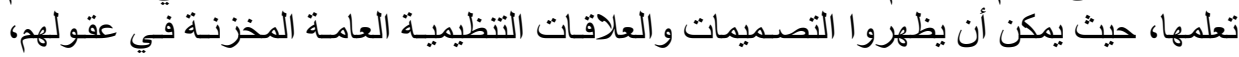

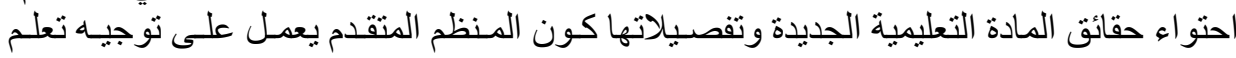

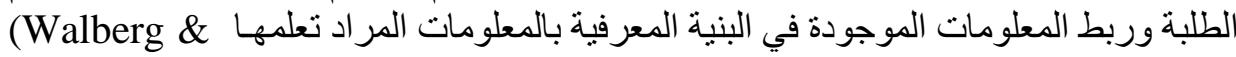

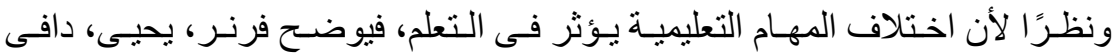

Paik,20oo)

(Duffy, Yahya, Furner, 2005, p 23)

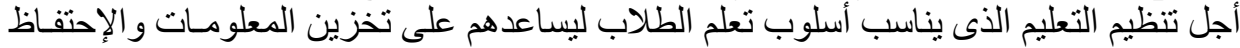

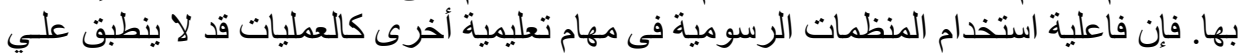

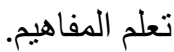

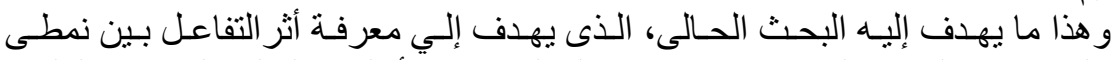

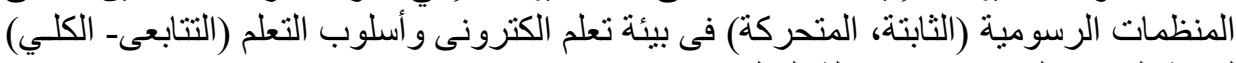
لتنمية المفاهيم لدي تلاميذ مرحلة التعليم الاساسي. 


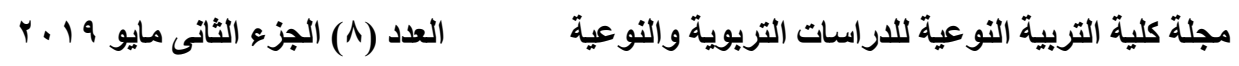

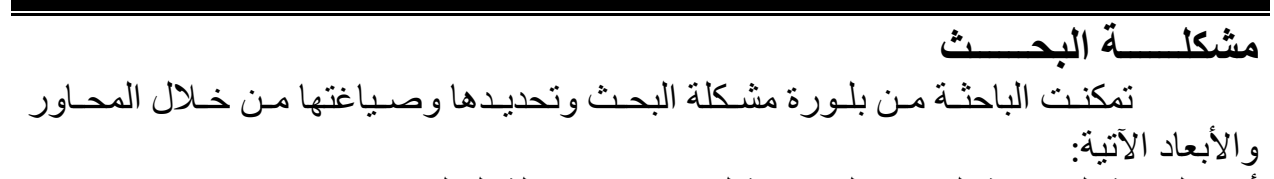

أولا:الحاجة إلى تتمية المفاهيم الجغر افية لدي تلاميذ مرحلة التعليم الاساسي.

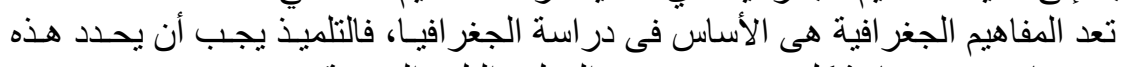

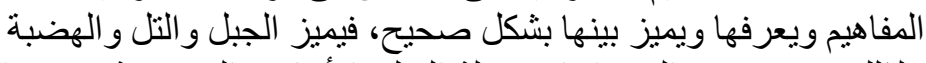

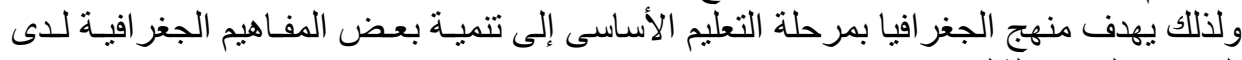

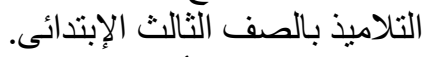

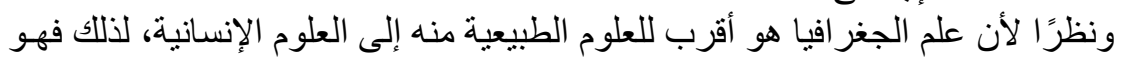

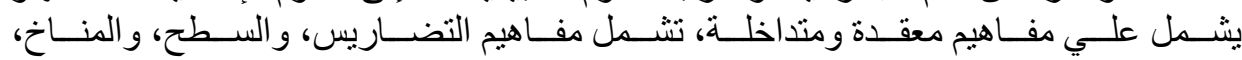

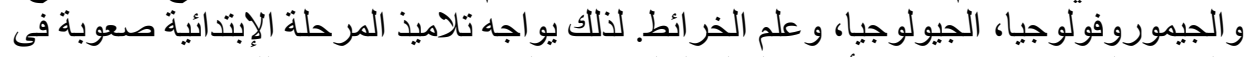

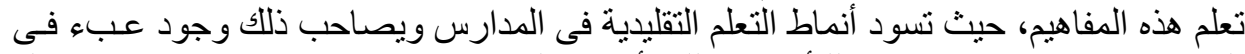

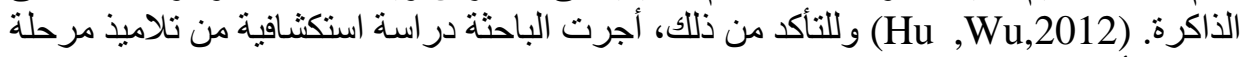

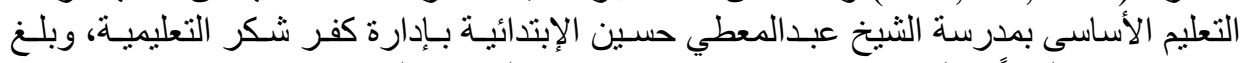

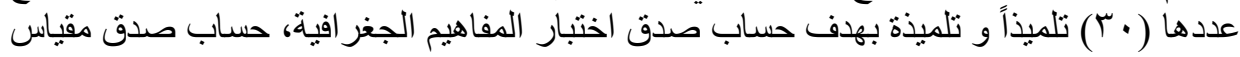
الإتجاه

وتوصلت إلى أن قيمة معامل الثبات لاختبار المفاهيم الجغر افية قيمـة كبيرة ومرتفعـة؛

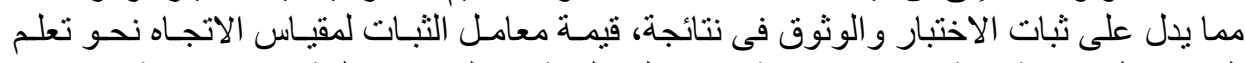

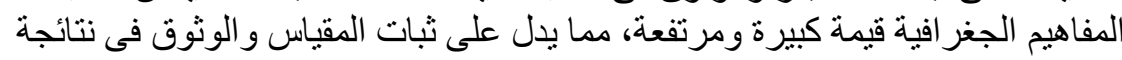

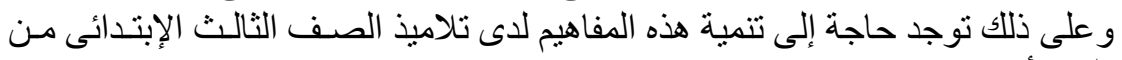

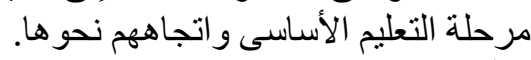

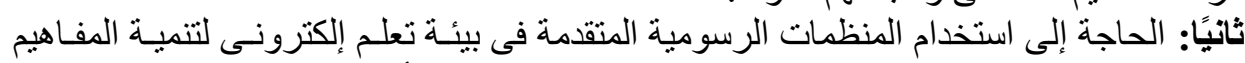

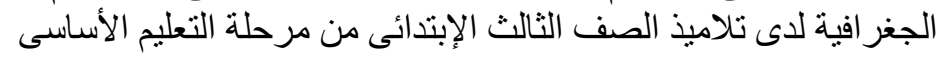

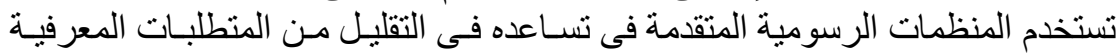

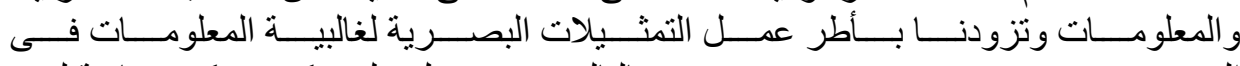

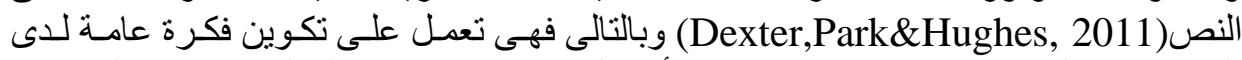

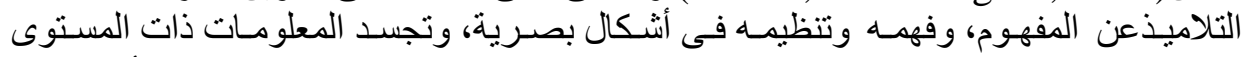

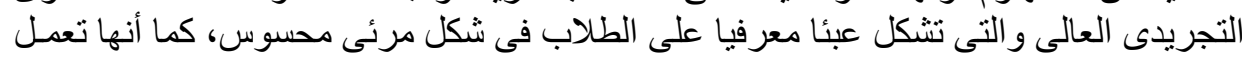

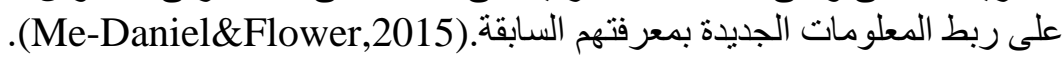

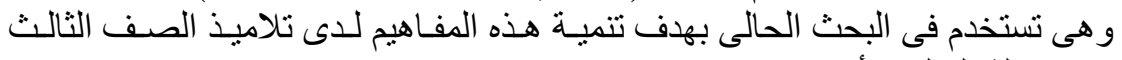

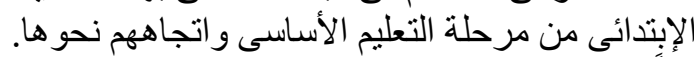

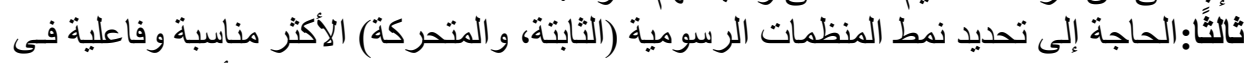

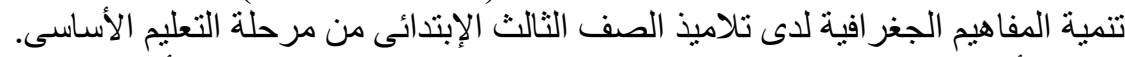

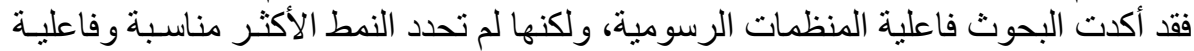
فى تعلم المفاهيم، حيث يختلف تأثير هذه المنظمات باختلاف طبيعة الرنية المهام التعليمية. 


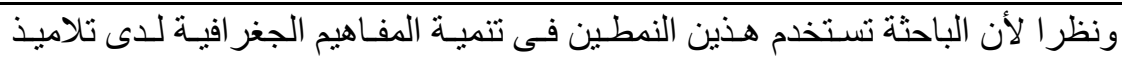

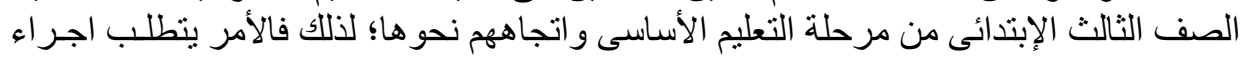

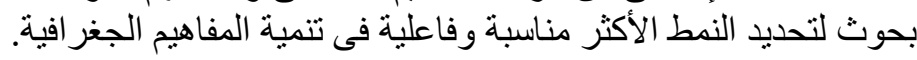

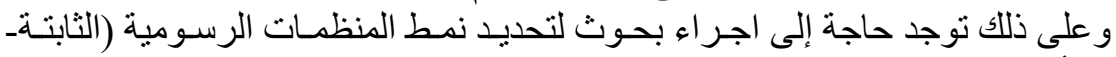

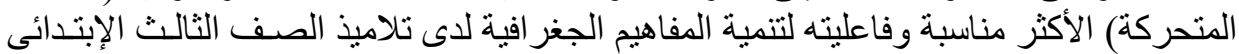

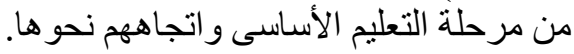

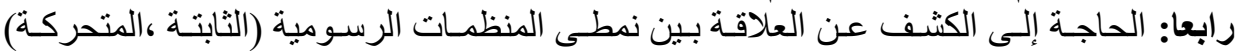

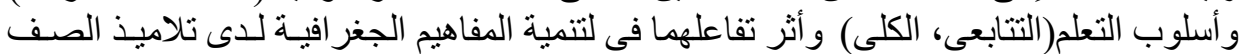

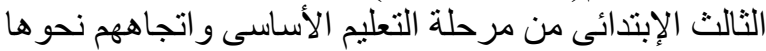

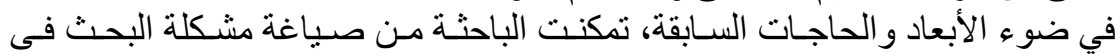

العبارة التقريرية الآتية: - الابعاد

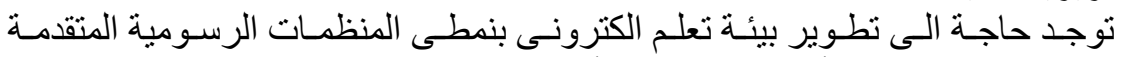

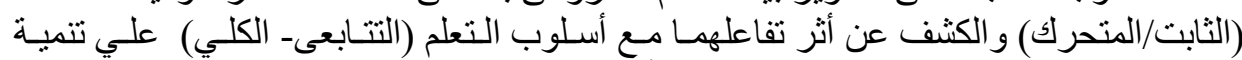

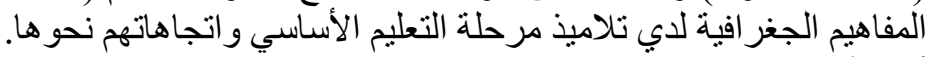

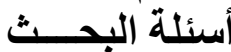

في ضوء ما سبق تمكنت الباحثة من تحديد المشكلة فى السؤال الرئيسى الآتى:

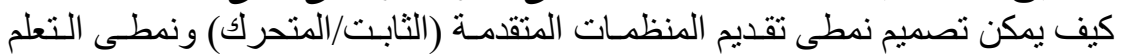

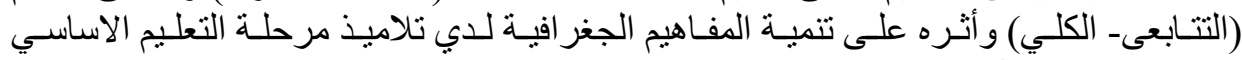

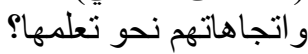

ويتفرع من السؤال السابق الأسئلة الفرعية الآتية:

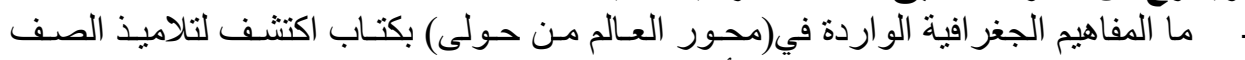

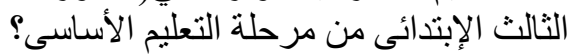

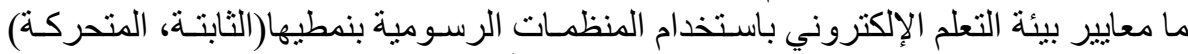

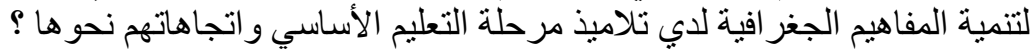

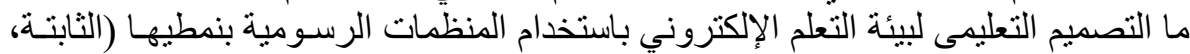

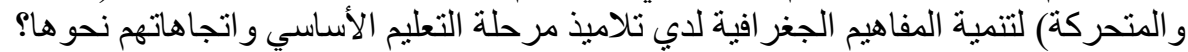

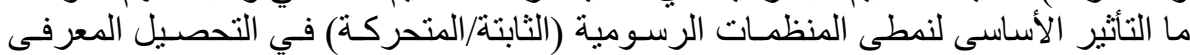

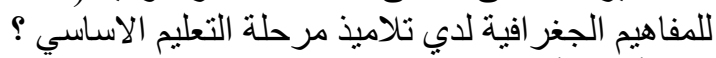

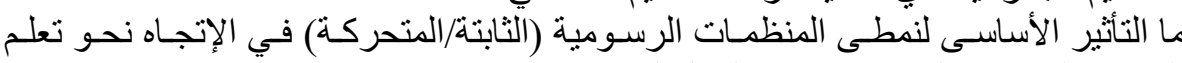

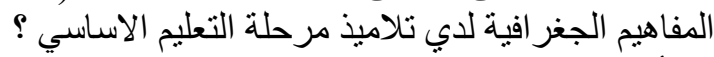

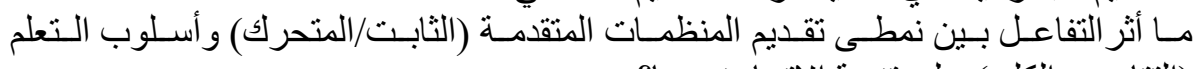

(التتابعى- الكلي) على تنمية الإتجاه نحو لفئ 
يهدف البحث إلى تنمية المفاهيم الجغر افية لدي تلاميذ مرحلـة التعليم الاساسي، وذلك

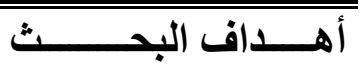

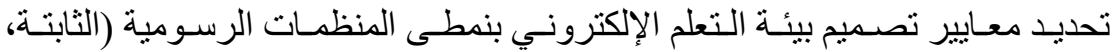

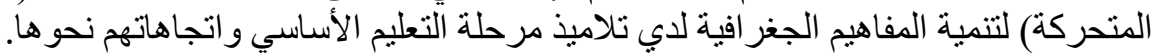

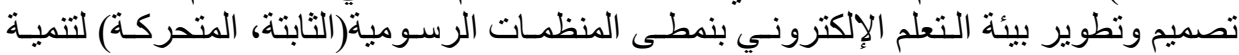

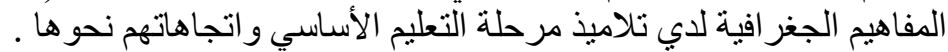

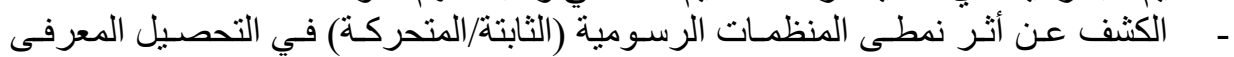

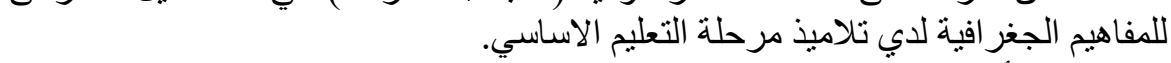

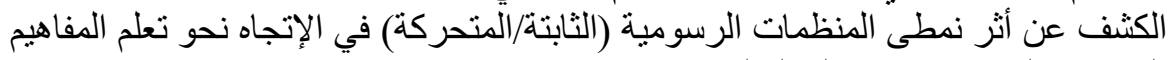

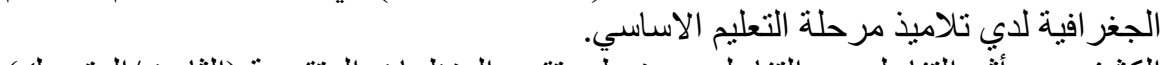

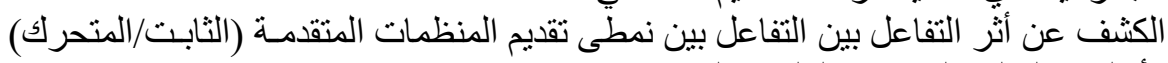

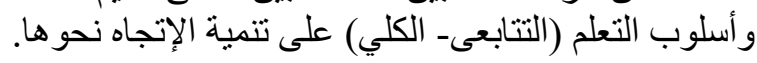
عينة البحث

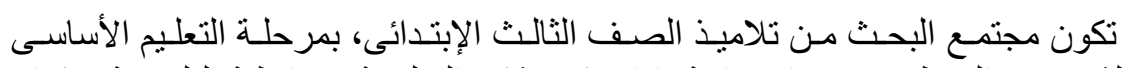

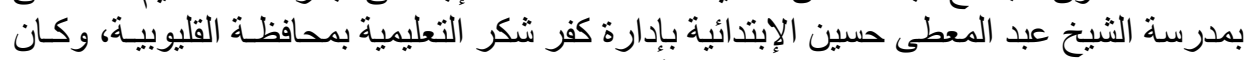

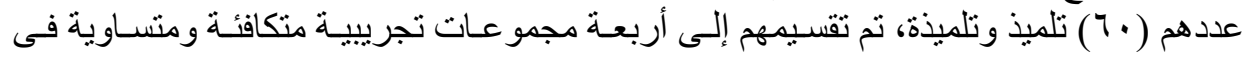

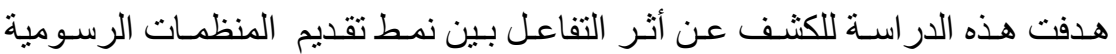

$$
\text { متغــيرات البحث }
$$

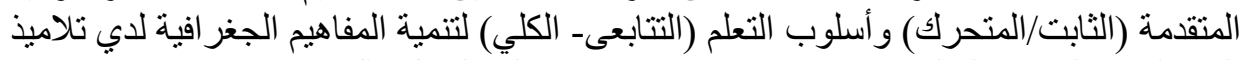

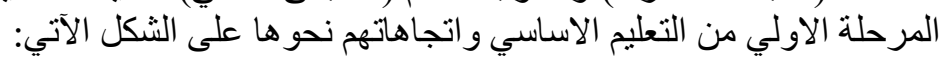

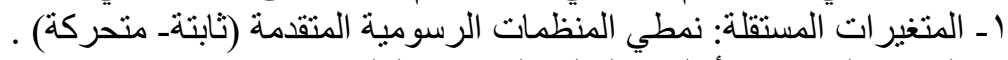

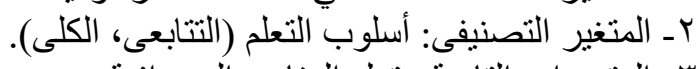

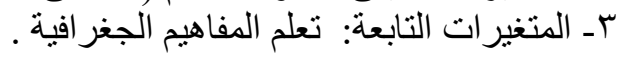

\section{منهج البحث}

نظر الأن البحث الحالى (Method Research Development) يعد فى تكنولوجيـا

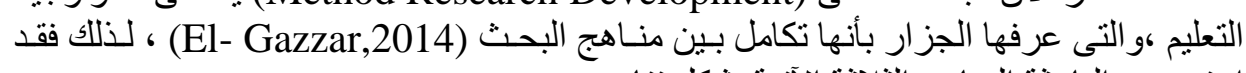

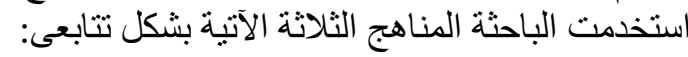

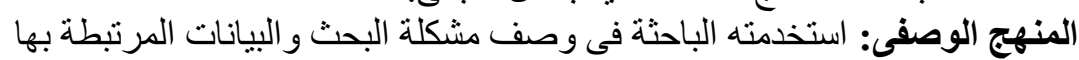

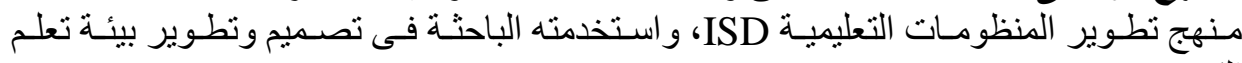

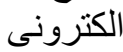
المنهج التجريبيى : استخدمته الباحثة لمعرفة أثر المتغير ات المستقلة على المتغيرات التابعة. 


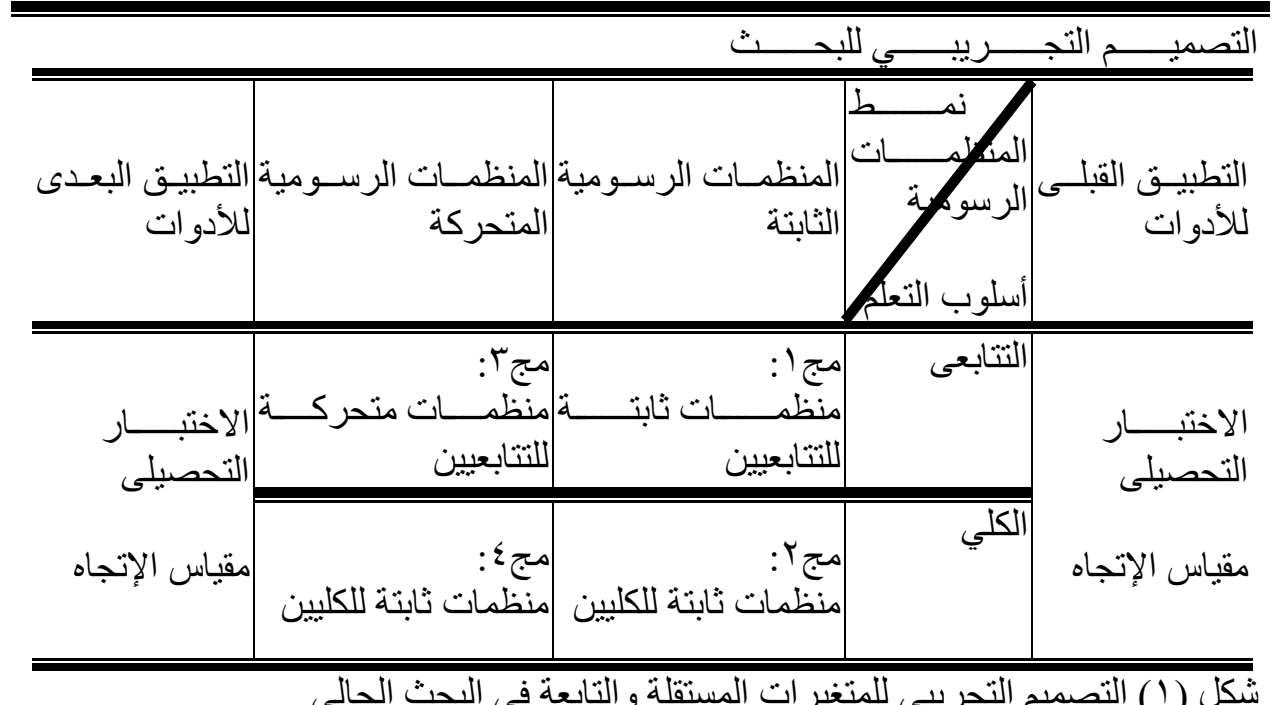

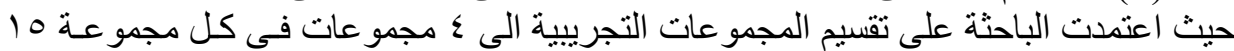

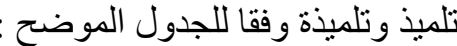

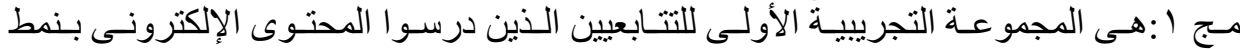

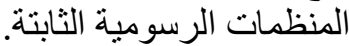

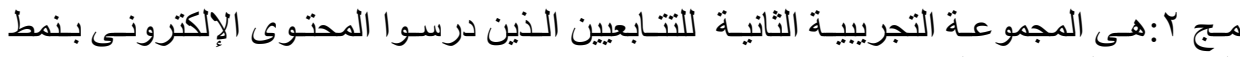
المنظمات الرسومية المتحركة. المبه

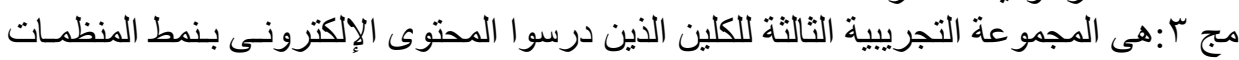

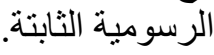
مج ؟ :هى المجمو عة التجريبية الر ابعة للكلين الذين درسوا المحتوى الإلكترونى بنمط المنظمـات

$$
\text { فــــروضة البحركة. }
$$

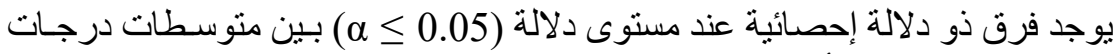

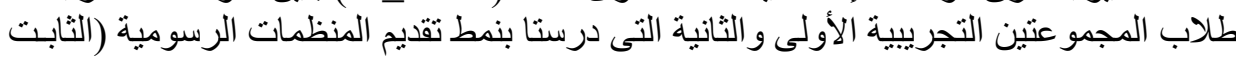

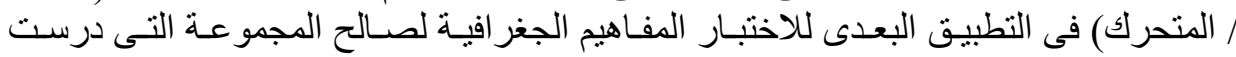

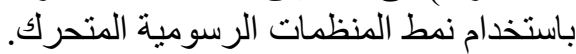

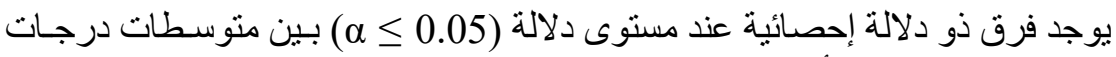

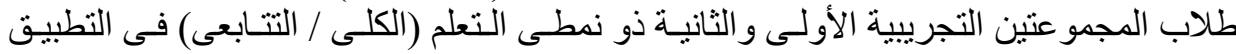

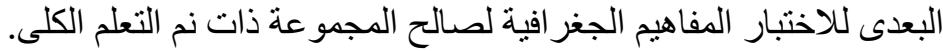




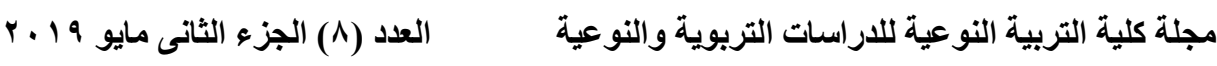

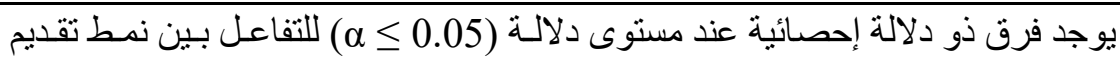

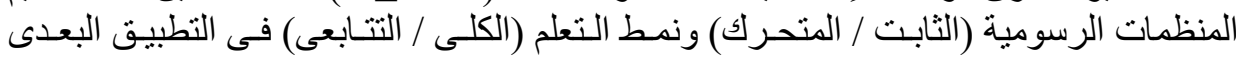
لاختبار المفاهيم الجغر افية.

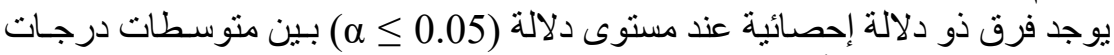

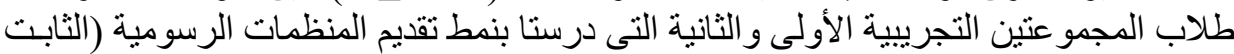

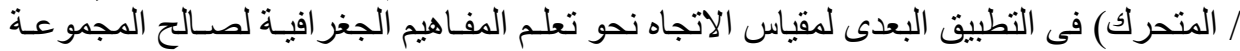

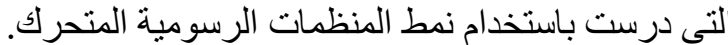
يوجد فرق ذو دلالة إحصائية عند مستوى دلالة (

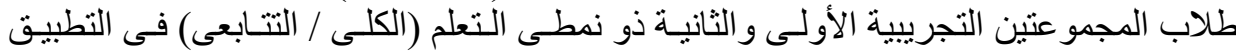

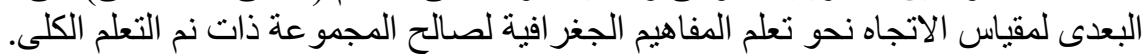

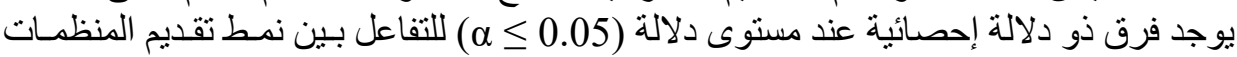

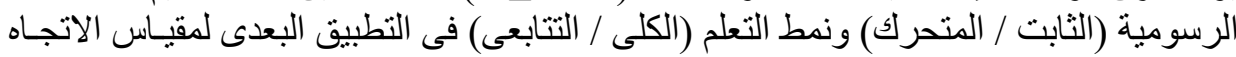
نحو تعلم المفاهيم الجغر افية.

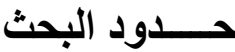
اقتصرت هذه الدر اسة على ما بأنئي: الحدود البشرية: اقتصر البحثث علثى عينة من تلاميذ الصف الثالث الإبتدائى قو امها ( ب) تلميذًا

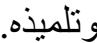
الحدود المكانية: تم تطبيق تجربة البحث بمدرسة الثيخ عبد المعطى حسين الإبتدائيـة ـ التابعـة

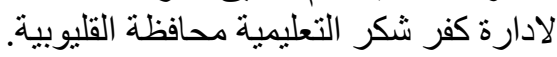

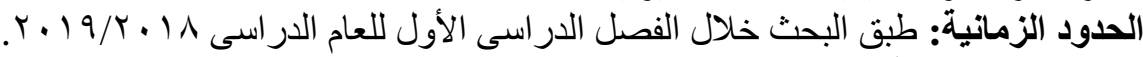

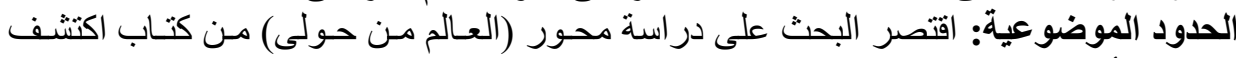

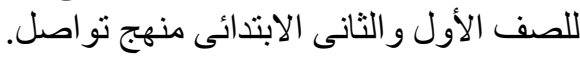

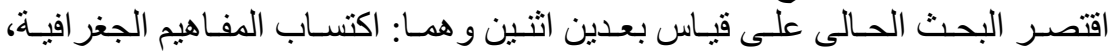
و اتجاههم نحو تعلمها.

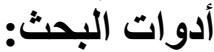
تمثلت أداتا القياس فى الأداتين الآتيتين:

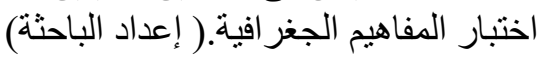

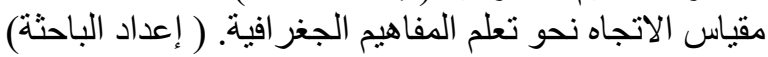

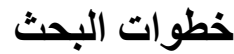
تم إجراء البحث وفقا للخطوات التحاتية:

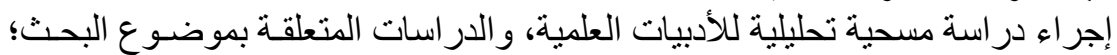

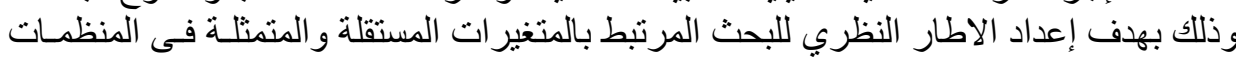

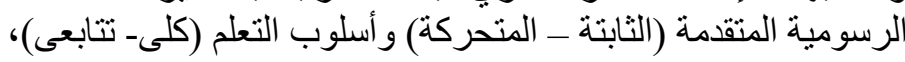




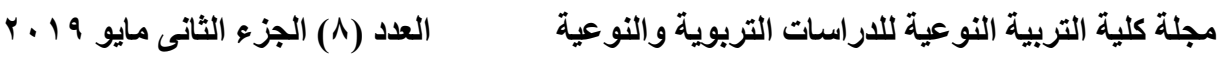

و المتغير ات التابعة منمثلة فى المفاهيم الجغر افية و الإتجاه نحو ها، بهدف الإستالال بـهـ

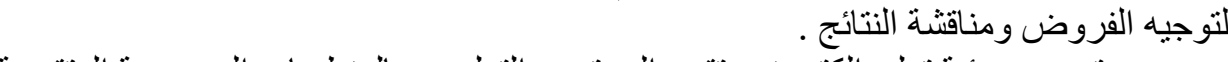

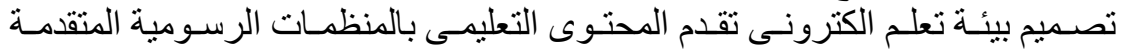

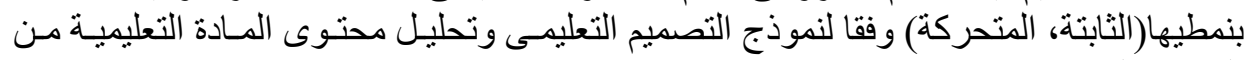

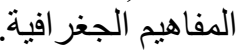

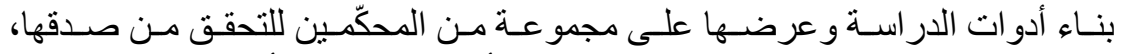

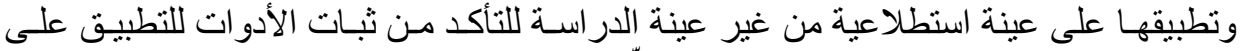

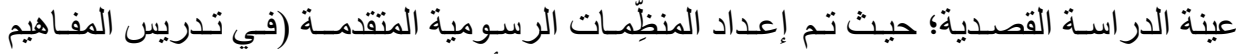

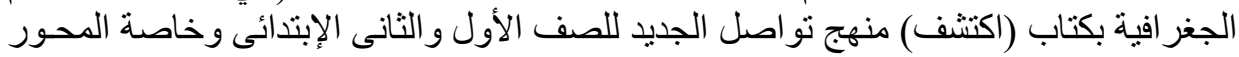

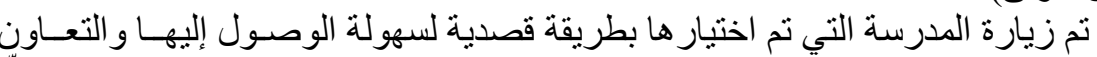

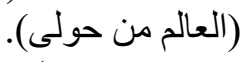

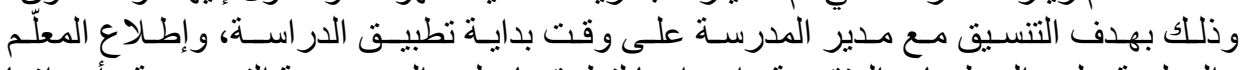

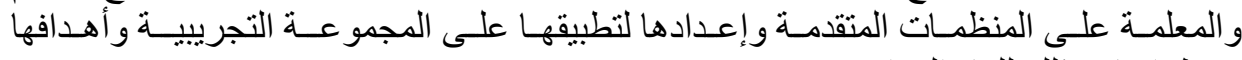

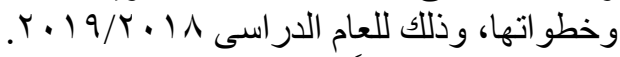

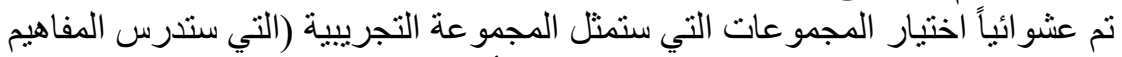

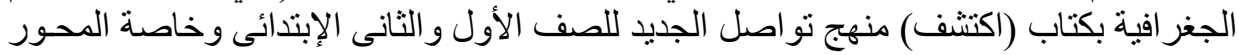

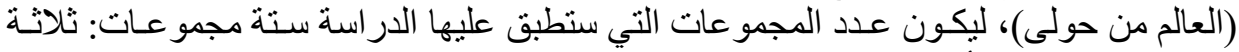

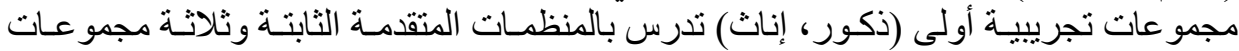

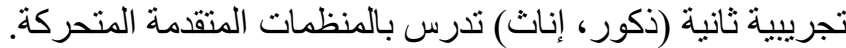

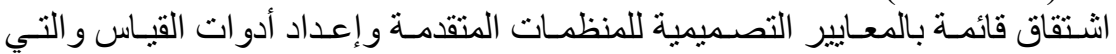

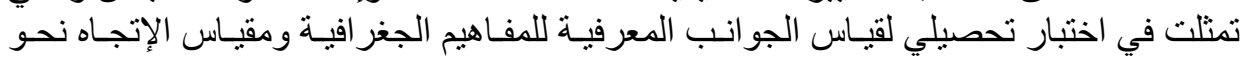

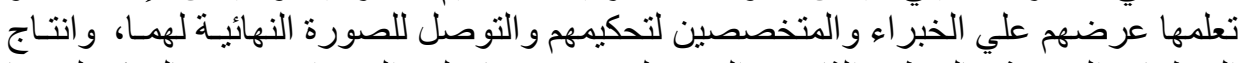

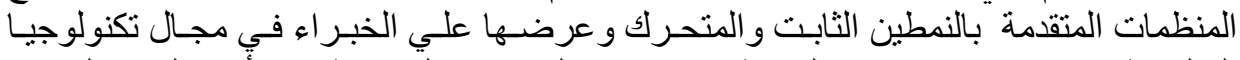

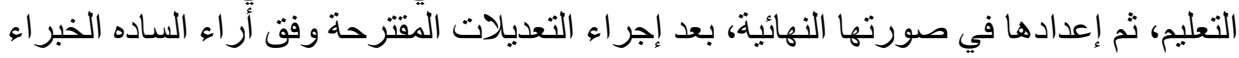

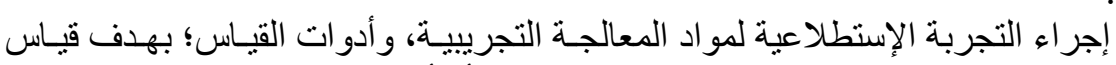

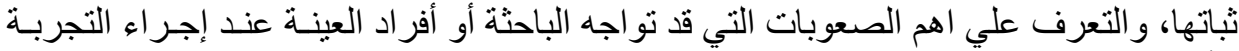
الأساسية للبحث. الترف.

اختبار عبنة البحث الأساسية وتطبيق الإختبار التحصيلي و مقياس الإتجـاه قبليـا للتأكد

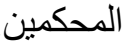

$$
\begin{aligned}
& \text { من تكافؤ المجمو عات الأربعة للبحث. }
\end{aligned}
$$

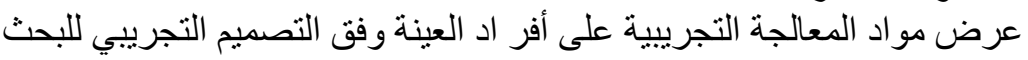

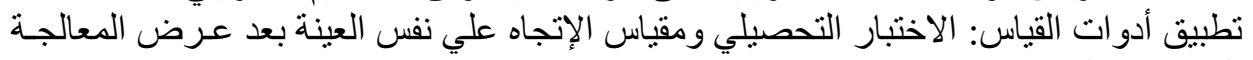

$$
\begin{aligned}
& \text { التجريبية عليهم. }
\end{aligned}
$$




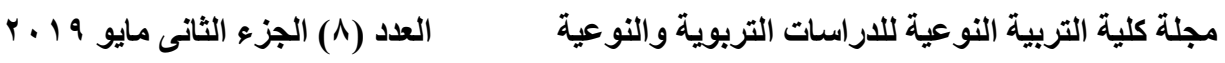

إجر اء المعالجة الإحصائية للنتائج، ومن ثم تحليل البيانـات، وحسـاب مـدي التغير في وني

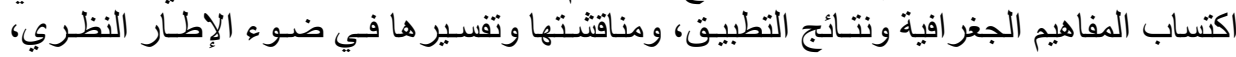

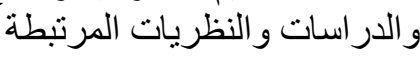

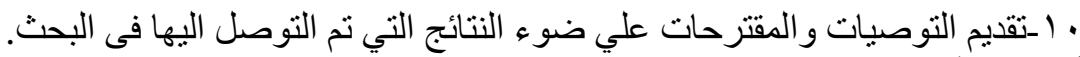

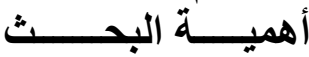

مما سبق تبرز أهمية هذا البحث في الآتي:

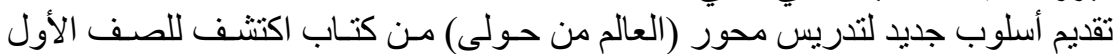

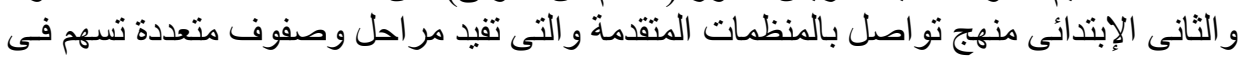
رفع مستوى اكتساب المفاهيم لدى الأنى التلاميذ.

يرى الكثير من المختصين أننا مقبلون على (مجتمع بلا أوراق) يعتمد على أنظمـة آليـة

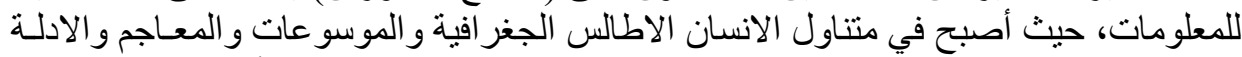

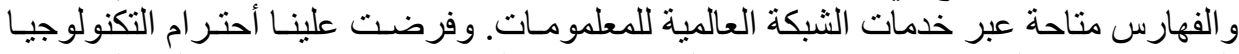

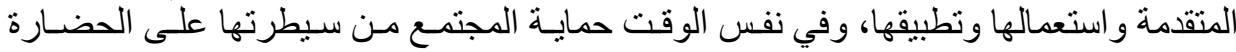

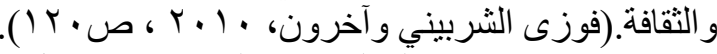

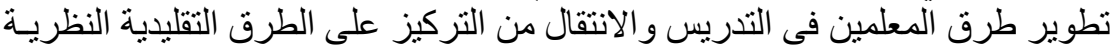

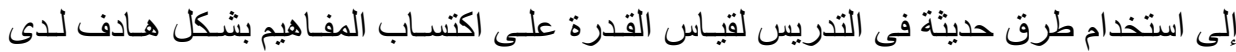

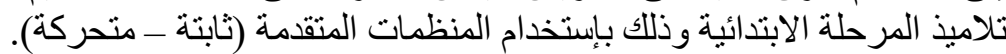

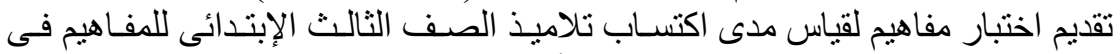

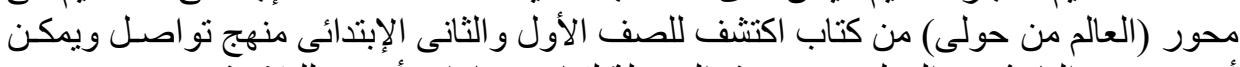

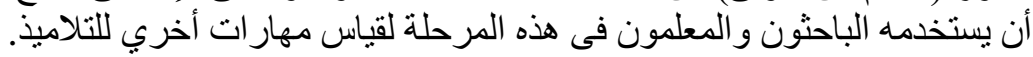

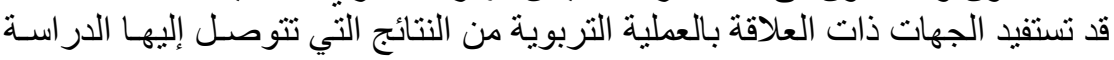

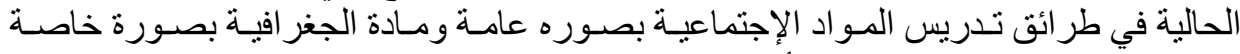
وتجريب طرق التدريس الحديثة للتأكد من فعاليتها ومنها المنظمات المنتقدة في اكتساب المفـاهيم

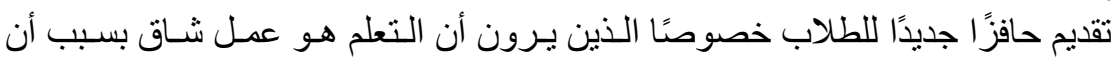

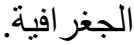

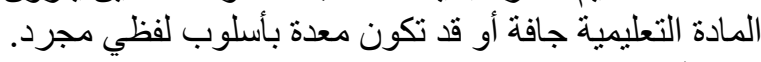

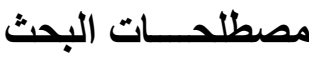

المنظمات المتقدمة: Organizer Advanced

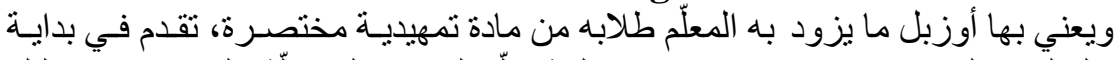

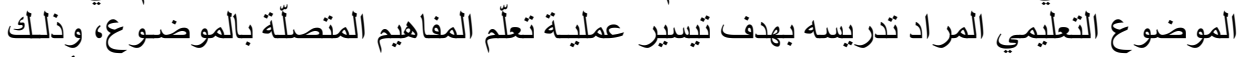

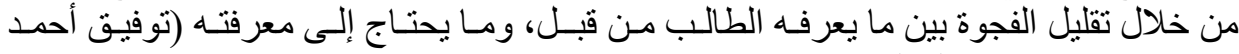

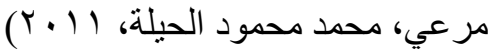

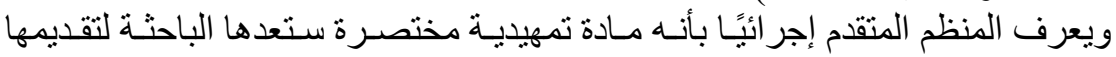

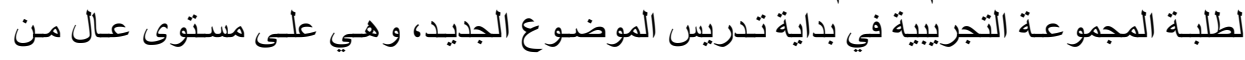




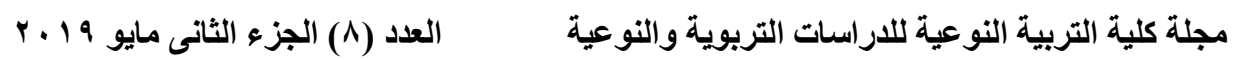

التجـرد و العموميـة، وتكون منظّمة بأثنكال مختلفة من أشكال المنظمات الرسومية تم إعدادها من

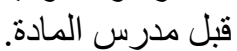

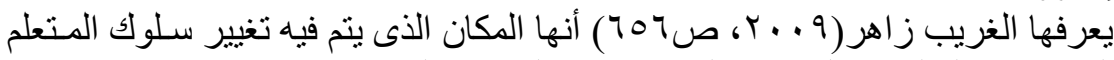

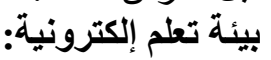

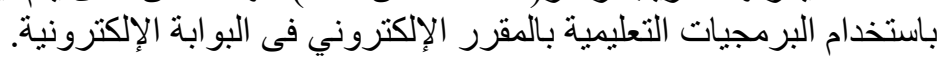

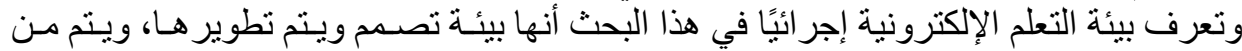
خلالها عرض المفاهيم الجغر افية باستخدام المنظمات الرسومية الجنات بنمطيها (نابتة ومتحركة).

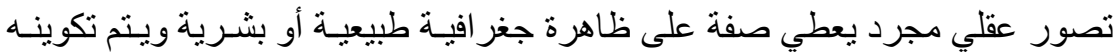

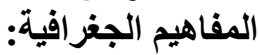

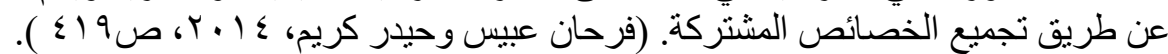

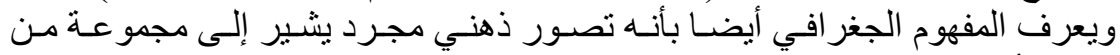

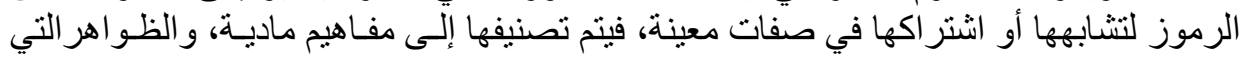

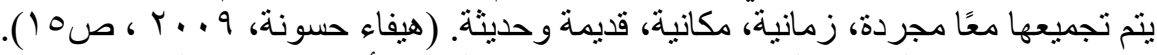

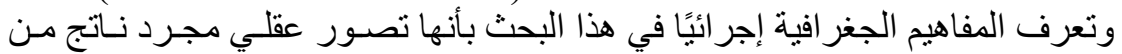

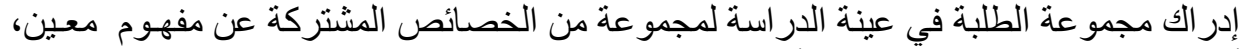

أو ظاهرة جغر افية معينة (طبيعية أو بشرية).

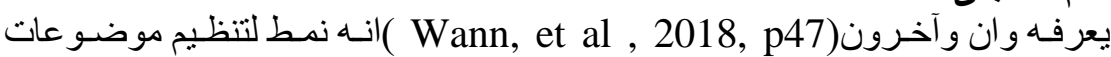

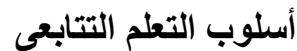

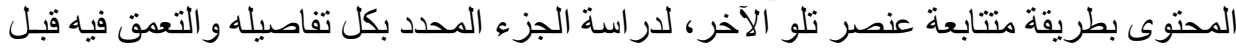

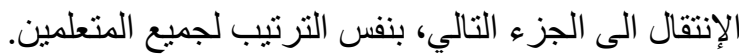

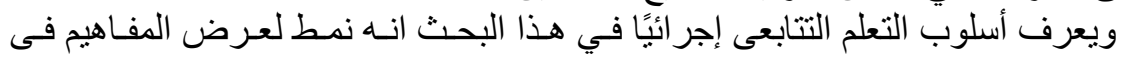

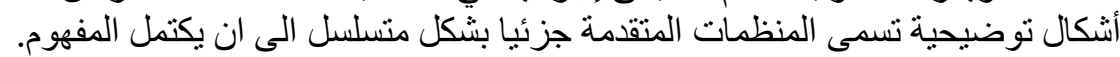

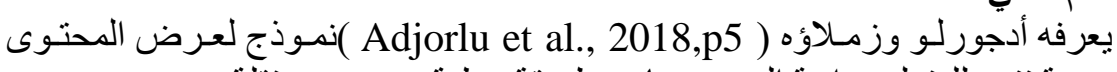

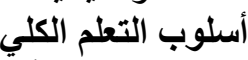

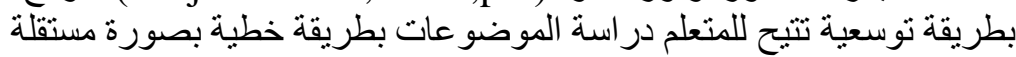

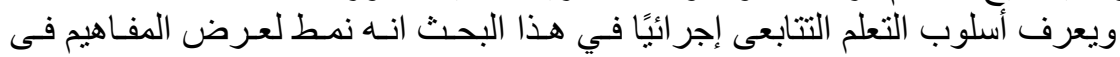
أنثكال توضيحية تسمى المنظمات المتقدمة و عرض التئي المفهوم كاملا بكل تفاصيله.

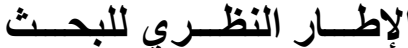

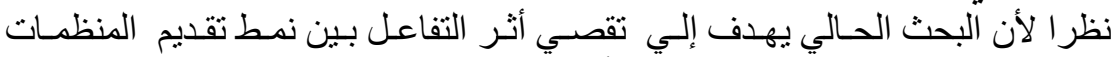

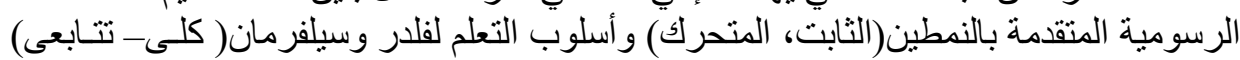

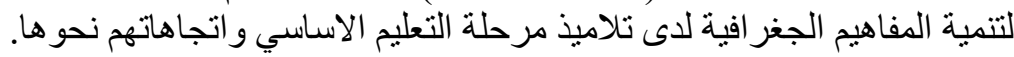
لذلك فقد تناول الإطار النظري للبحث الإثى المحاور الآتية:

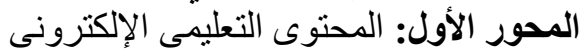

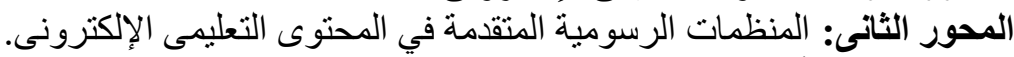
المحور الثالث: أسلوب التعلم (الكلى و التتابعى) الثمئ) 


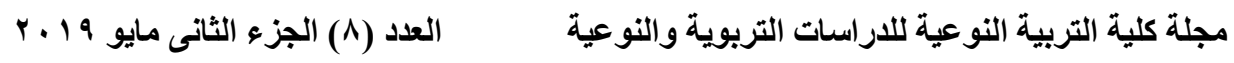

المحور الرابع: المفاهيم الجغر افية لتلاميذ المرحلة الإبتدائية

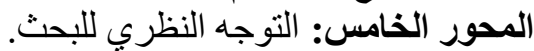

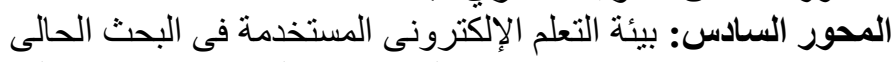

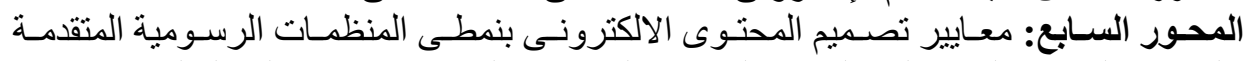

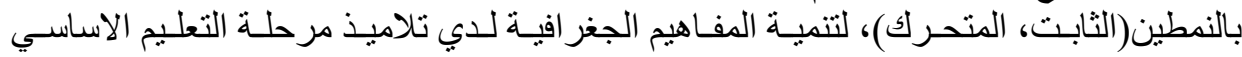
و اتجاهاتهم نحوهنا. المحور الثامن: نموذج التصائميم التعليمى المستخدم فى البحث الحالى.

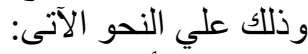
المحور الأول : المحتوى الألتهليمى الإلكترونى: تتناول الباحثة من خلال هذا المحور الإنى النقاط الآتية: -

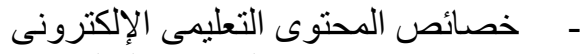

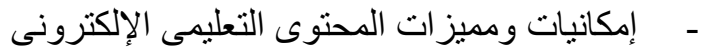

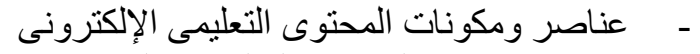
-

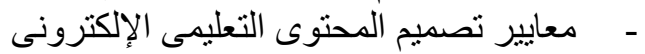

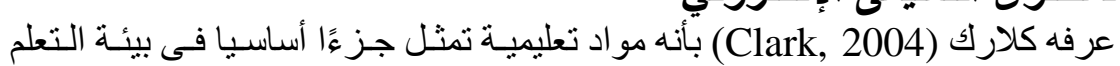
تعريف المحتوى التعليمى الإلكتروني

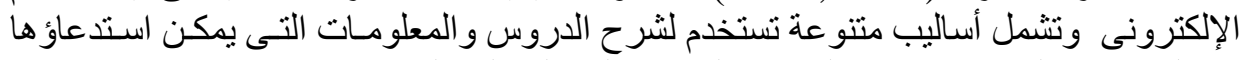

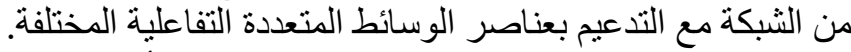

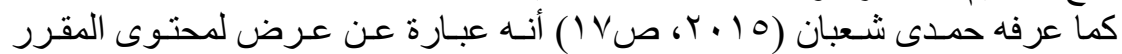

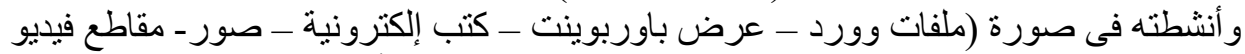

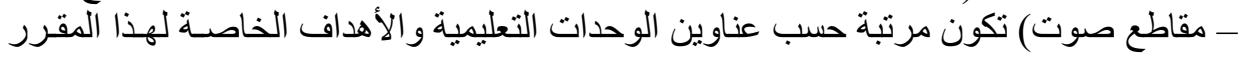
و على ذلإنك بمكن تعريف المحتوى الإلكتروني بأنه المصادر العلمية الإلكترونية التي تم

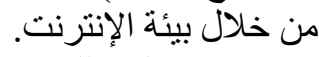

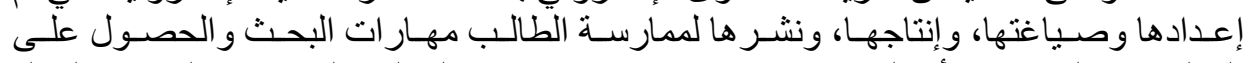

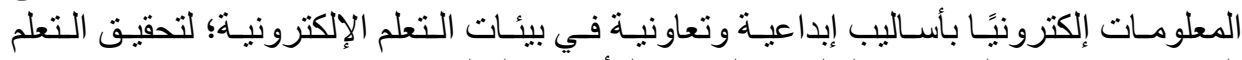

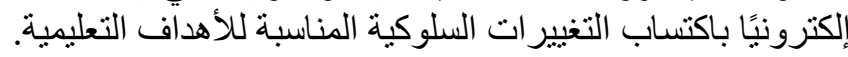

$$
\text { خصائص المحتوى الإلكتروني: }
$$

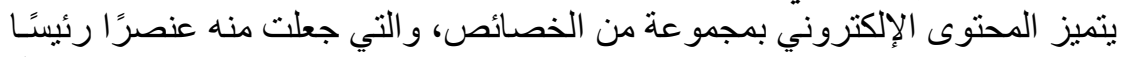

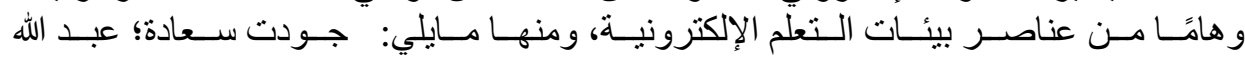

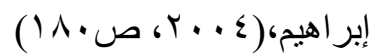
يتضمن وسائط متعددة تفاعلية تدعم عملية التعلم على شكل مثير ات علىي الثانــة عنـــ

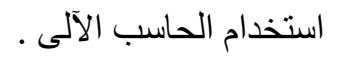




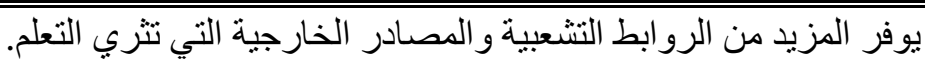

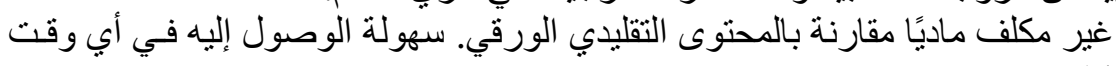

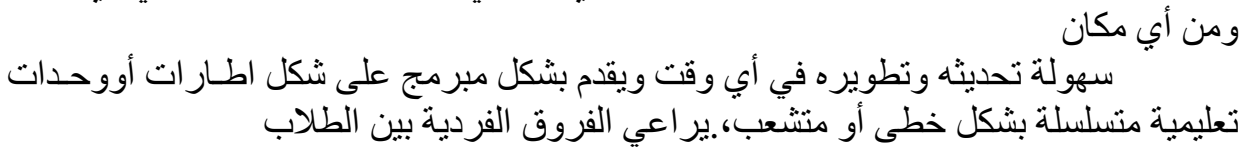
عناصر المحتوى الإلكترونى

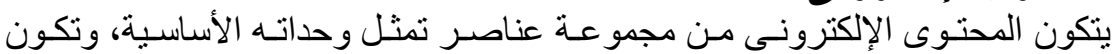

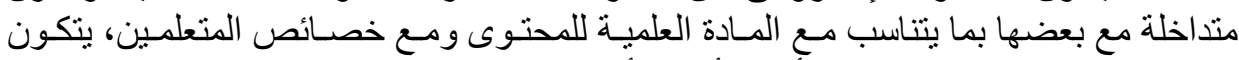

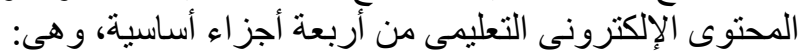

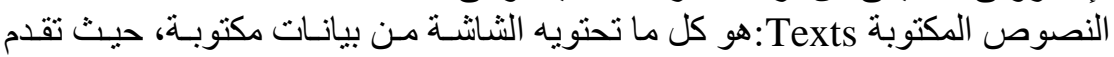

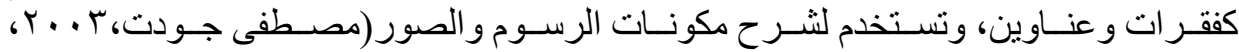

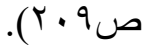

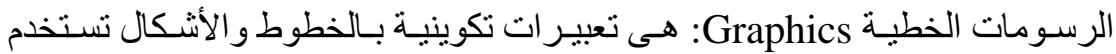
فتتوضيح وشرح المفاهيم و المبادئ و القو اعد وتبسيط المعلومات الصعبة. (عبد اللطيف الجزار

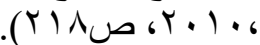

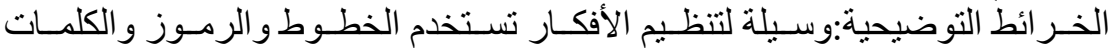

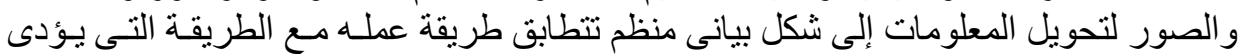

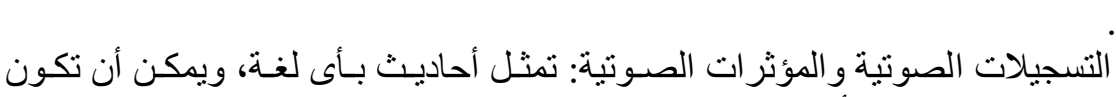

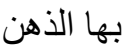

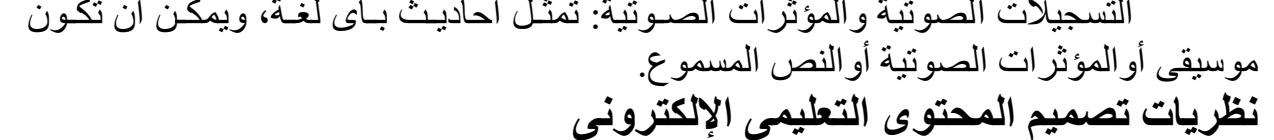

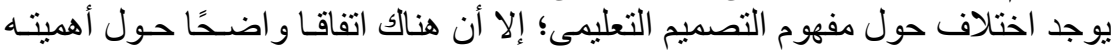

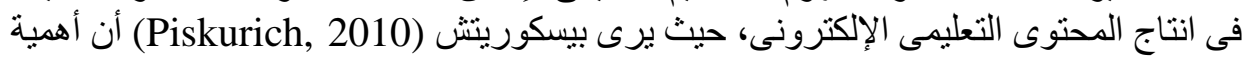

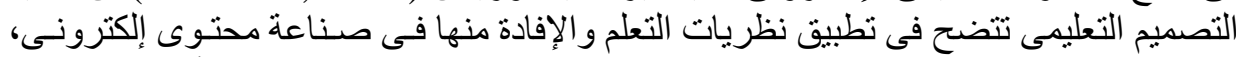

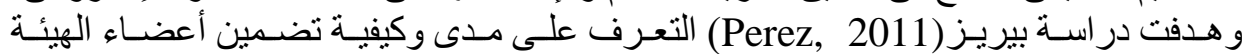

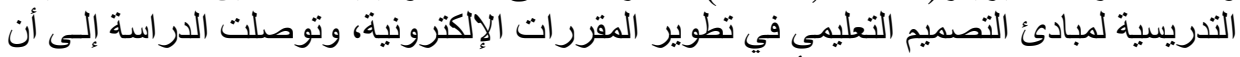

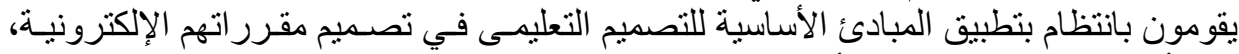

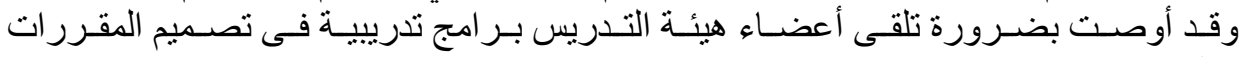

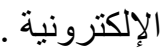

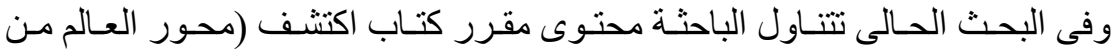

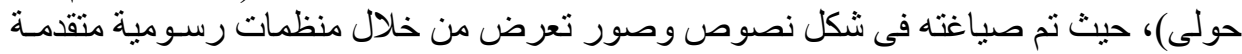

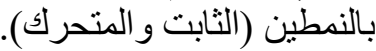




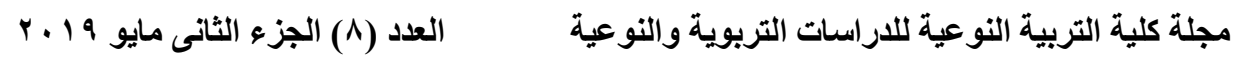

\section{معاييز تصميم المحتوى التعليمى الإلكتروني}

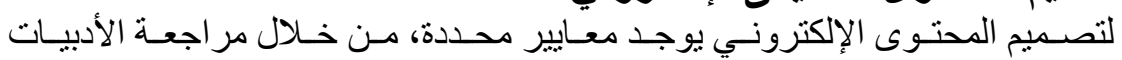

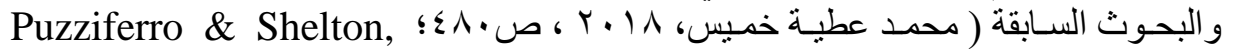
2008, p.120-122; Magoulas, Chen \& Papanikolaou, 2003, p5) أن يتحقق مبدأ الإستمرار Continuity:ويقصد بــاته العلاقـة الر أسية للمحتوى، بحيث

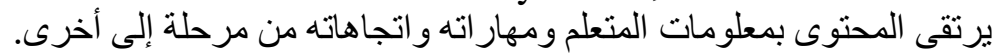

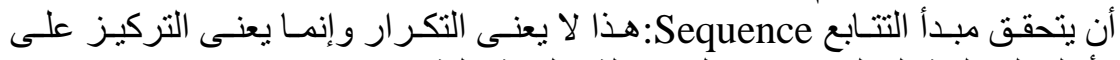
المستويات أعلى لمعالجة المعلومات فى كل مرحلة تعليمية تالية.

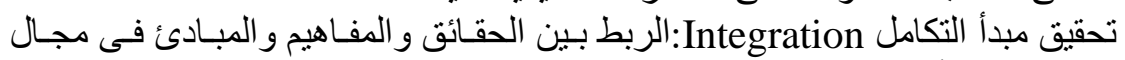

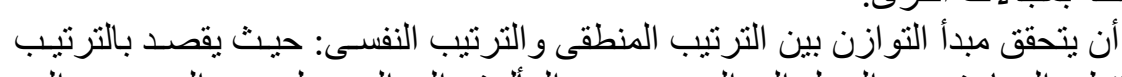

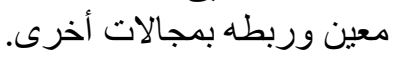

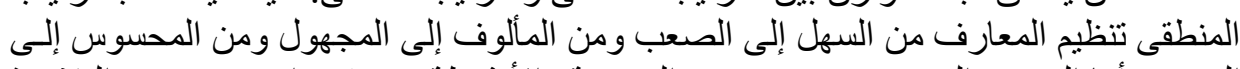

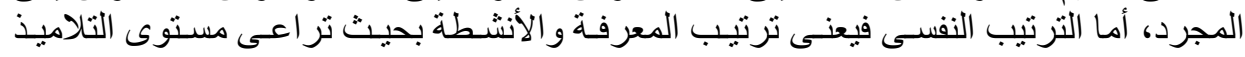
أن يتيح المحتوى استخدام أكثر من طريقة للتعلم وخصائصهم.

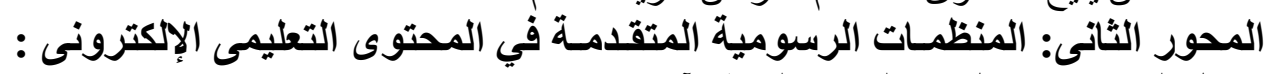

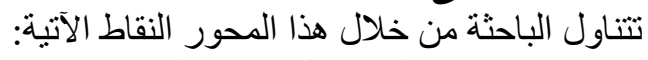

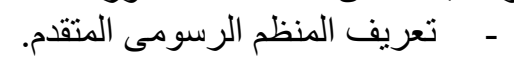
- م - مصائص المنظمات الرسومية المتقدمة.

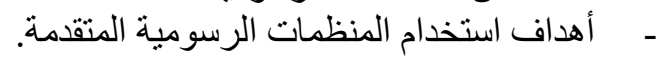

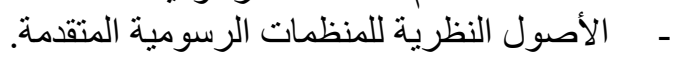

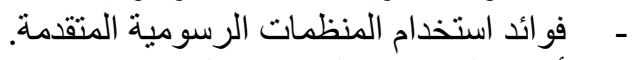
- م - أنواع النظمات الرسومية المتقدمة.

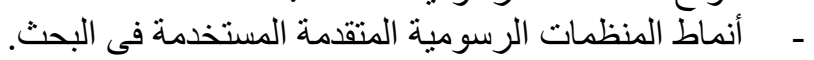
-

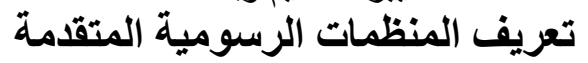

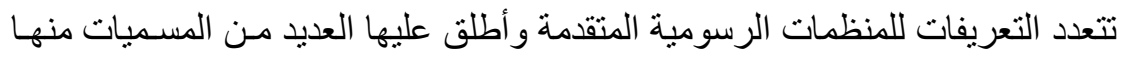

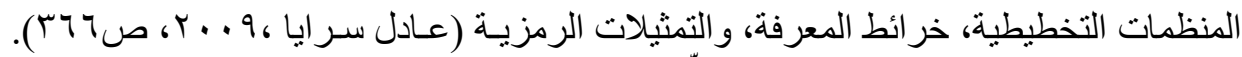

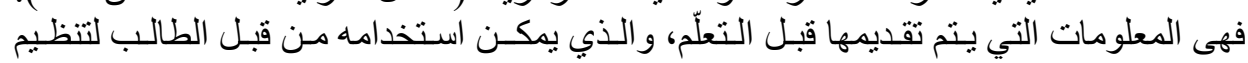

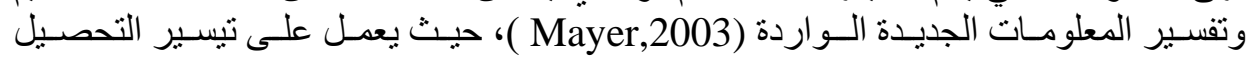

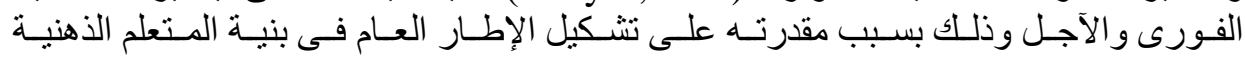

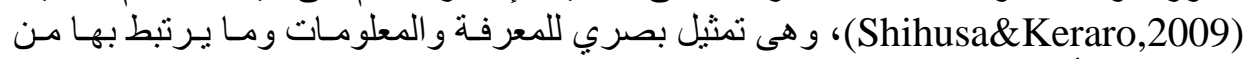
مفاهيم،وتعد أداة فعالة لتنشيط الذاكرة من خلال الحو ثئس (Ropic\&Abersek,2012) 


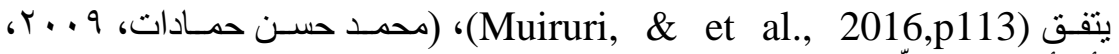

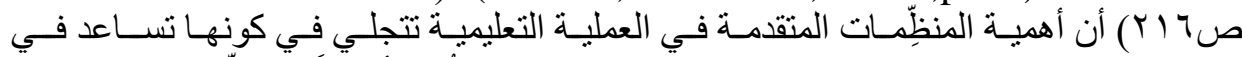

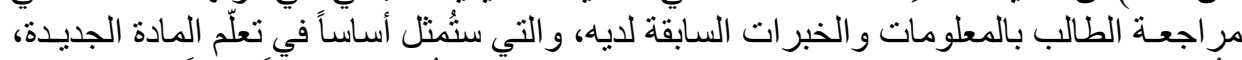

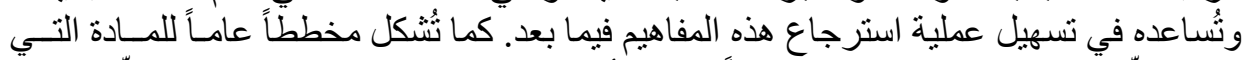

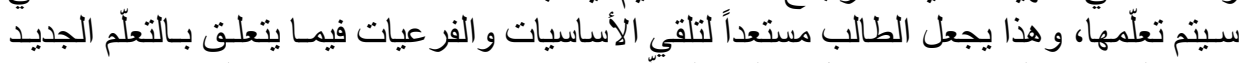

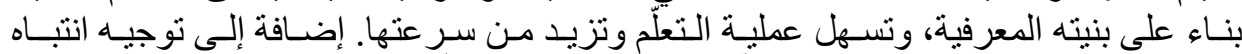

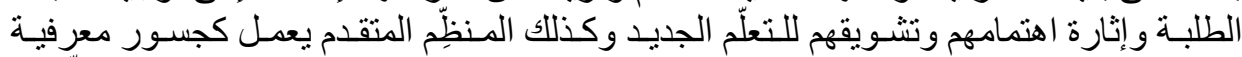

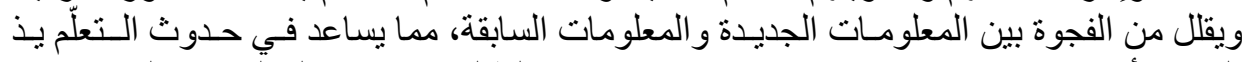

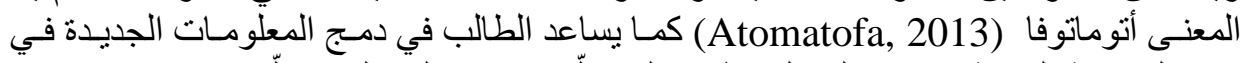

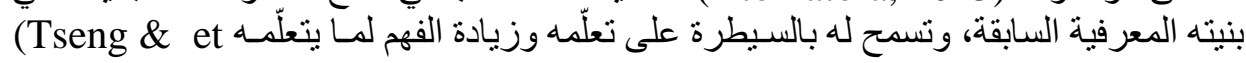

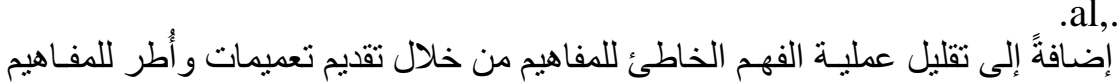
.al, . 2002)

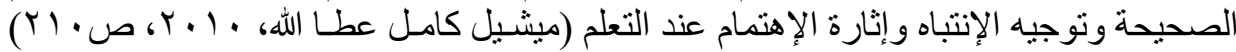

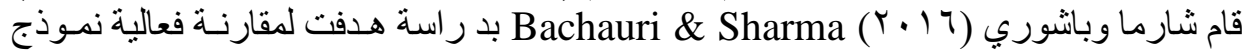

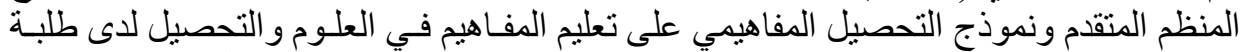

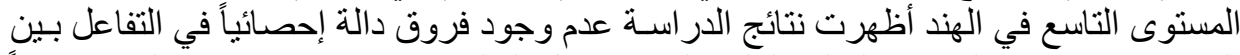

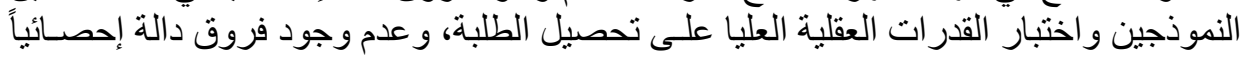

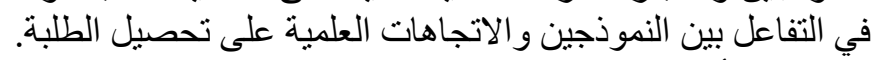

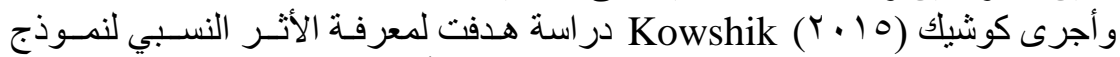

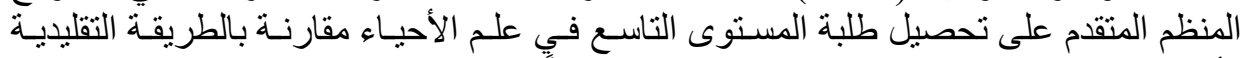

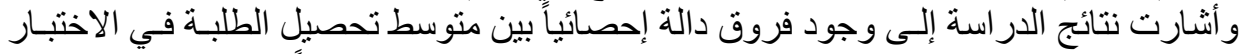

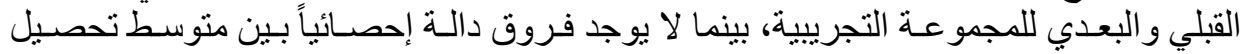

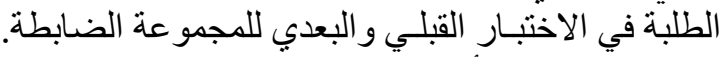

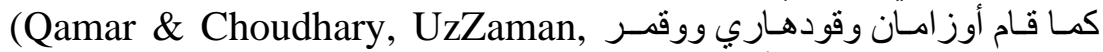

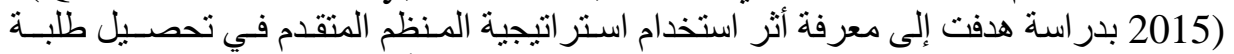

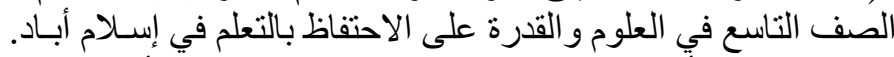

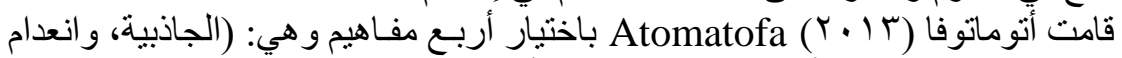

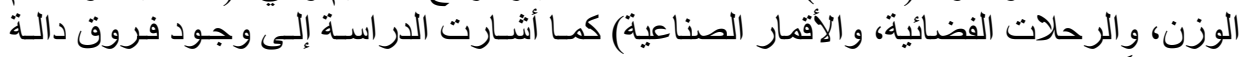

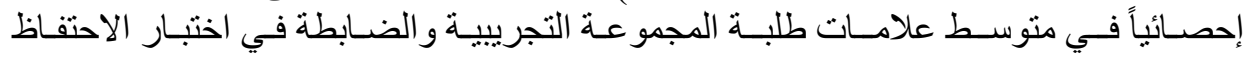

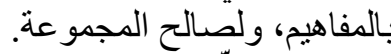
أنواع المنظِّماتِ المتقدمة المِّة

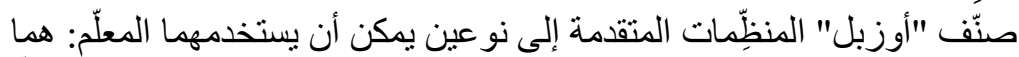

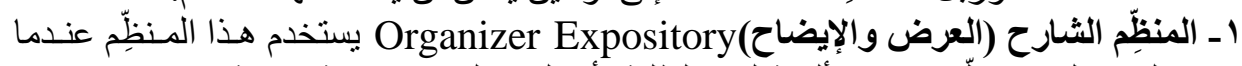
تكون المادة المر اد تعلّمها غير مألوفة لإى الطلبة، أي ليس لديهم معرفـة سـابقة عنهـا. ويستخدم 


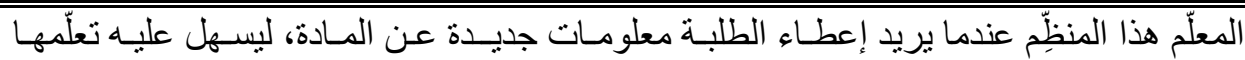

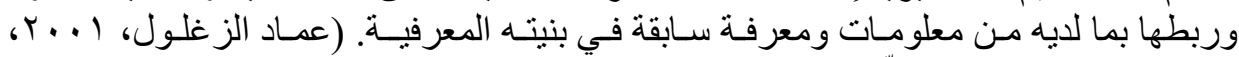

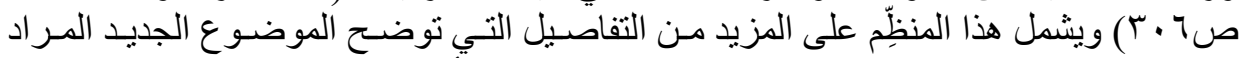

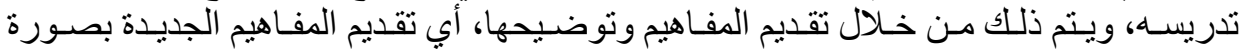

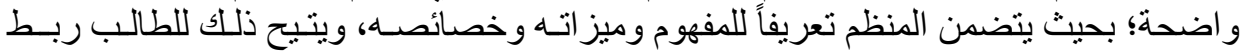

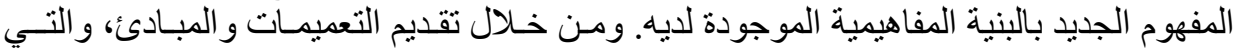

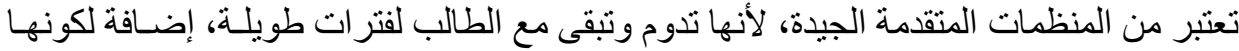

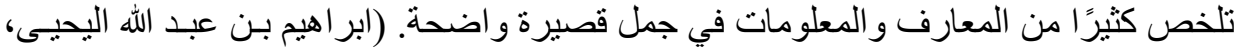

Comparative Organizer المنظم المقارن

جاءت تسمية المنظٍِّ بهذا الاسم من عملية المقارنة التي تتم أثناء التعلّم، ويستخدم عندما

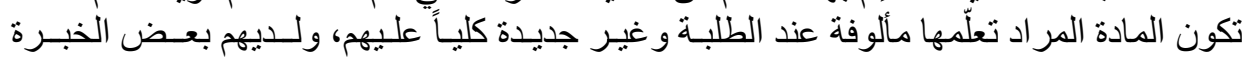

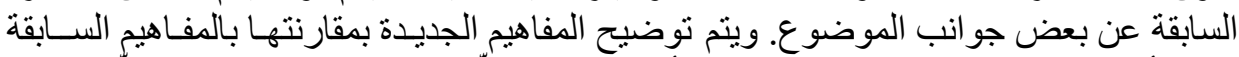

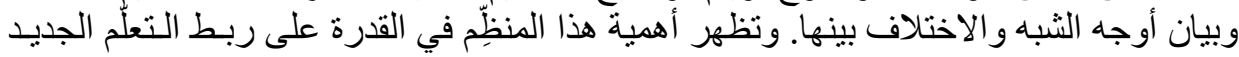

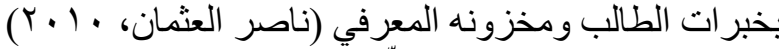

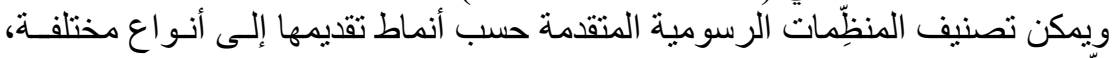

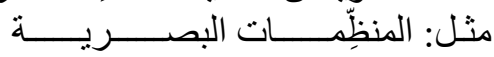
Adapted from Adler, C.R. (Ed). 2001

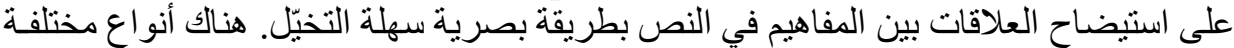

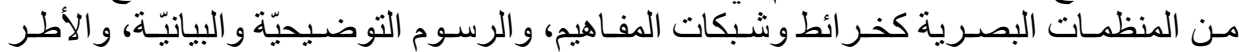

ومجمو عات المفاهيم ذات العلاقة الوثيقة.

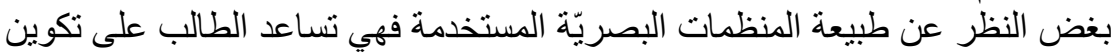

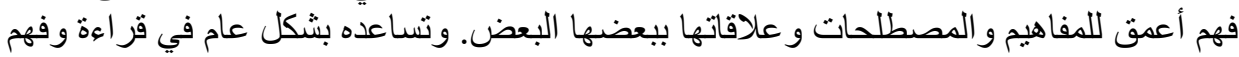

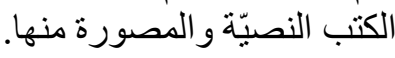

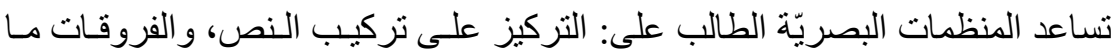

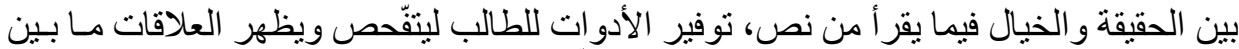

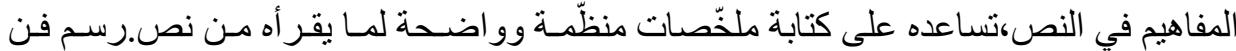

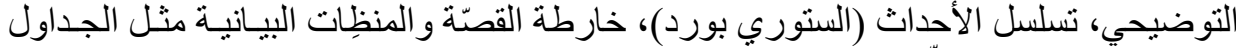

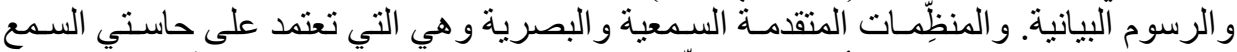

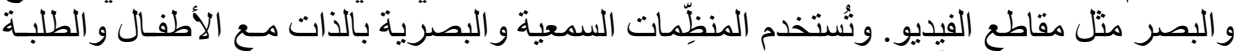

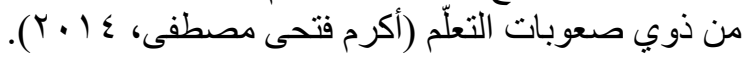

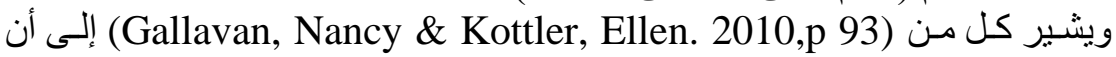

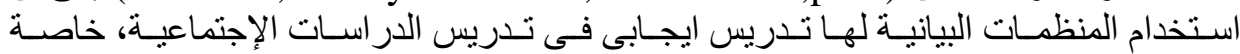

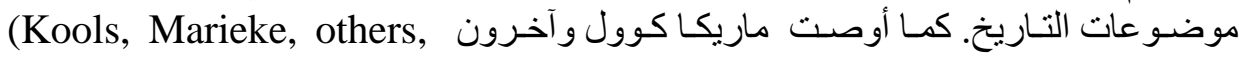




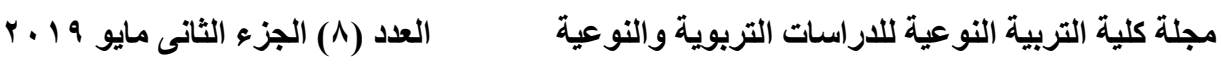

(2006, 670) بضرورة تضمين المناهج الدر اسية المنظمات البيانية، حيث أنها تساعد على فهم

العلاقات بين المفاهيم الواردة في الكتب الدر اسية الدية

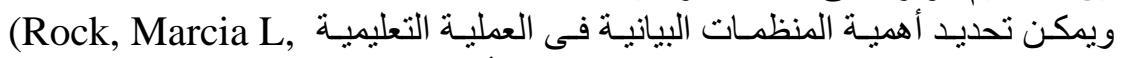

2004,p 10) (Zollman, Alan, 2009 (A),4)

للموضوع. تسهم فى تنمية عمليات التفكير لدى التلاميذ كالإستتناج و التنظيم و التخطيط.

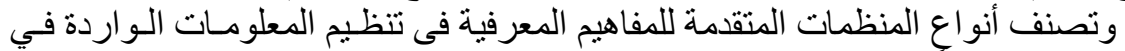

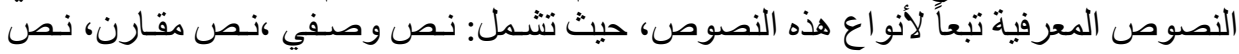

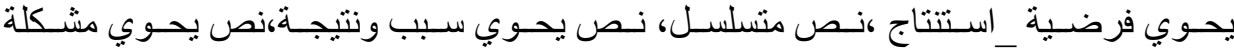

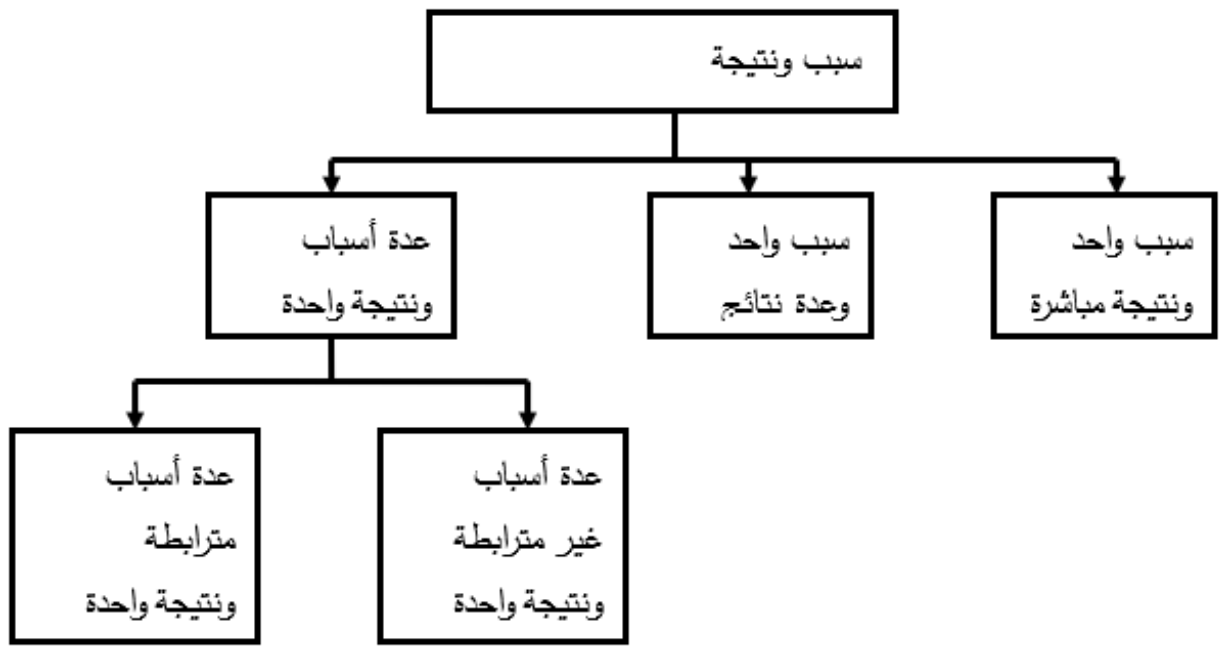

وحل.(Dexter,Park,Hughes,2011) من خلال البحث الحالى تستخدم الباحثة الأنواع التالية من المنظمـات المتقدمـة لعرض
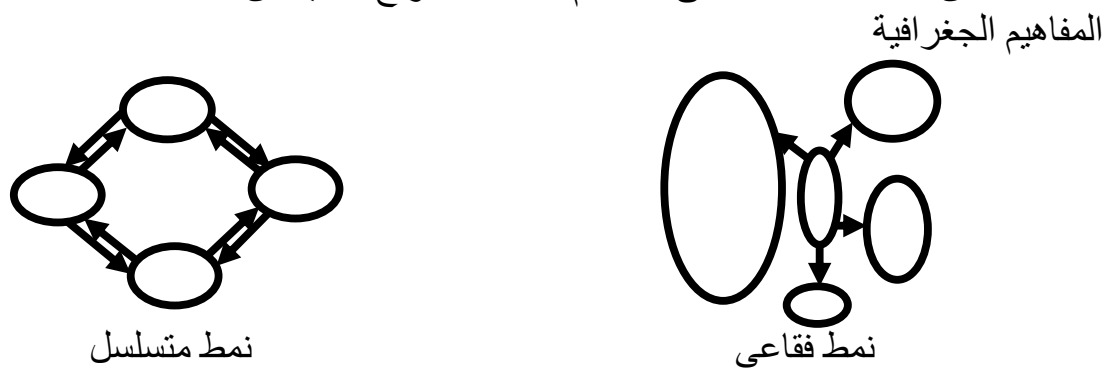


\section{خصائص المنظِّمات المتقدمة}

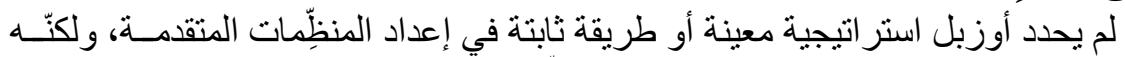

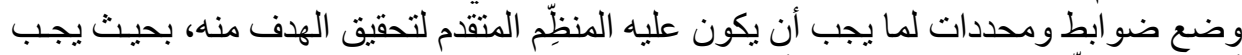

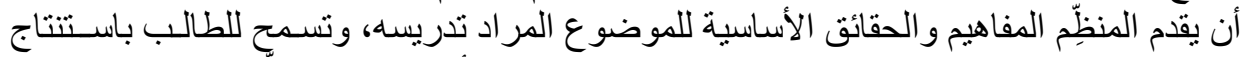

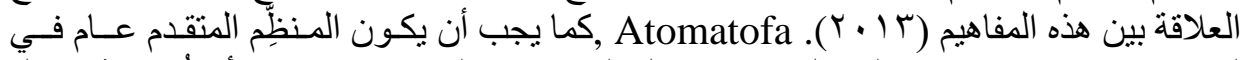

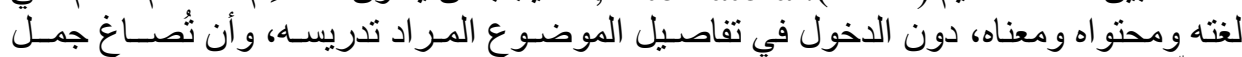

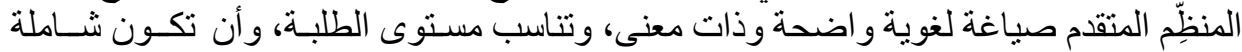

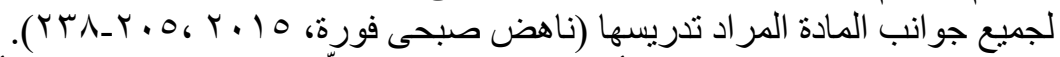

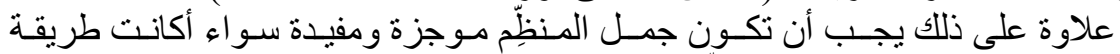

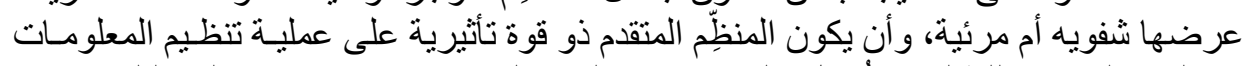

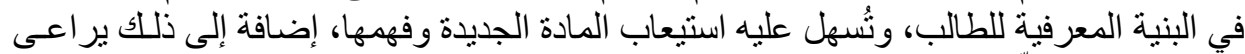

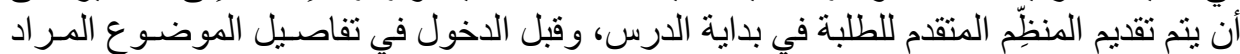

Chen, 2007) ت تدريسه

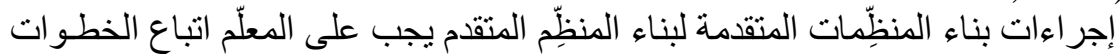

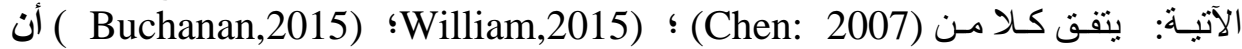

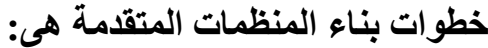

الاطلاع على المادة التعليمية الجديدة لمعرفة المنات المتطلبات السابقة لهذه المعرفة.

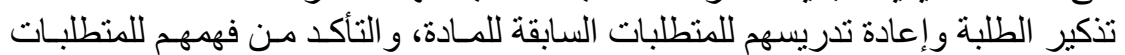

السابقة.

تلخيص المبادئ العامة والأفكار الرئيسية الموجودة في الوحدة.

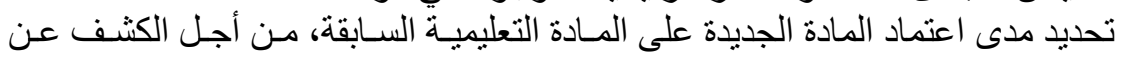

تحديد مو اصفات المنظِّّم المتقدم وبنائه؛ بحيث تكون الأفكار فيـه متسلسـلة كمـا وردت أوجسه الثبه و الاختلاف بينهما.

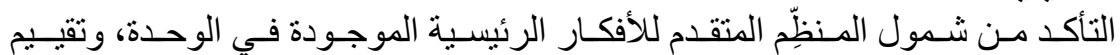

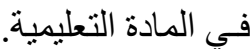
صـلاحيته و العمل على تنقيحه. تحديد الطرق و الأنشطة والوسائل التعليمية المناسبة. معاييز تصميم وبناء المنظمات المنات المتقدمة

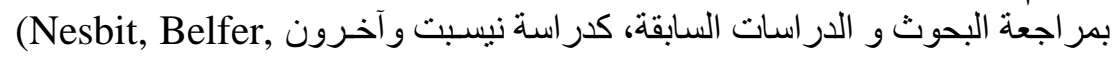
,honeye , Weil, \& Calhoun, 2000 ; Mayer \& ودراسـة \& \&argo, 2002 Alexander, 2010) تـم التوصـل إلـى المعـيير التـى يجب مر اعاتهـا لتصـميج وبنـاء المنظمـات الرسـومية

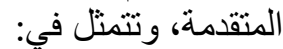
الأصالة: تعنى تمثيلّ المنظمات الرسومية المتقدمة للحقائق، المفاهيم، المبادئ. 


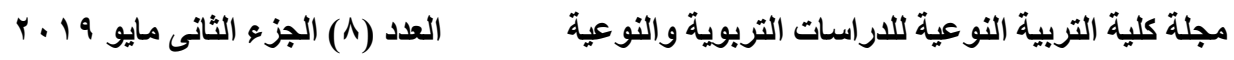

الوضوح والبساطة: أن تكون عناصر المادة التعليمية مبسطة لتسهل استيعابها، و استخدام وسائل

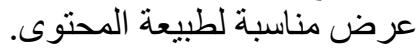

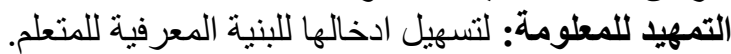

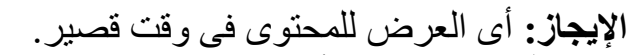

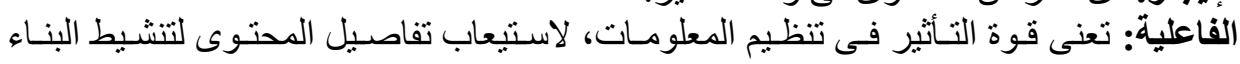

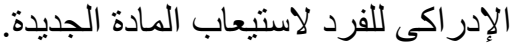
الثمولية: استيعاب و احتو اء تفاصيل الماديل المحتوى التعليمى. المحور الثالث:أسلوب التعلم (التتابعى والكلى الثلى) -

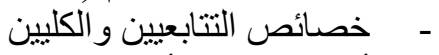

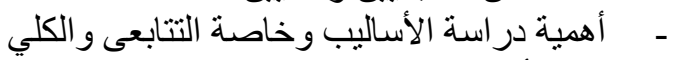
- - مقاس أسلوب التعلم (التتابعى و الكلى) تعريف أساليب التعلم

نشأت فكرة أساليب التعلم Learning Styles من أن جميع الطلبة مختلفون في ذكائهم

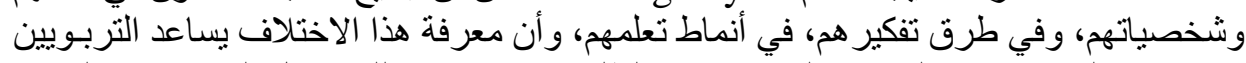

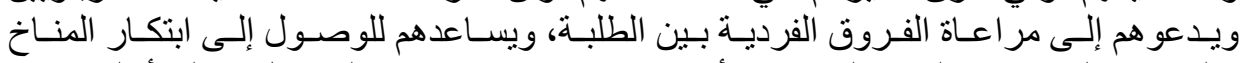

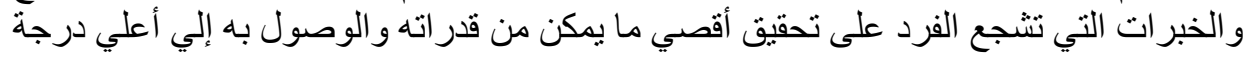
عرفها فلبينج وبونويل (Fleming \& Bonwell, 2002) بأنه الطريقة التي يستقبل

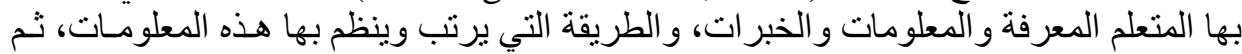

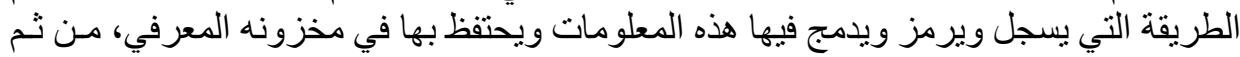

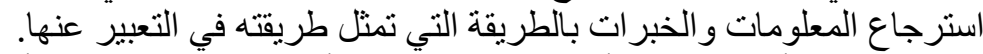

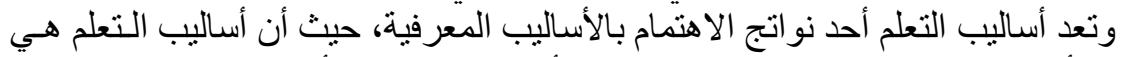

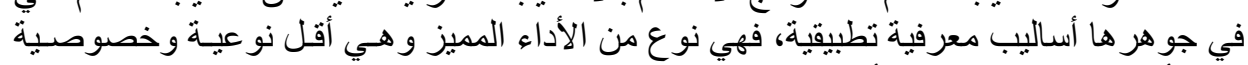

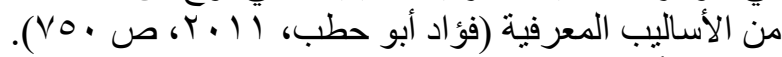
تعريف أسلوب التعلم (التتابعى والكلى)

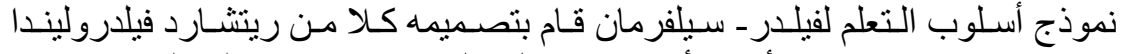

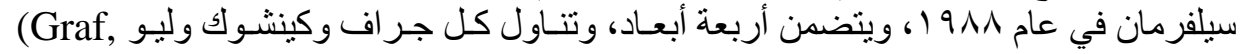

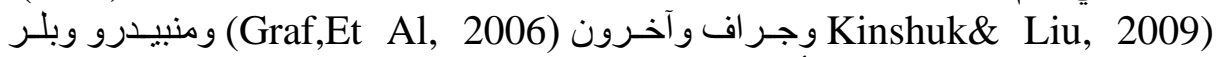

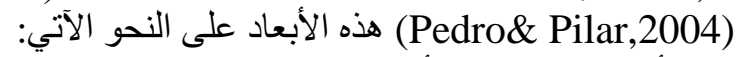
ا ـ الأسلوب العملي_ التأملي بـ الأسلوب الحسي- الحسي- الحسبي

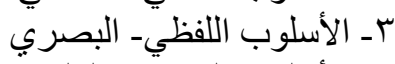

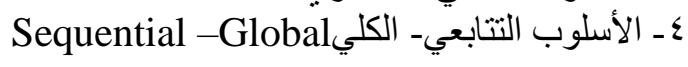




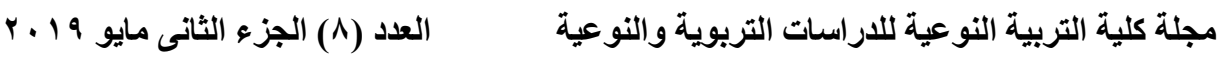

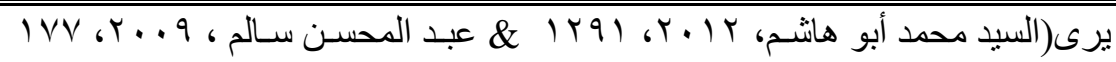

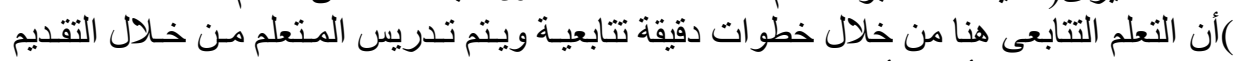

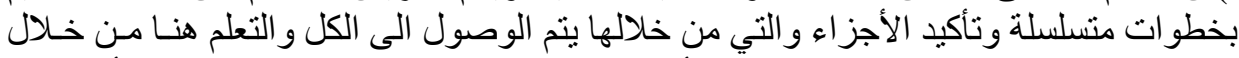

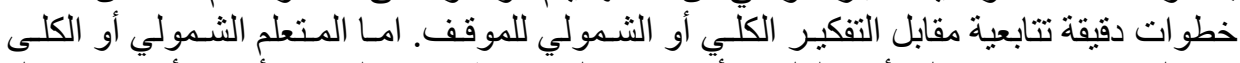

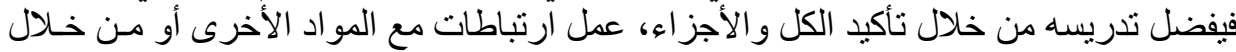

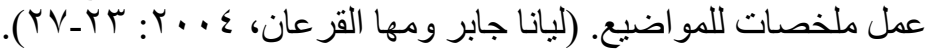

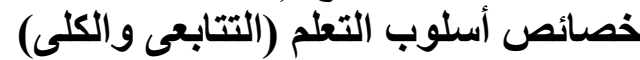

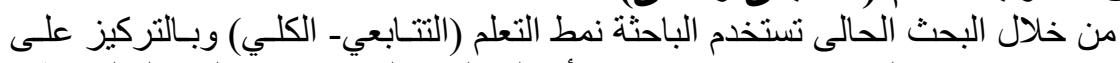

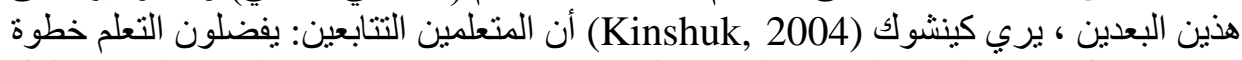

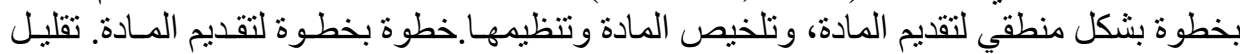

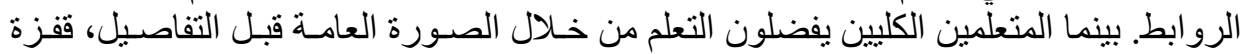

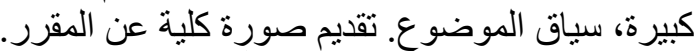

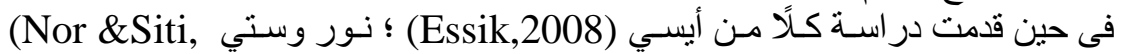

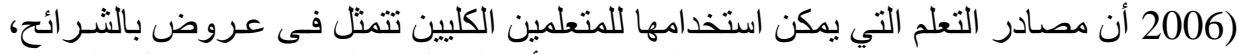

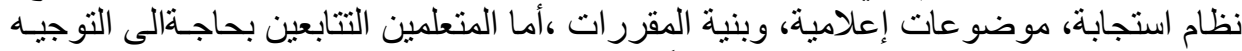
وأن يكون لدى المتعلم مسار تعلم محدد مسبقاً. أهمية دراسة الأساليب وخاصة لإن التثابعى والكلي

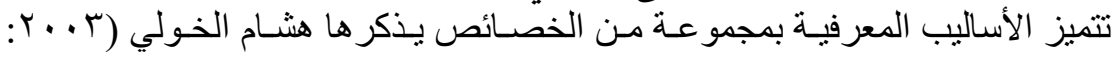

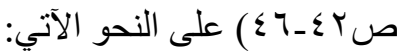

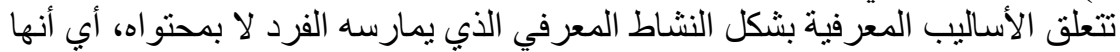

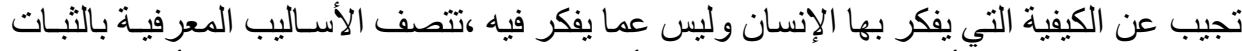

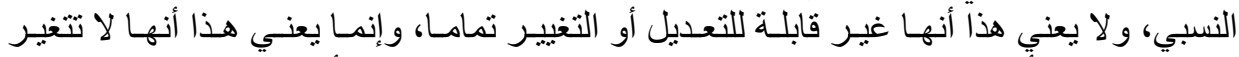

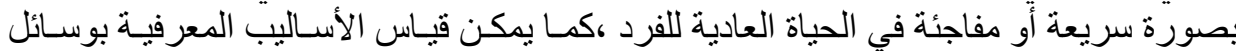

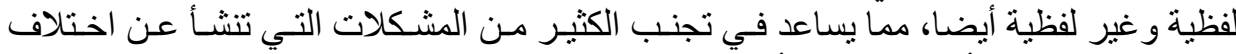

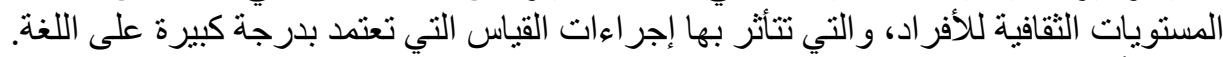
قياس أسلوب التعلم (التتابعى والكلى التئ)

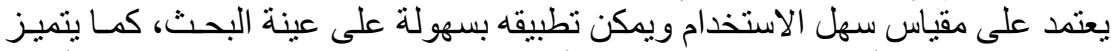

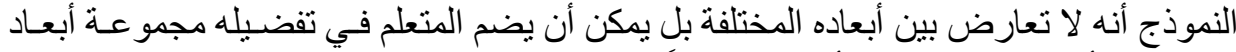

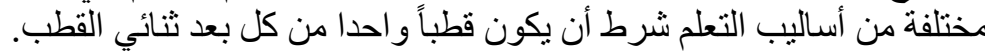
المحور الرابع: المفاهيم الجغرافية التئل لتلاميذ المرحلة الإبتدائية:

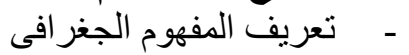

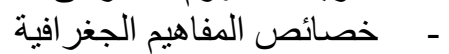
- - أهمية تعلم المفاهيم الجغر افية لتلاميذ المرحلة الإبتدائية - 


$$
\begin{aligned}
& \text { - - ماذج تعلم المفاهيم الجغر افية }
\end{aligned}
$$

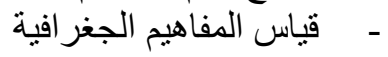

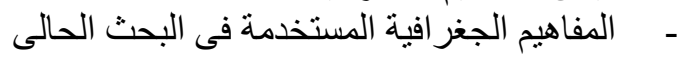

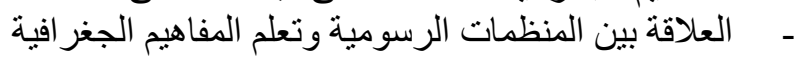

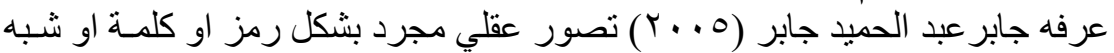

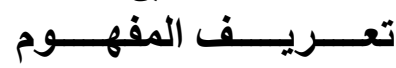

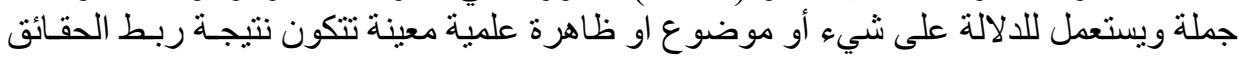

بعضها ببعض و ايجاد العلاقات القائمة بينها

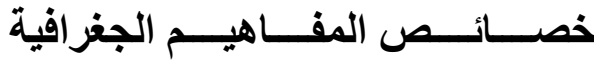

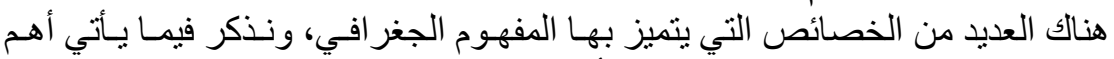

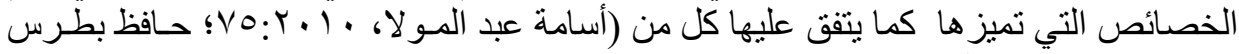

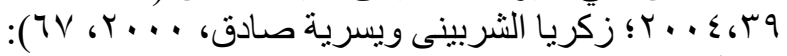

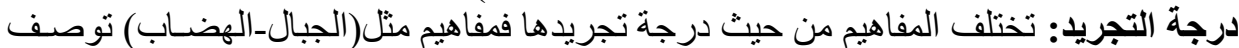

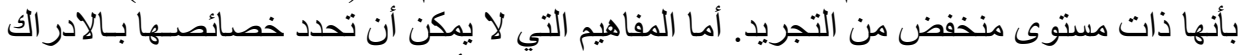

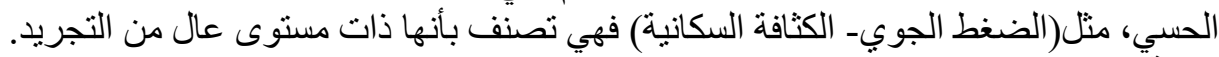

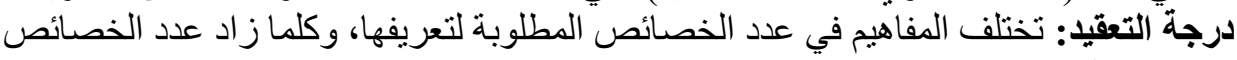

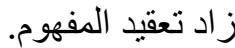
درجة تركيز الأبعاد: بعض المفاهيم يمكن أن تثتق معناها من واحد أو اثثنين من الخصائص التي بتساوى كل منها من حيث أهمينها.

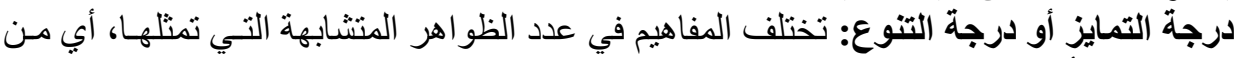

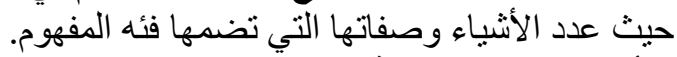
التأثر بالخبرات السابقة: يعتمد تكوين المفاهيم على خبر اتل التهات المتعلمين السابقة.

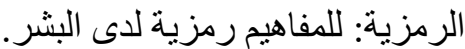
القابلية للتصنيف: بمكن أن تشكل تنظيمـات أفقيـة وعموديـة ومـن التصنيف الأفقي المرتفعـات

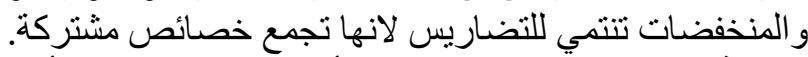

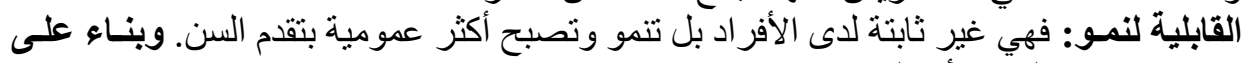

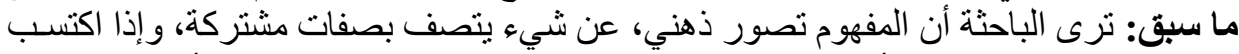

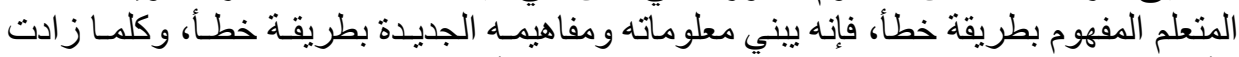

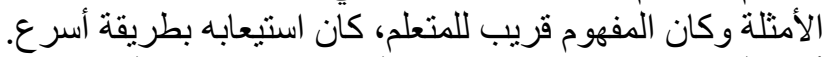

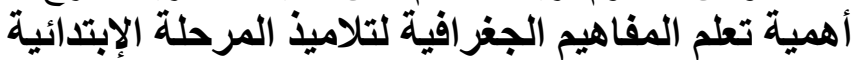

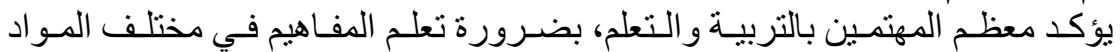

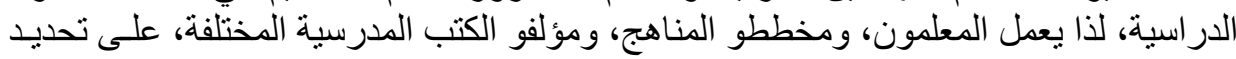

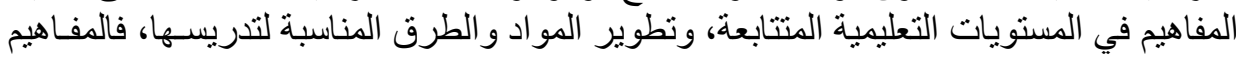


تشكل الأساس للتعلم، ومن أهمها؛ الأكثر تقدما كتعلم المبادئ، وتعلم حل المشكلات (أمانى عبده،

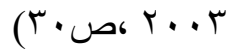
تؤدي در اسة المفاهيم إلى زيادة قدرة التلاميذ على استخدام المعلومات في مواقف حلـ المشكلات. تؤدي در اسة المفاهيم إلى تـوفير أسـاس لاختيـار الخبرات، وتنظم الموقف التعليمي، وتحديد الهذف من المنهج.

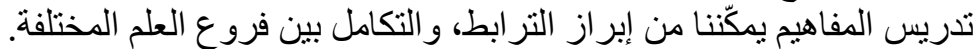

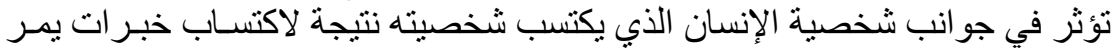
بها فتصبح جز عن من هذه الثخصية.

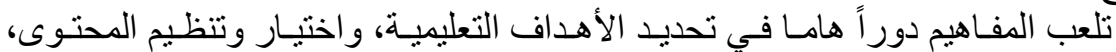
و الوسائل التعليمية، ووسائل تقويمها.

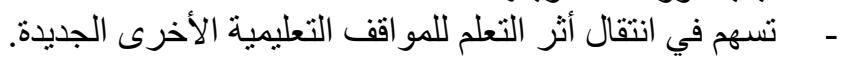

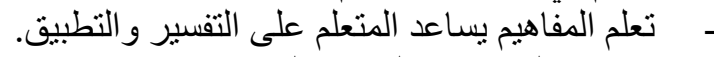

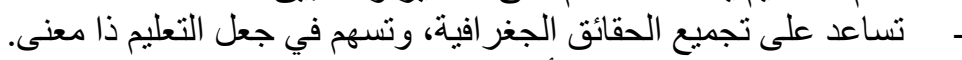

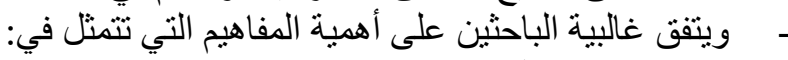

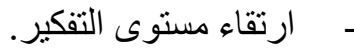
- - اختز ال التعقيد البيئي و اختز ال الحاجة إلى التعمم المستمر - - توجيه النشاط وتجعل التعمع ممكناً.

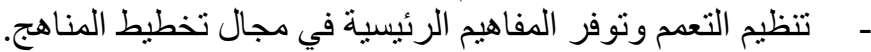

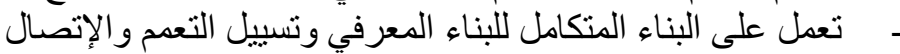

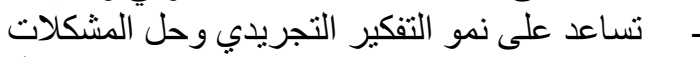

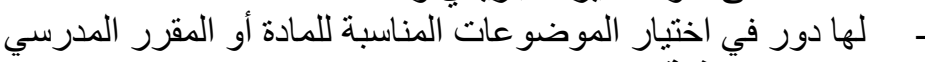

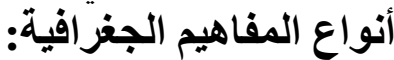

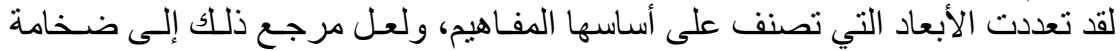

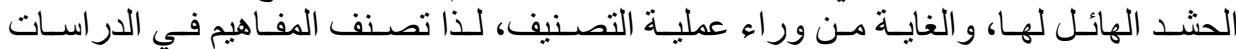

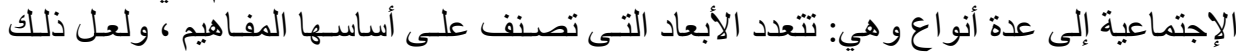

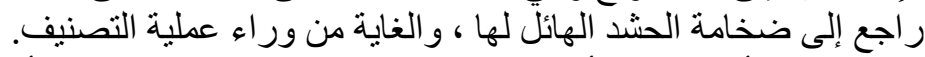

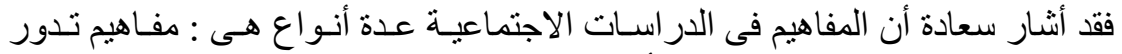

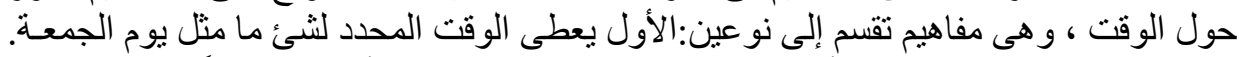

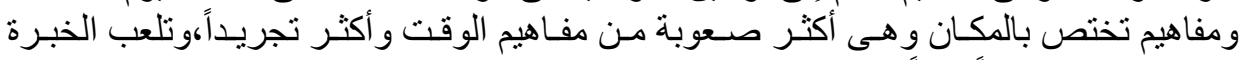

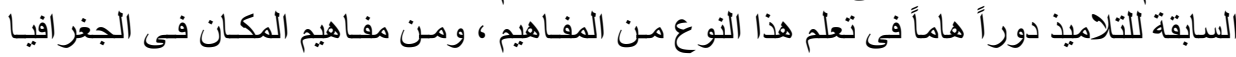

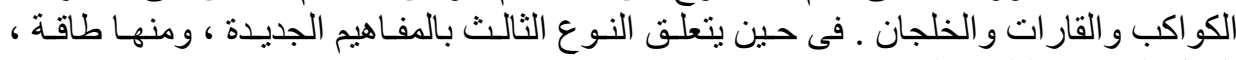

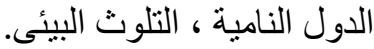




\section{أنواع المفاهيم ثُلاثة هى:}

ا - المفهوم الرابط Conjunctive concept

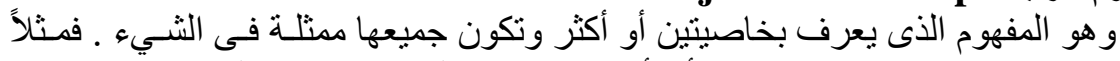

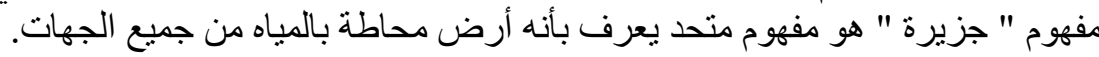

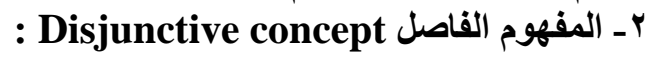

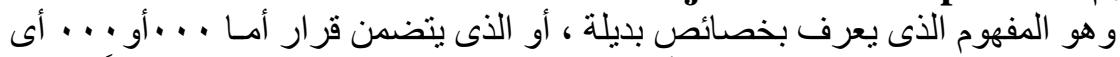

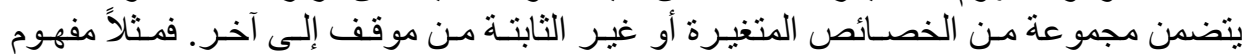

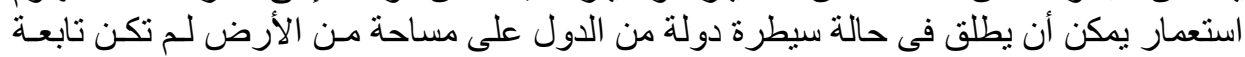

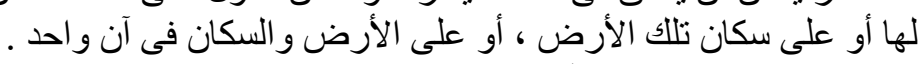

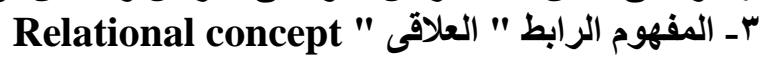

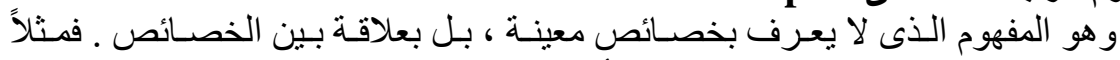

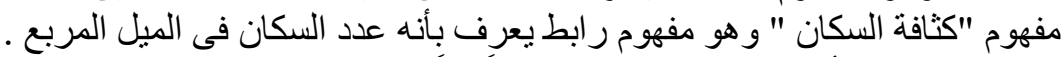

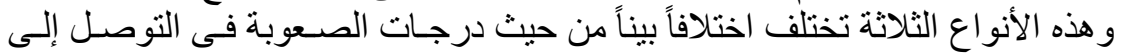

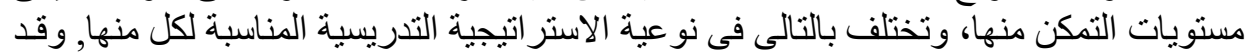

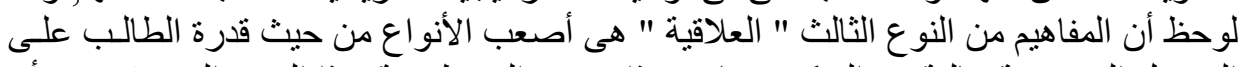

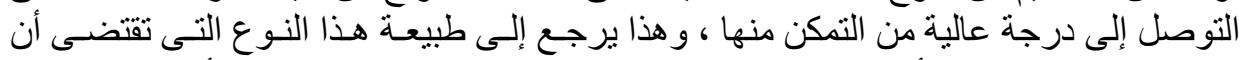

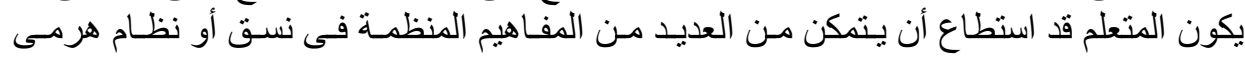

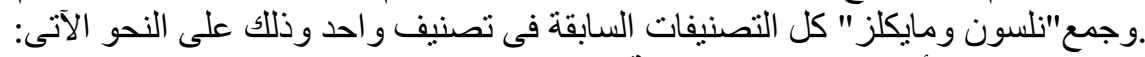

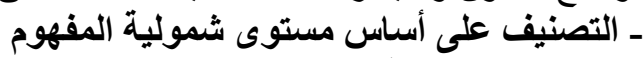

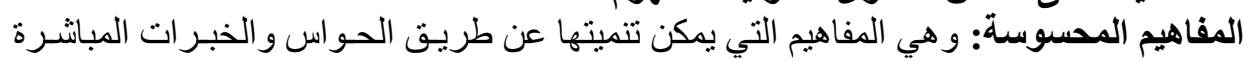

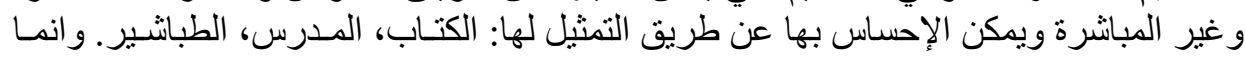

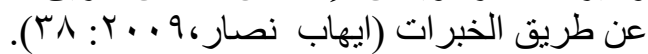

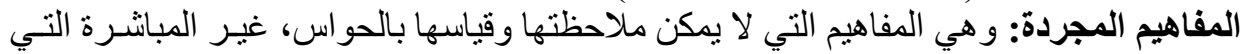

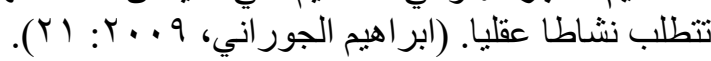

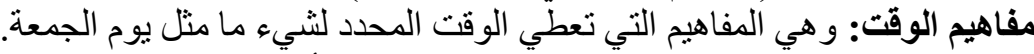

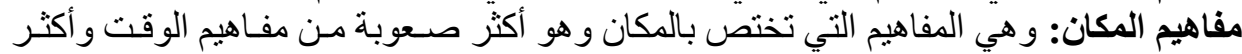

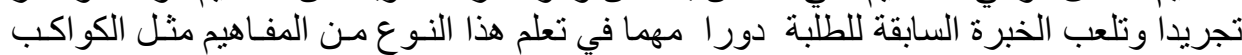

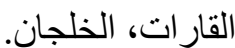

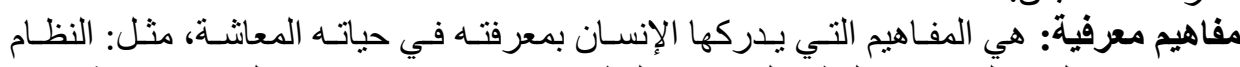

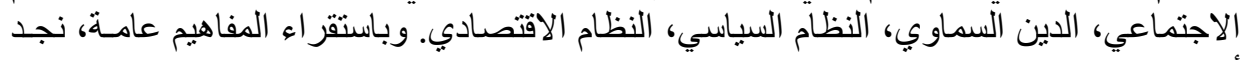
إما أن تكون مفاهيم قديمـة موجودة في البيئة الطبيعية منذ لحظة وجو دها مـن قبـل الله، أنها:

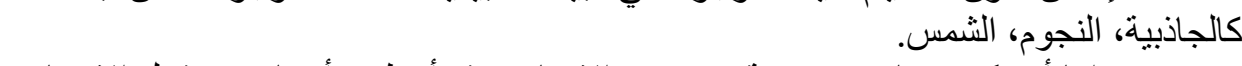

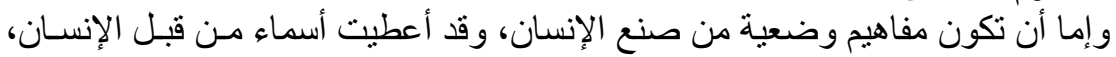

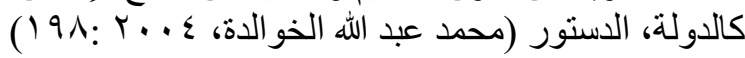




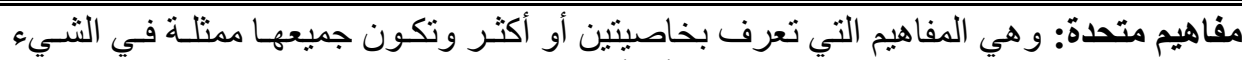

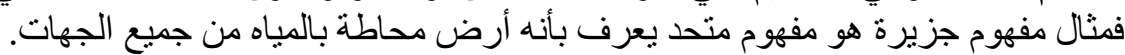

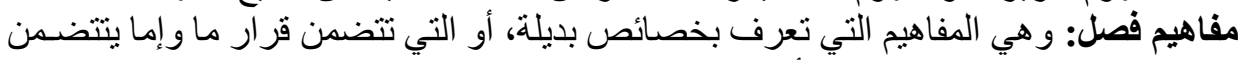

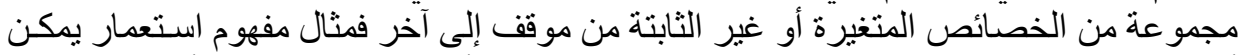

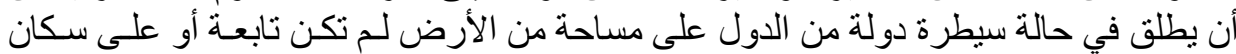

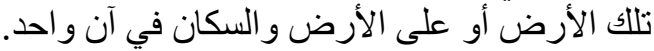

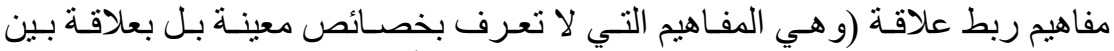
الخصائص فمثال مفهوم كثافة السكان و هو مفهوم ر رابط يعرف بأنه عدد السكان في الميل لمربع.

- - ت تؤدي المفاهيم إلى المساهمة الفاعلة في تعلم التلاميذ بصورة سليمة.

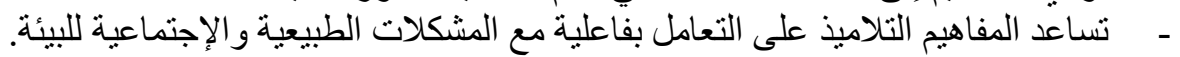

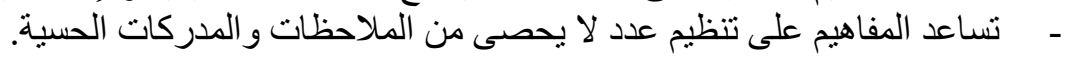
- - - - تساعد المفاهيم على تنظيم الخبرة العقيمة.

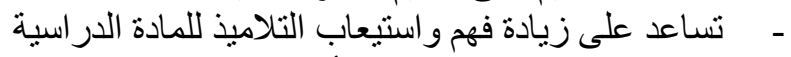

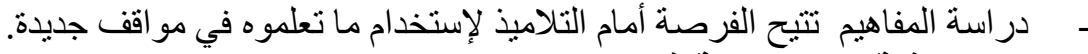

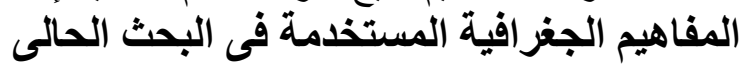

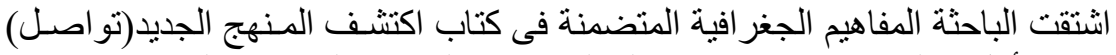

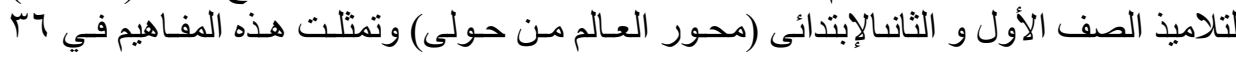

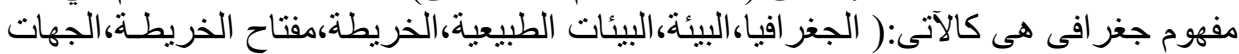

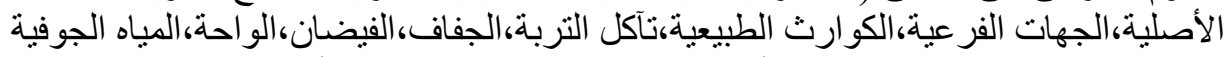

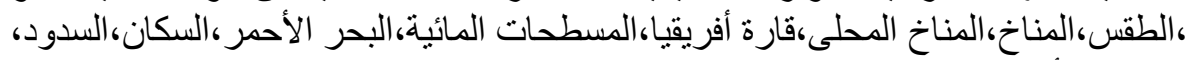

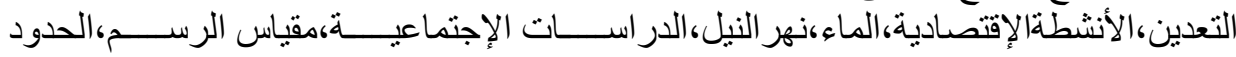

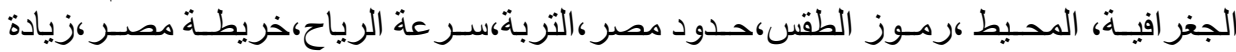

العلاقة بين المنظمات الرسومية (Advance organizers) وتعلم المفاهيم الجغر افية (السكان، القارة)

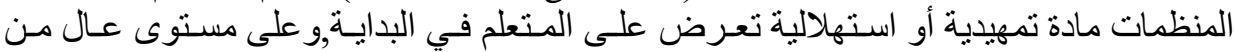

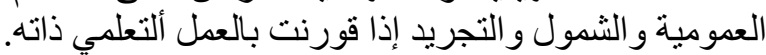

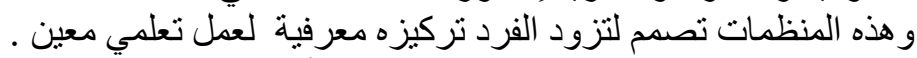

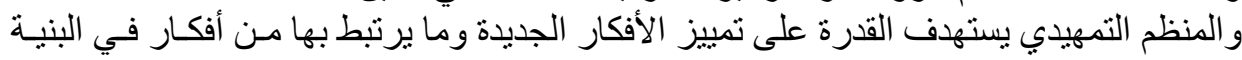

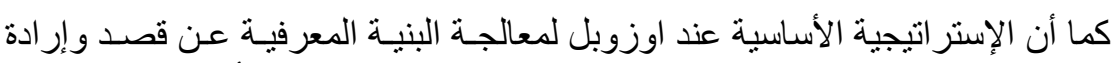

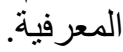

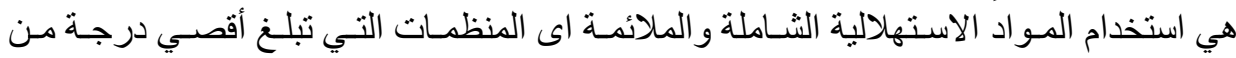

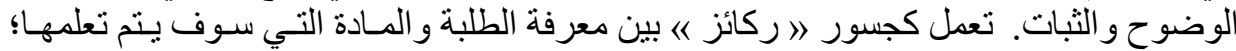
حيث يمكن أن يظهروا التصميمات و العلاقات التنظيمية العامة المخزنة في عقو لهم، و على سبيل 


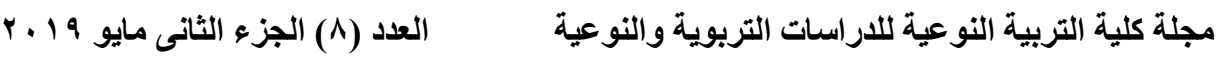

المثال، فإنه قبل تعليم التنظيم الإداري في الدولة، قد يكون من المناسب الحديث عن هيكل التنظيم

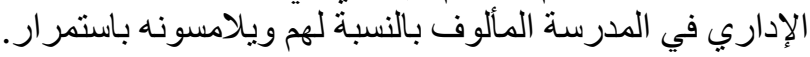

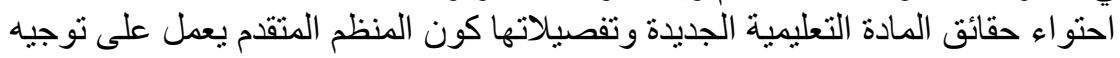

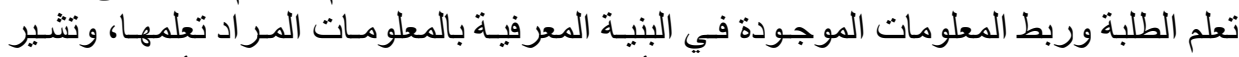

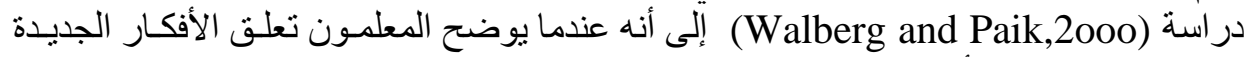

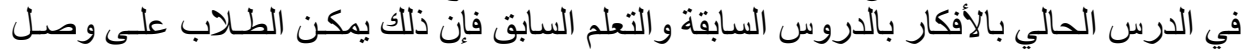

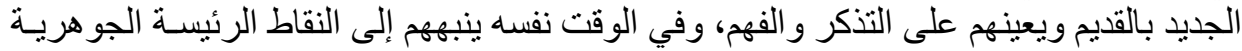

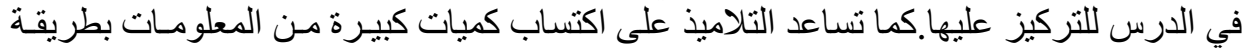

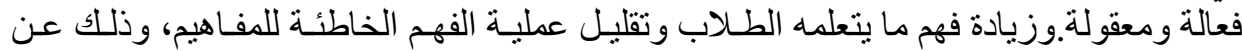

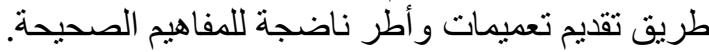

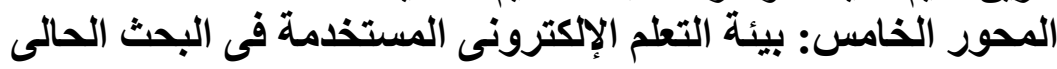
Electronic Learning Environment

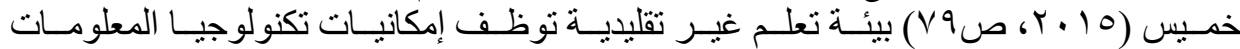
و الاتصالات، لتصميم عمليات التعلم و إدارتها، وتقويمها وتطوير هاو التحقق من تـو افر الأجهزة

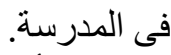
" مراعاة أنماط عرض المحتوى، وذلك من خلال:

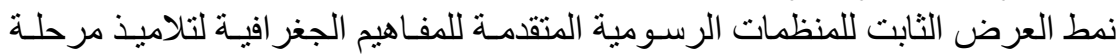
المط العرضى المتحرك للمنظمات الرسومية المتقدمة للمفاهيم الجغر افية لتلاميذ مرحلـة

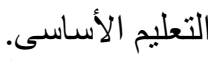

نم إستخدام بعض البر امج مثل برنامج معالج النصوص Word Microsoft للكتئة

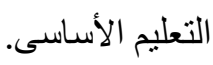

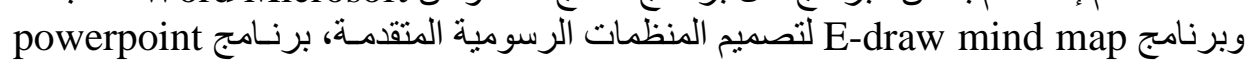

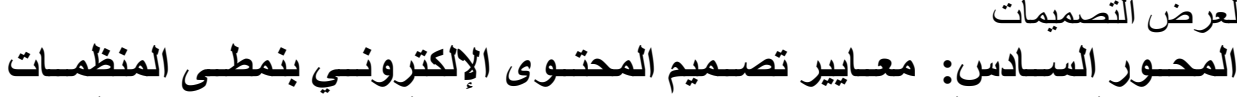

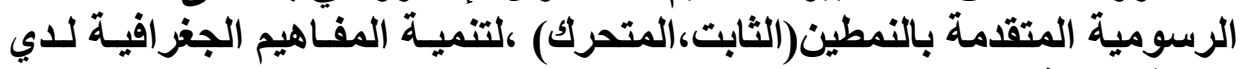

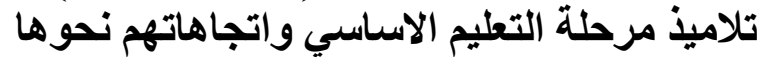

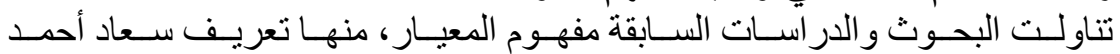

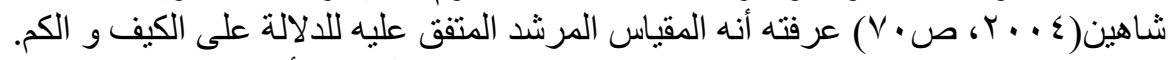

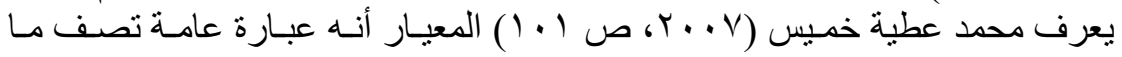

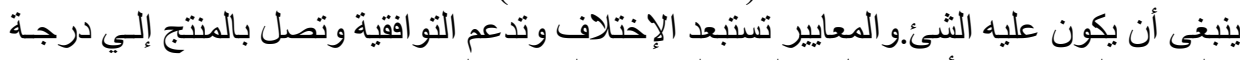

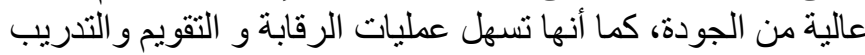

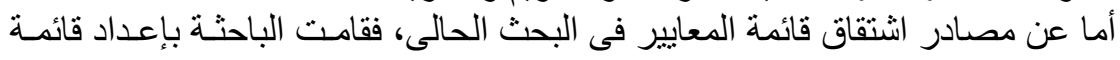

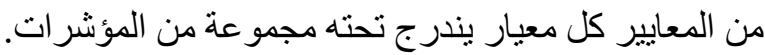




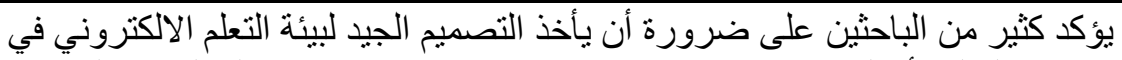

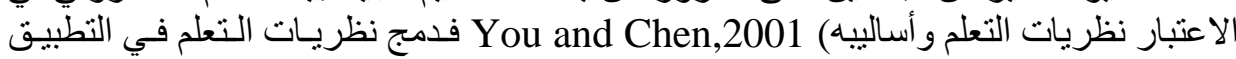

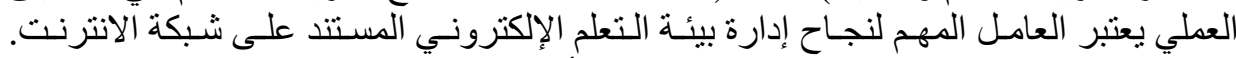

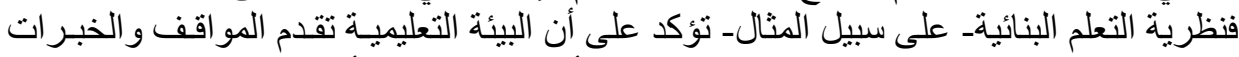

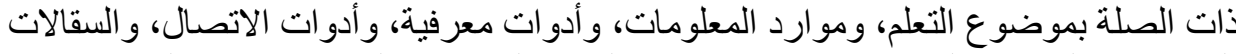

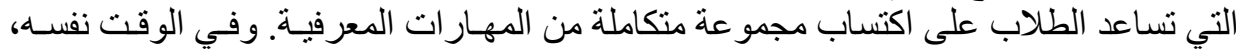

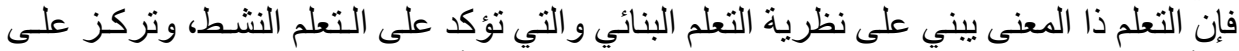

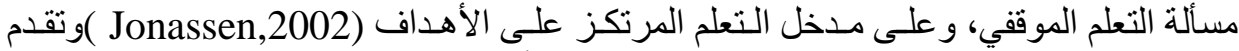

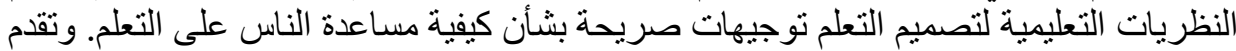

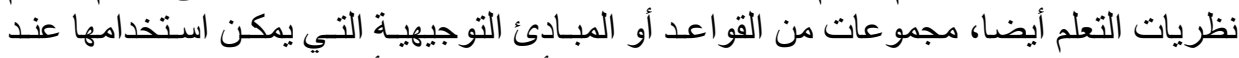

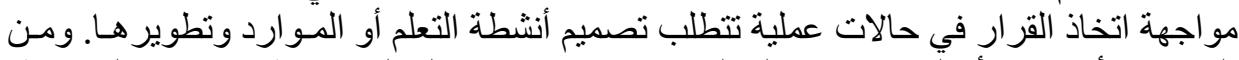

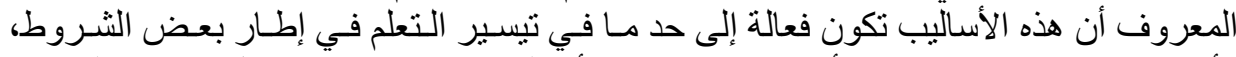

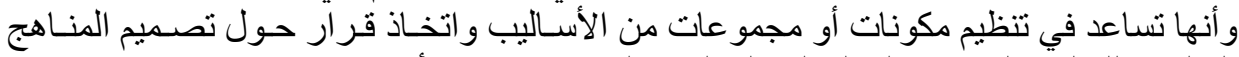

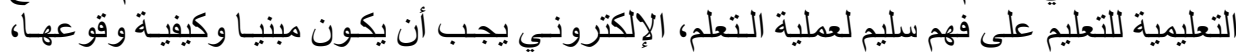

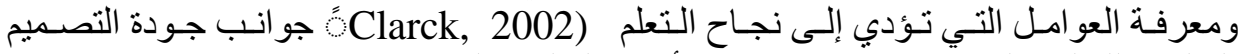

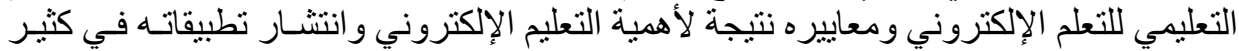

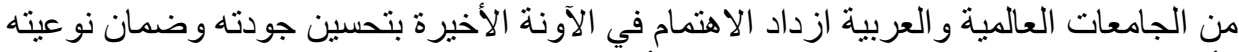

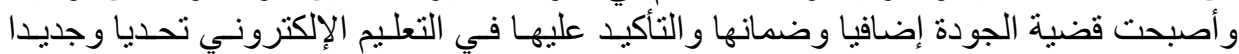

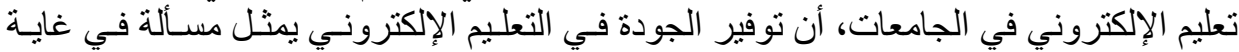

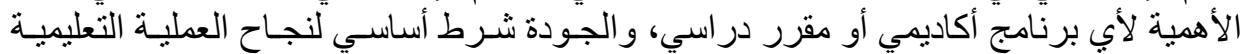

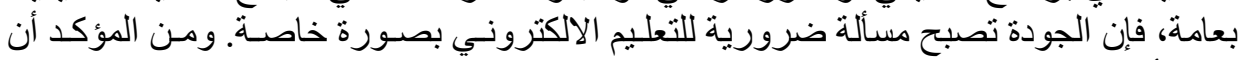

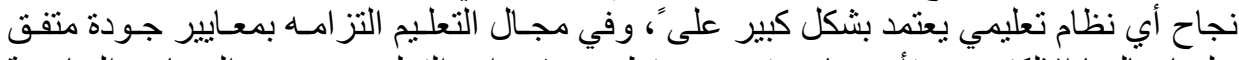

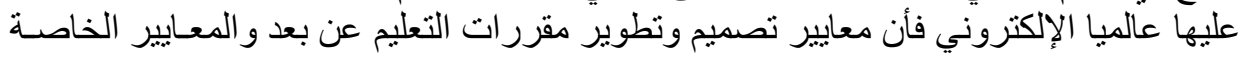

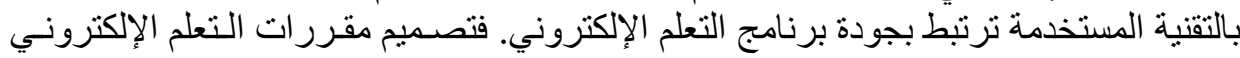

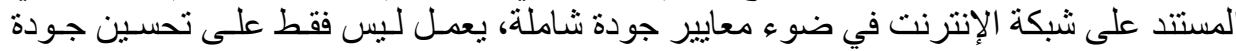

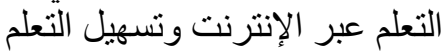

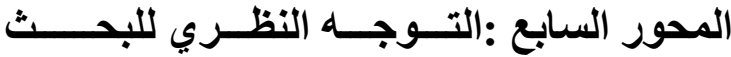

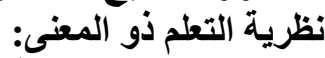

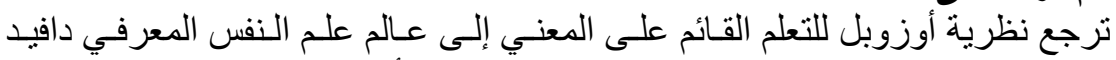

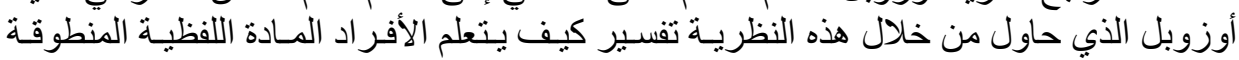

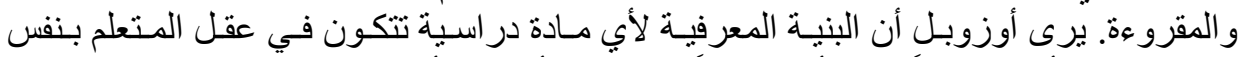

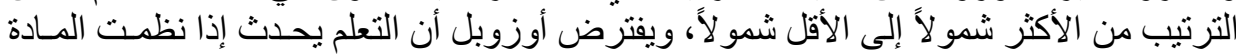

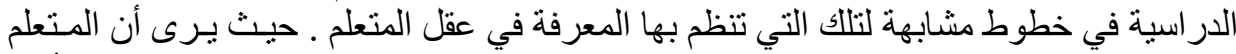

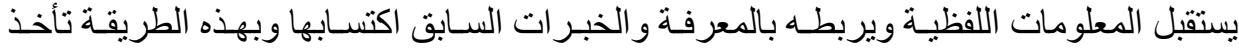

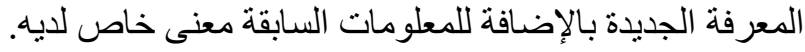




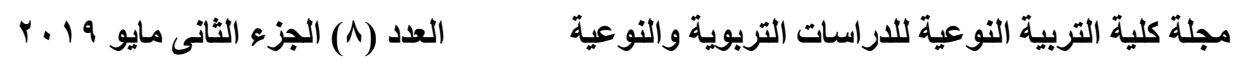
تنظيم المحتوى يقترح أوزوبل للوصول إلى تعلم قائم على المعنى مبدأين لتنظيم المحتوى :

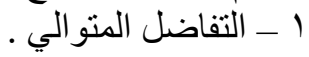

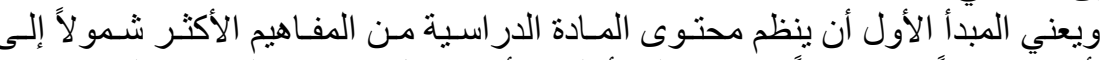

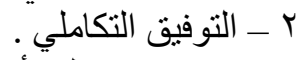

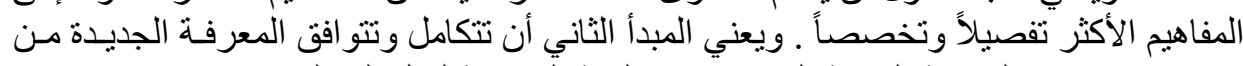

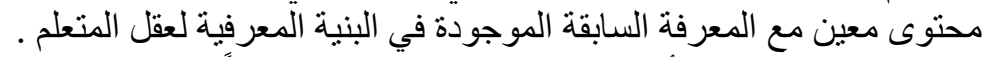

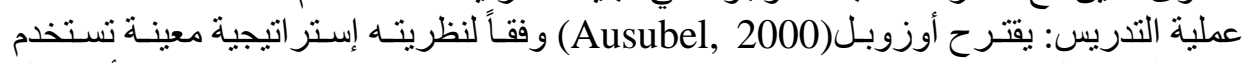

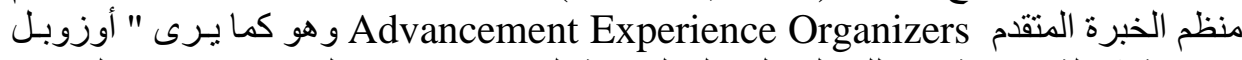

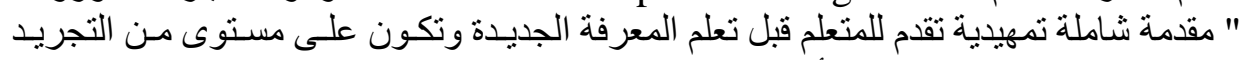

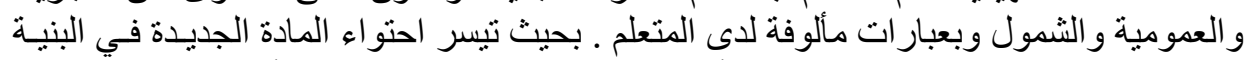

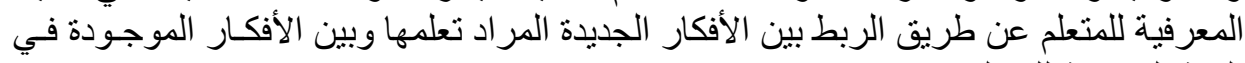

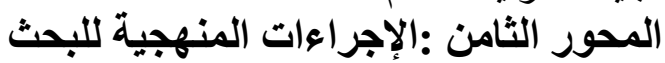

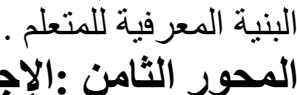

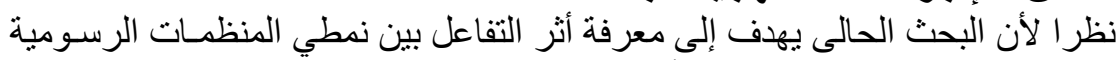

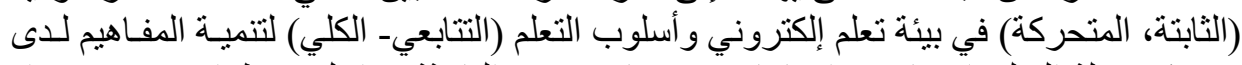

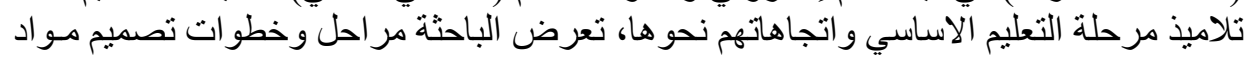

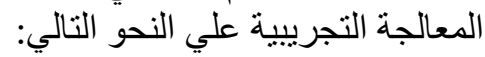

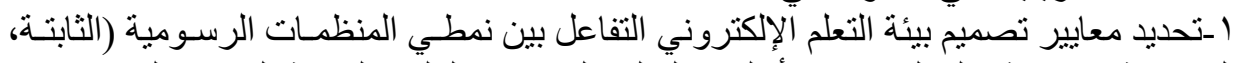

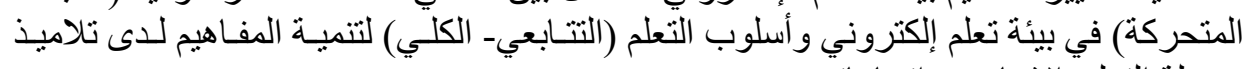

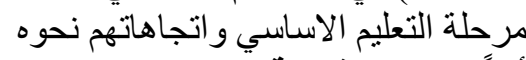

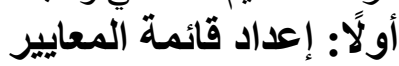

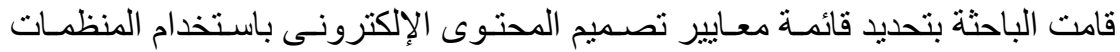

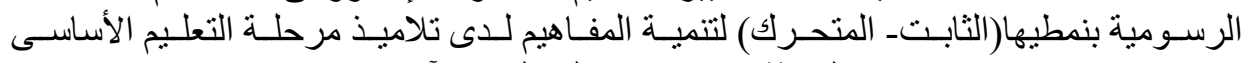
و اتجاهاتهم نحو ها.حيث اتبعت الباحثة الاجر اءات التهات على النحو الآتى: هدف قائمة المعايير

تهدف القائمة الى إعداد معايير تصميم بيئة التعلم الإلكترونسى القائمـة على المنظمـات

الرسومية المتقدمة بنمطيها (الثابتةـ المتحركة معايرة).

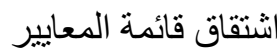

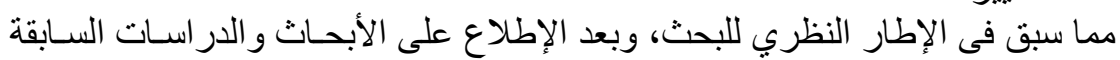

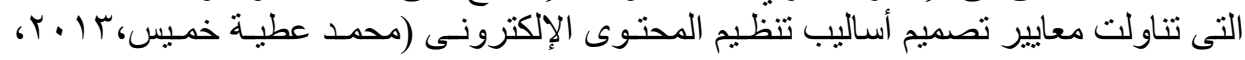

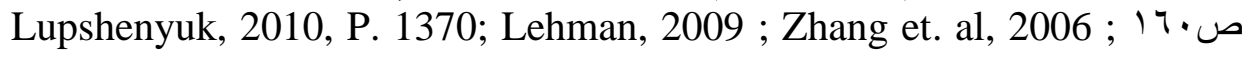

Diamond, 2000 , p.125 ; Reigeluth 2000 , p. 81) اعداد قائمة المعايير فى صورتها المبدئية

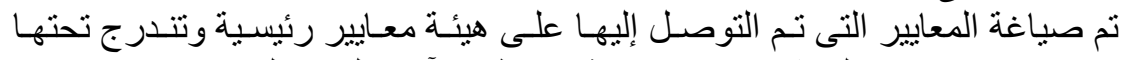

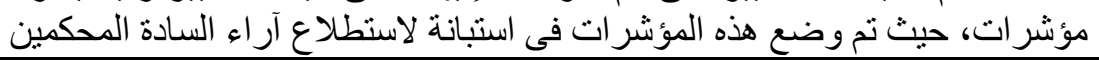




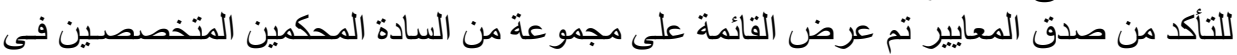

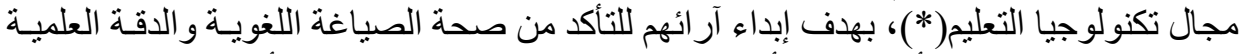

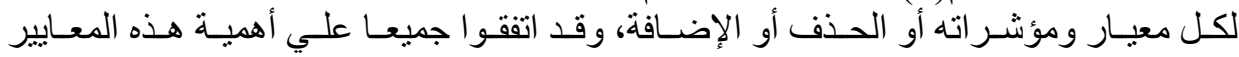

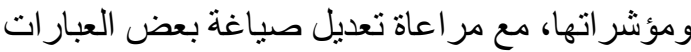
التوصل إلى الصورة النهائية

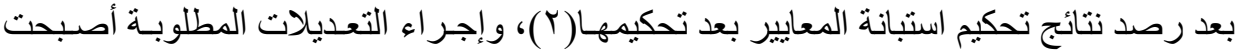

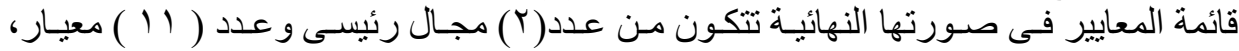
تتضمن (V V ) مؤشرًا وهى:

\begin{tabular}{|c|c|c|}
\hline 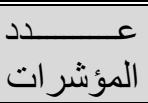 & \multicolumn{2}{|l|}{ 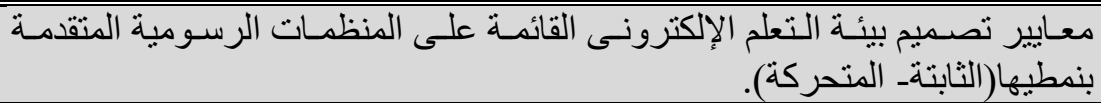 } \\
\hline & \multicolumn{2}{|c|}{ المجال الأول: التصميم التربوى للمنظمات الرسومية المتقدمة بنمطيها(الثابتة_ المتحركة) } \\
\hline 0 & التعليمية المحددة. & \\
\hline $\mathrm{V}$ & 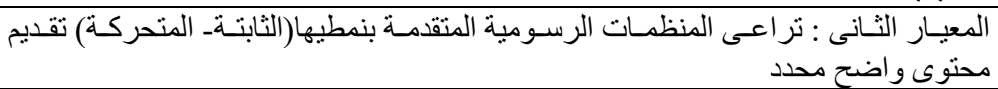 & r \\
\hline $\mathrm{r}$ & 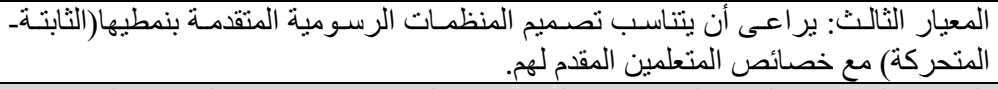 & r \\
\hline & \multicolumn{2}{|l|}{ المجال الثانى: التصميم الفنى المنظمات الرسومية المتقدمة بنمطيها(الثابتةــ المتحركة) } \\
\hline$\Lambda$ & تصميمها. الرابع: ير اعى المنظمات الرسومية المتقدمة بنمطيها(الثابتةـ المتحركة) البساطة فى & $\varepsilon$ \\
\hline$\Lambda$ & 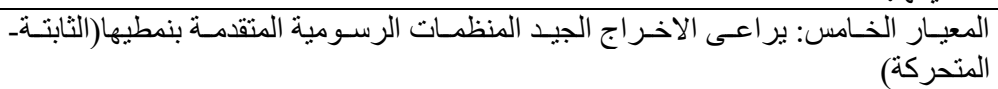 & 0 \\
\hline r & الخطوط بشكل سليم. & 7 \\
\hline$\Gamma$ & 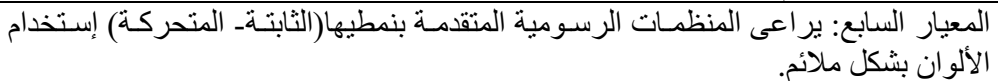 & $\mathrm{V}$ \\
\hline r & 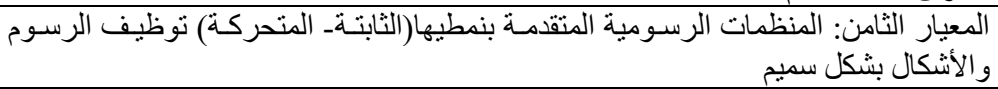 & $\Lambda$ \\
\hline r & 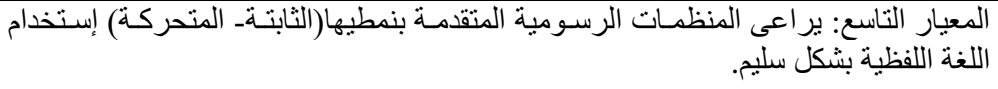 & 9 \\
\hline 0 & المعيار العاثر : بر اعى أن تصمم المنظمات الرسومية المتقدمة بشكل يسهل & 1. \\
\hline r & المعيار الحادى عشر: ير اعى أن تصمم المنظمات الرسومية المنقدمة قابلية إعادة الإستخدام & 11 \\
\hline
\end{tabular}




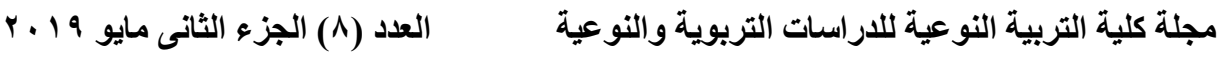

و التصميم التعليمى لبيئة التعليم الإلكترونسى باستخدام نمـوذج محمد عطيـة خمبيس للتصميم و التطوير التعليم التيعيم

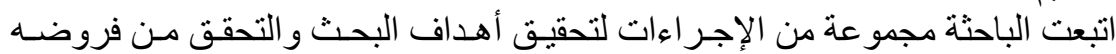

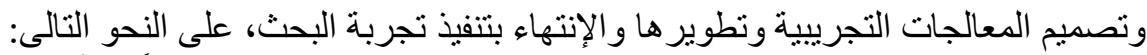

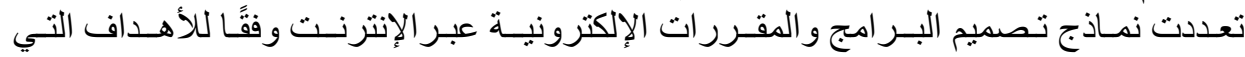

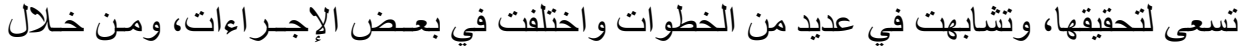

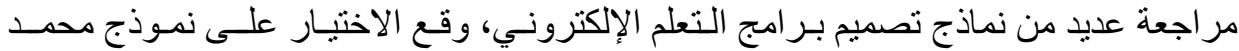

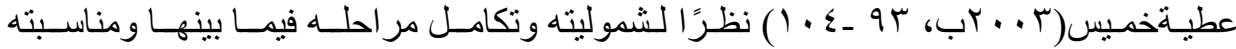

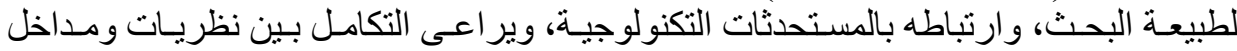

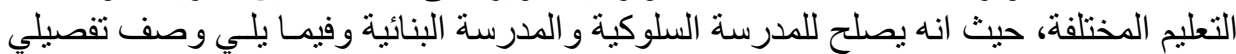

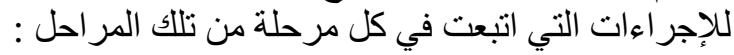

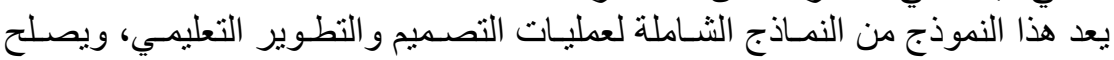

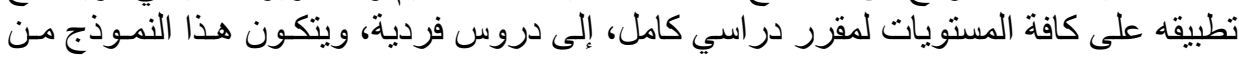

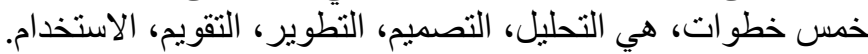

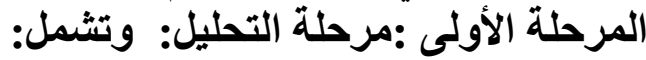

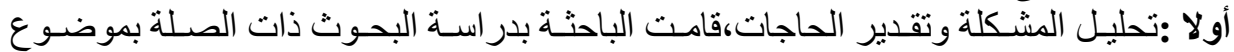

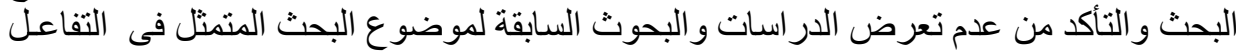

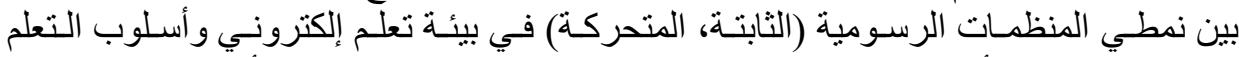

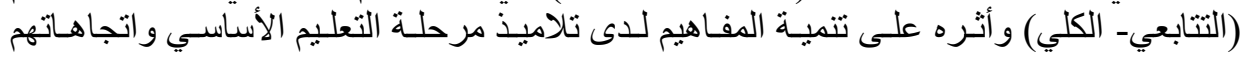

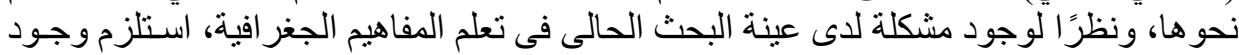

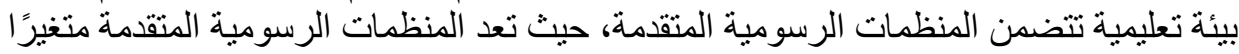

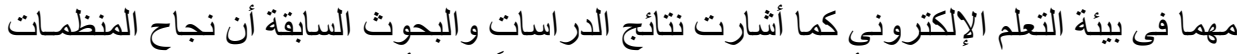

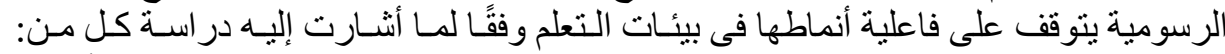
الت 2002

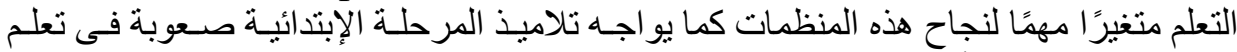

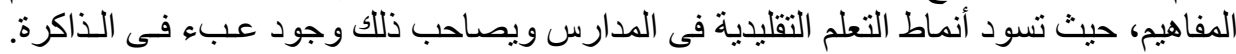

.(Hu \&Wu, 2012)

ثاتيا: تحليل المهمات التعليمية، وذلك بتحليل الغايـات و الأهداف العامـة إلى مكوناتهـا الرئيســة

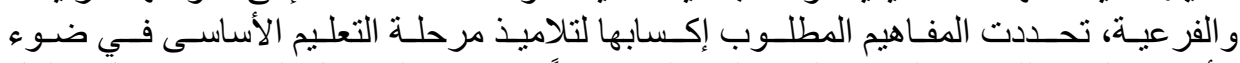

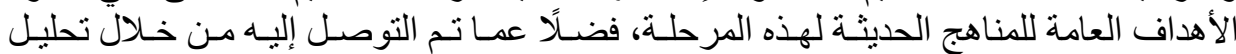

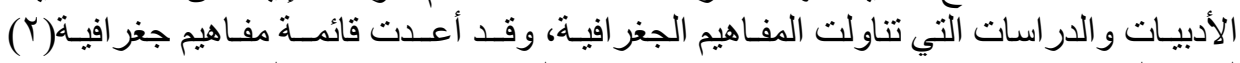

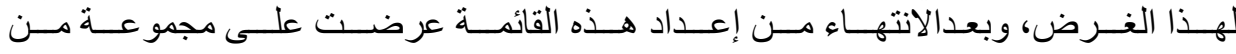




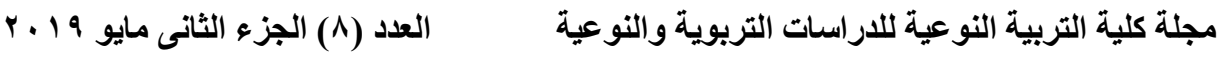

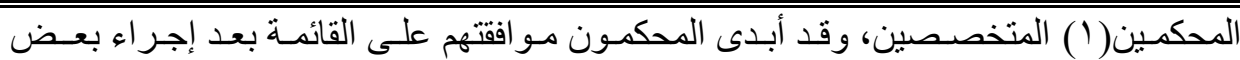

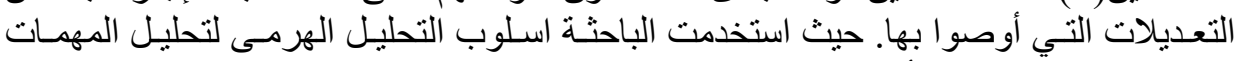

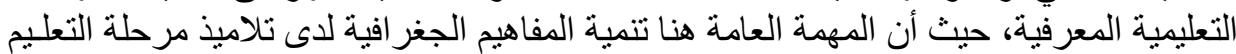

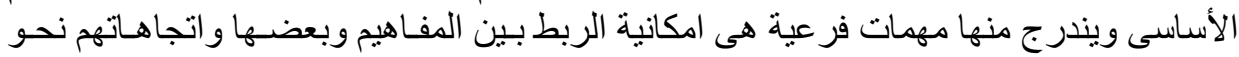

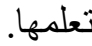
ثالثا: تحليل خصائص المتعلمين وسلوكهم المدخلي، وذلك بتحديد خصائص المتعلمين وقدر اتهم

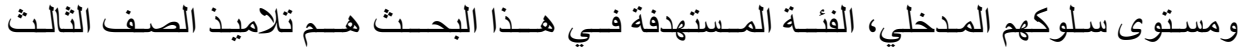

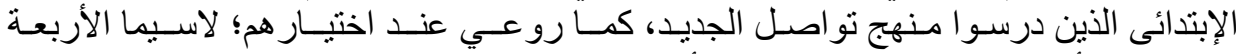

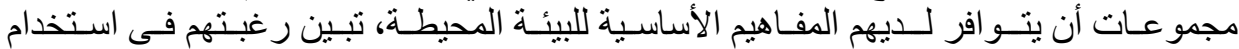

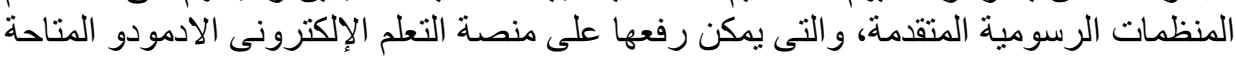

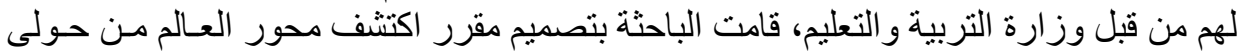

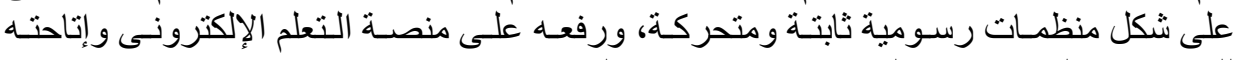

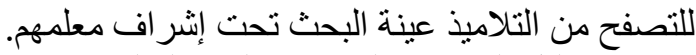

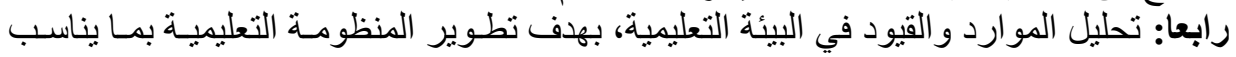

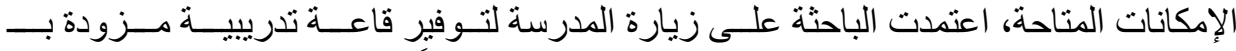

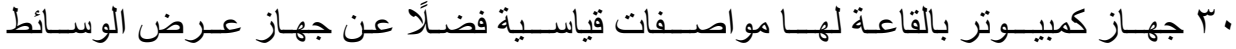

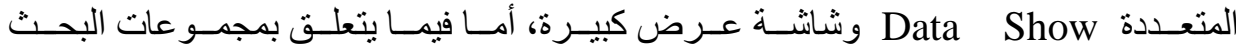

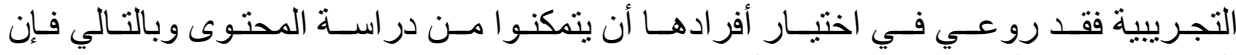

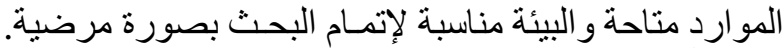

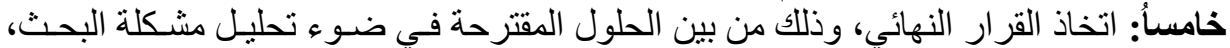

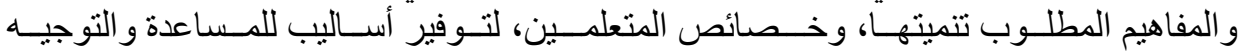

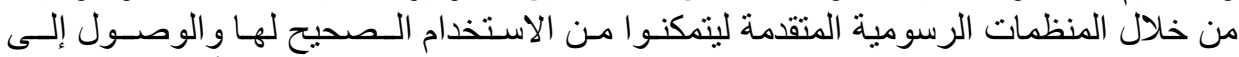

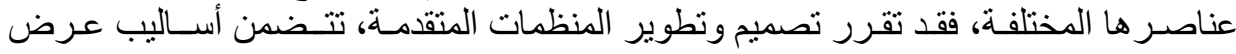

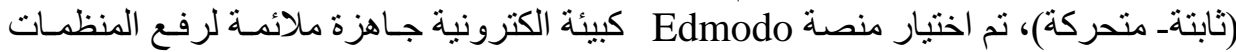

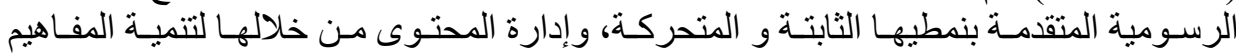

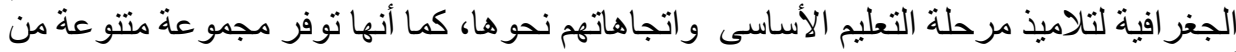

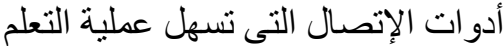

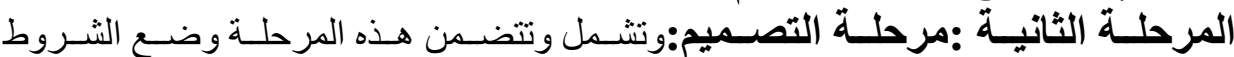

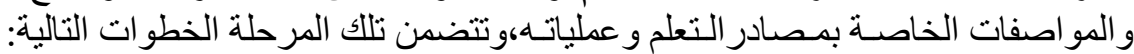

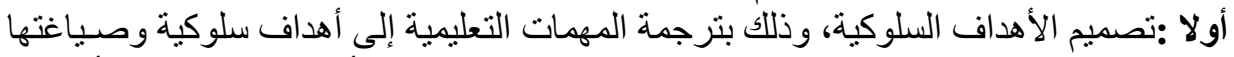

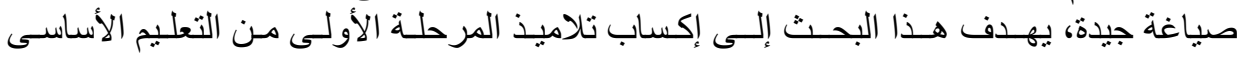

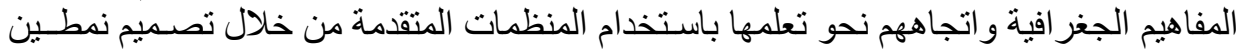

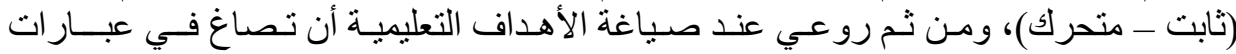




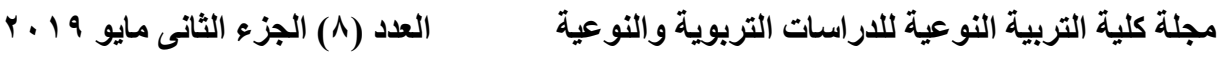

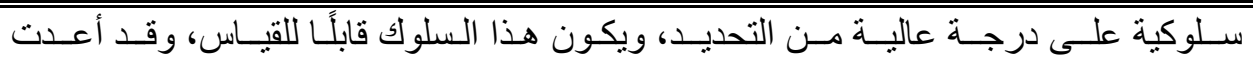

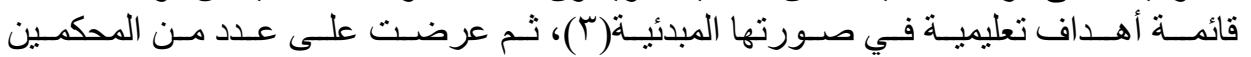

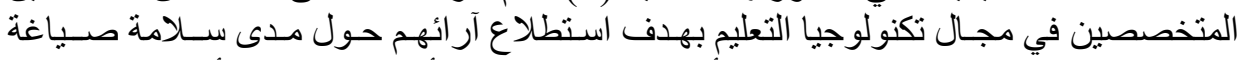

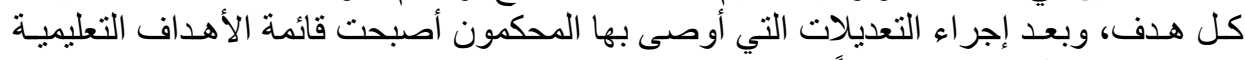
في صورتها النهائية (ع ؟ ) هدفًا.

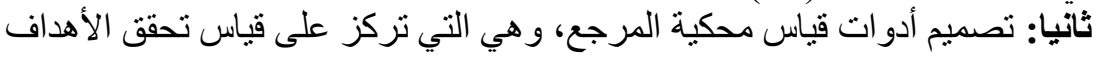

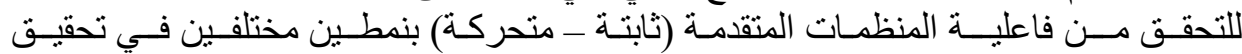

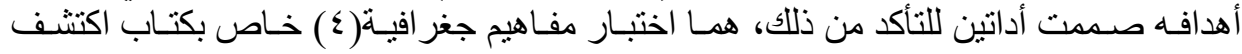

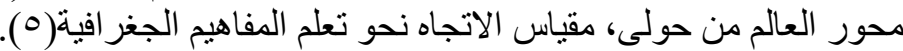

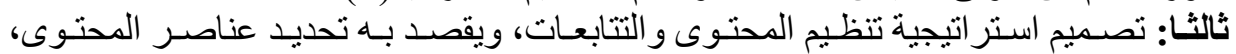

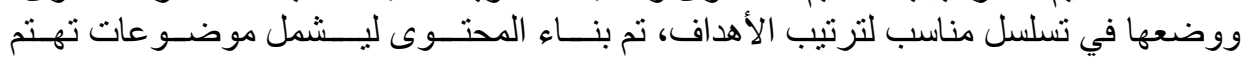

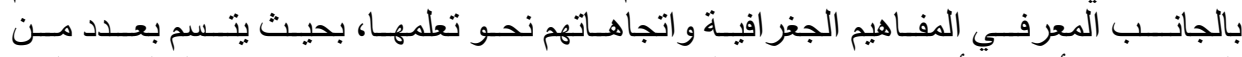

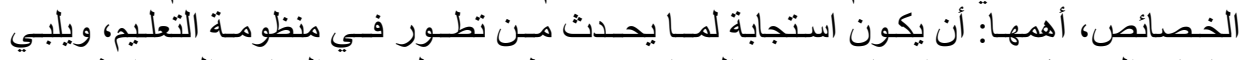

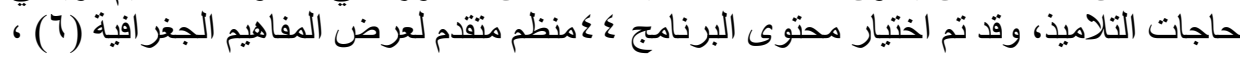

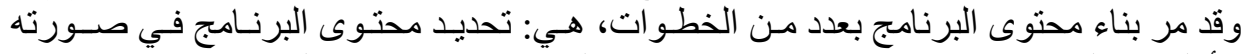

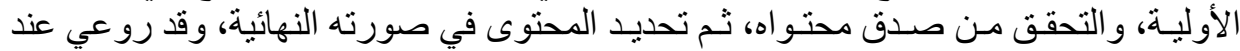

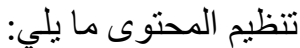

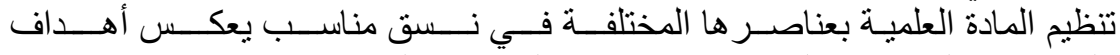

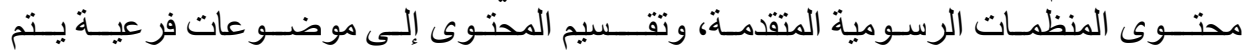

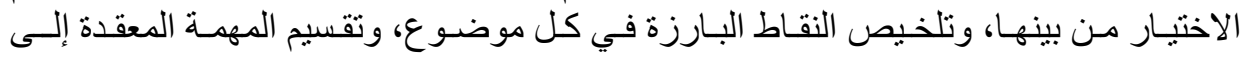

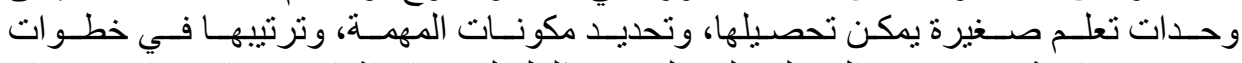

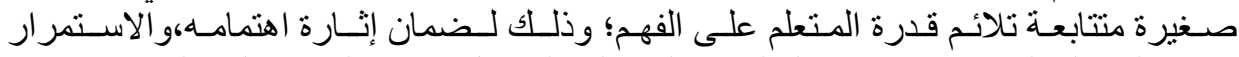

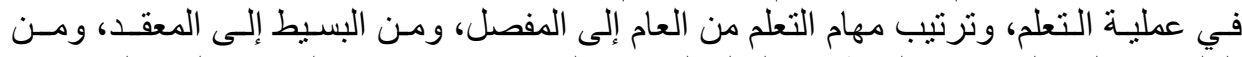

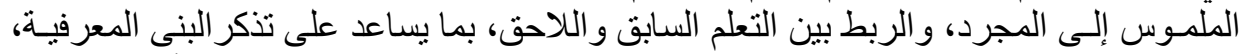

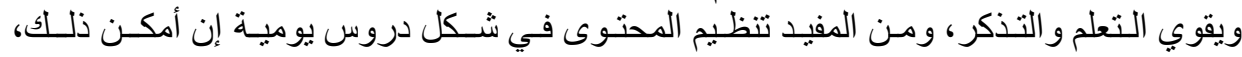

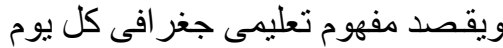

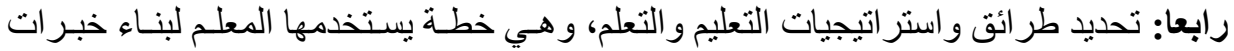

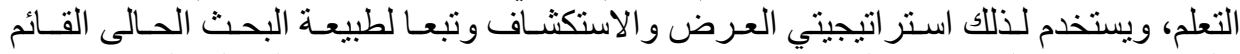

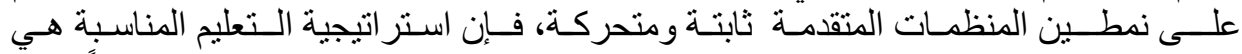

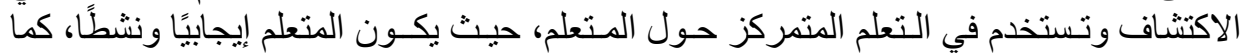




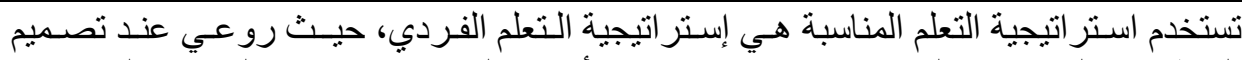

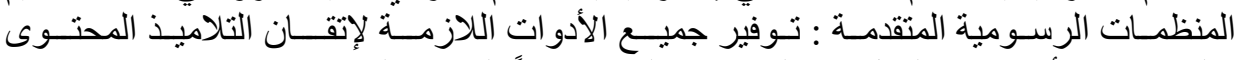

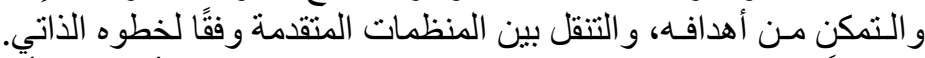

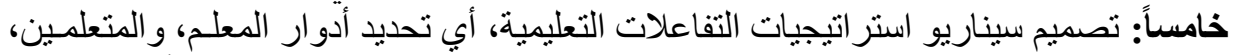

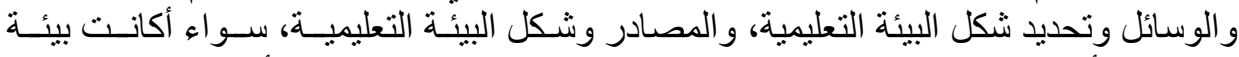

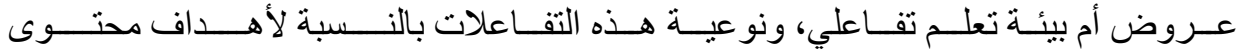

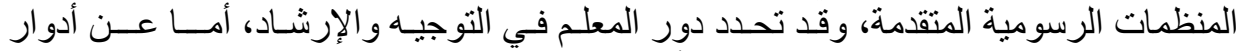

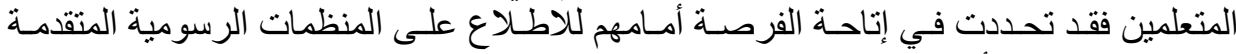

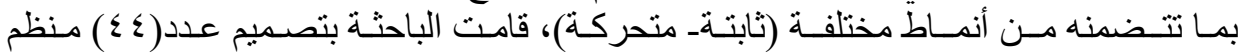

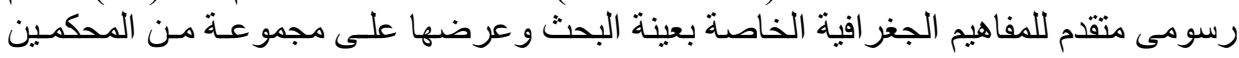

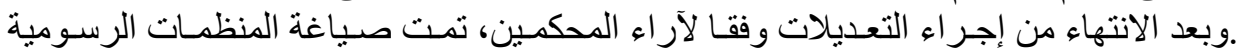

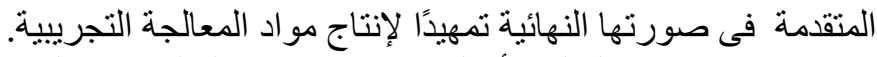

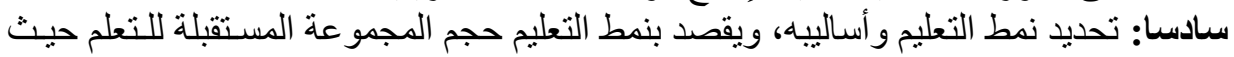

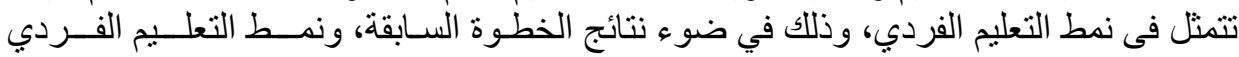

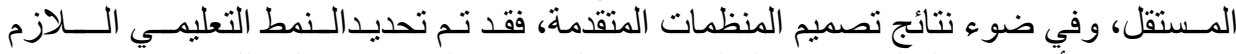

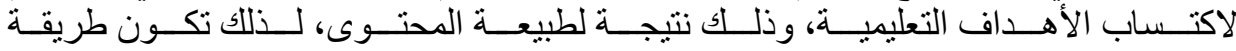

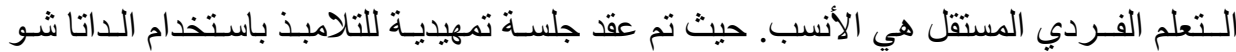

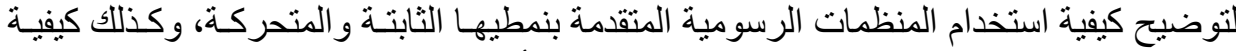

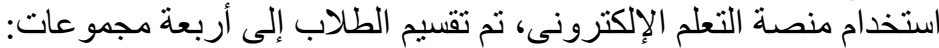

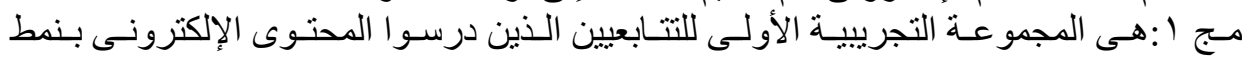
المنظمات الرسو مية الثابتة.

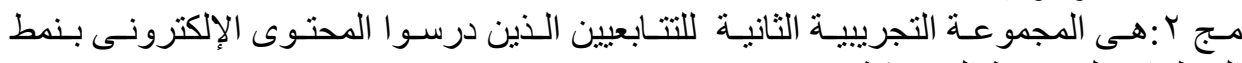
المنظمات الرسو المية المتحركة. المجئ.

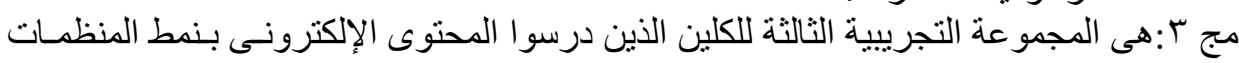

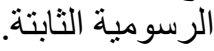

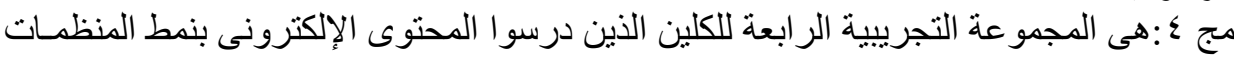

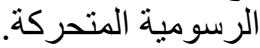

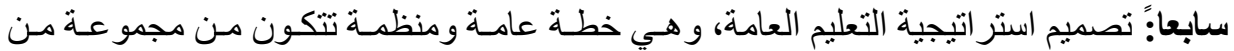

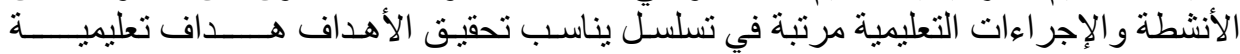

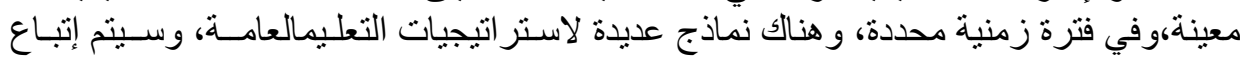

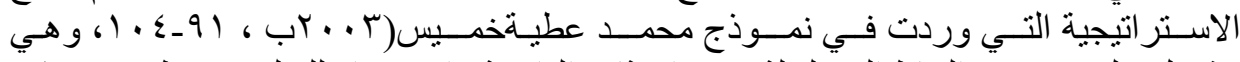

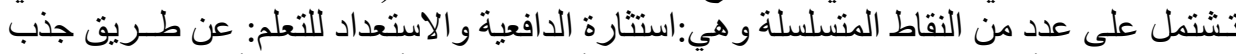

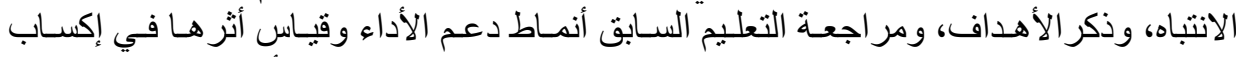

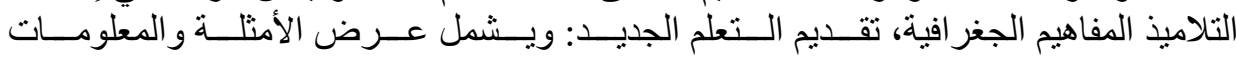

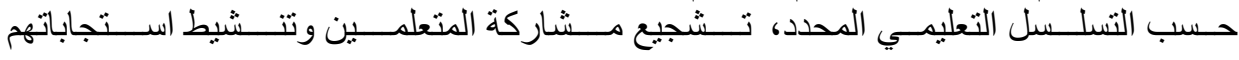




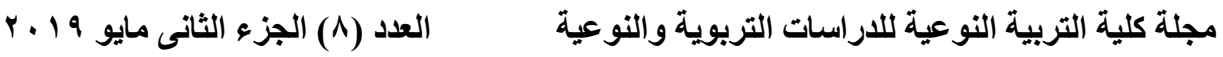

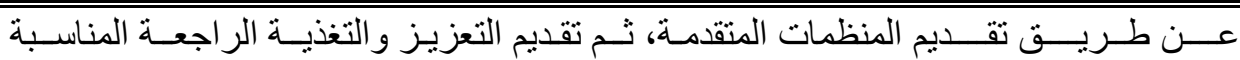

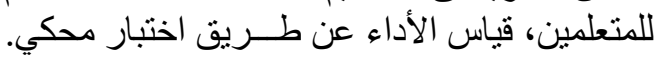

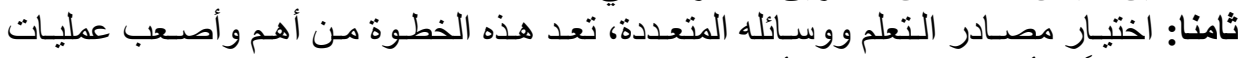

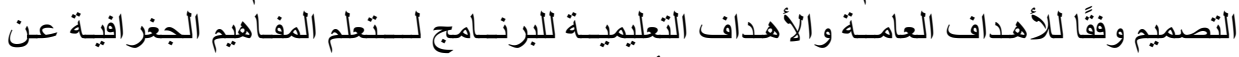

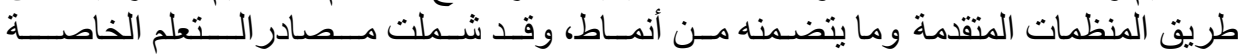

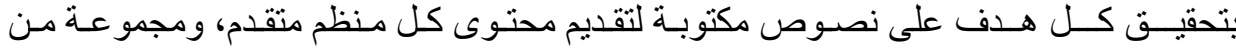

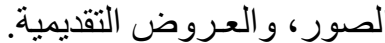

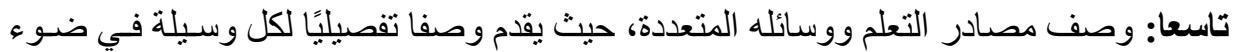

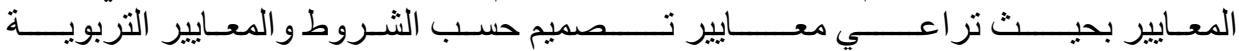

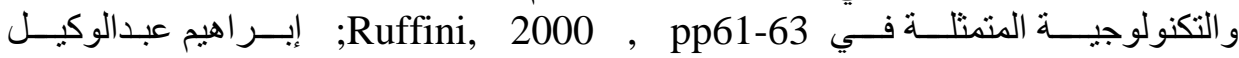

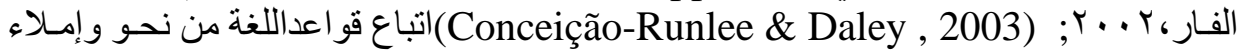

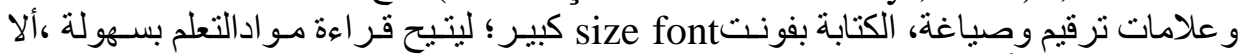

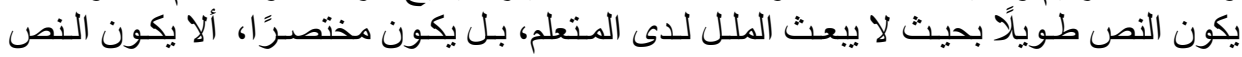

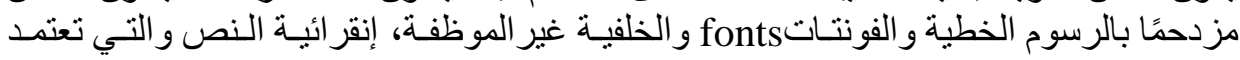

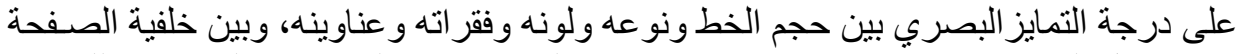

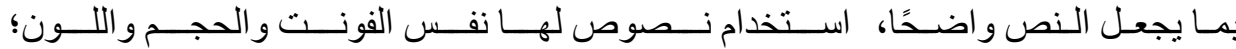

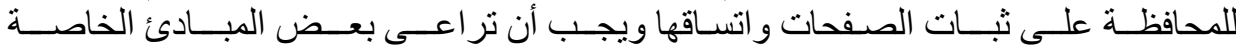

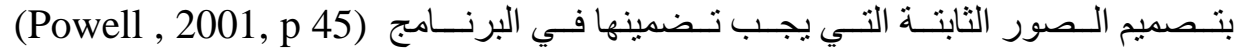
(Ruffini, 2000 , pp 60 - 62)

عاشراً: اتخاذ القرار بشان الحصول على المصادر أو إنتاجها، وذلك في ضـوء نتـائج عمليـات

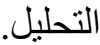
المرحلة الثالثة :مرحلة التطوير التعليمي:

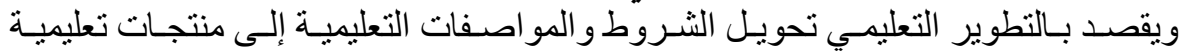

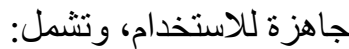

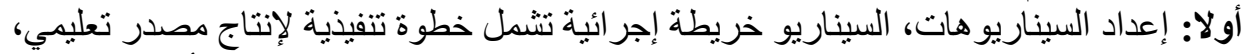

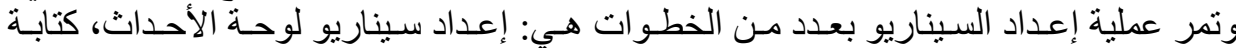

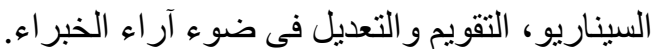

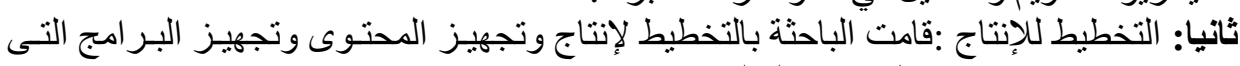

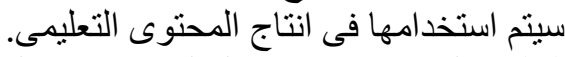

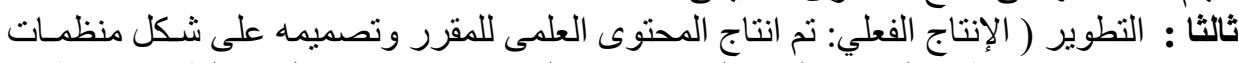

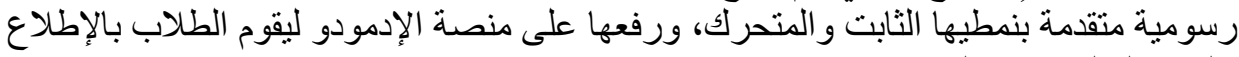

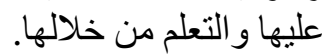

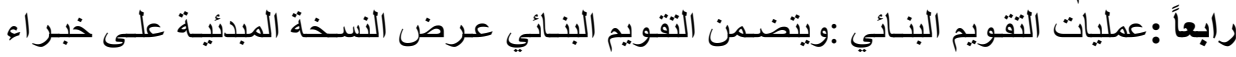

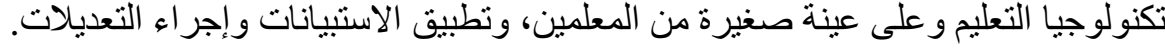
المرحلة الر ابعة :مرحلة التقويم النهائي: 


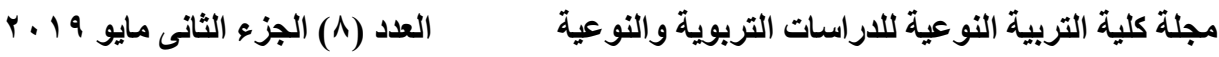

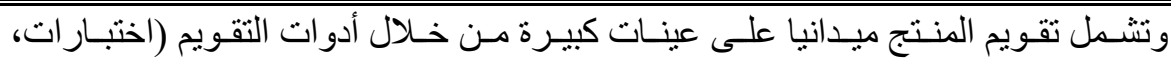

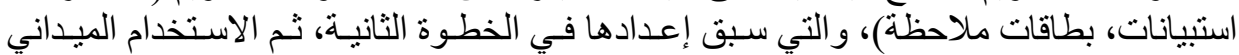

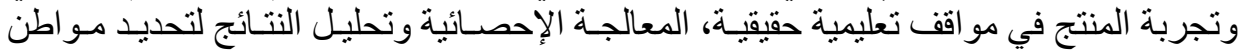

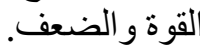
المرحلة الخامسة :مرحلة النشر والاستخدام والمتابعة:

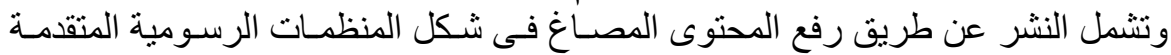

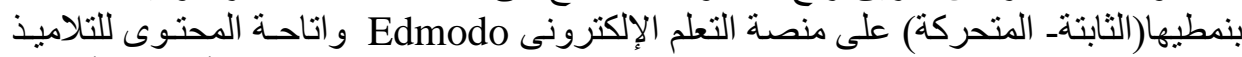

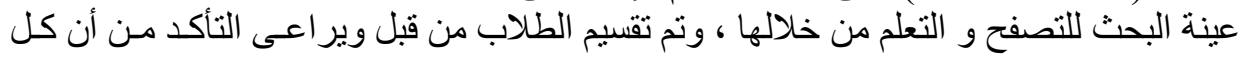
تلميذ فى مجمو عته الصحيحة التبني ويتضمن تجريب المستحدث؛ وذلك بغرض التأييد و القبول للمنتج، وتبني المنتج من قبل الأفر ادو المنظمات ولتئن

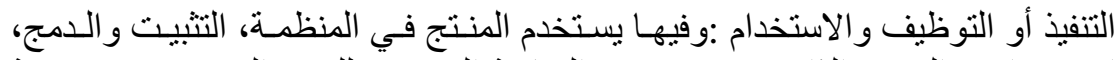

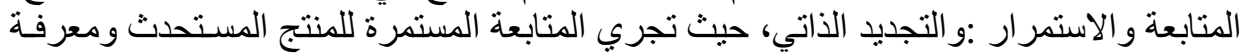

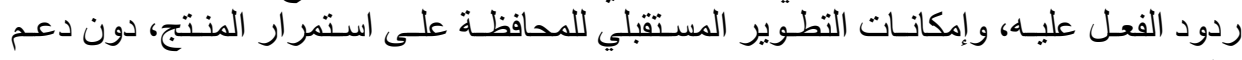

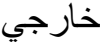

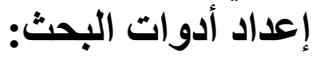

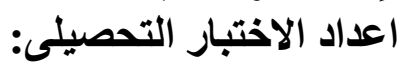

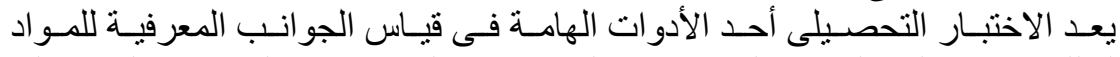

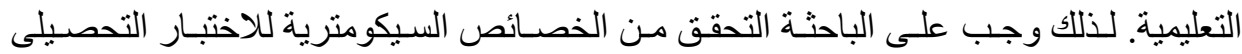

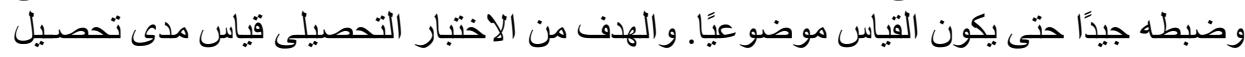

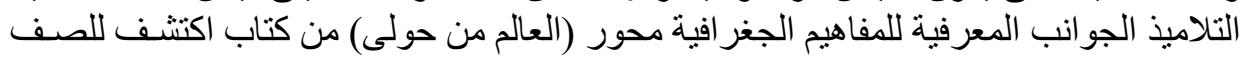

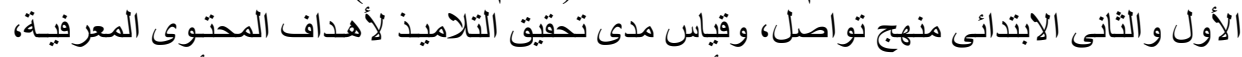

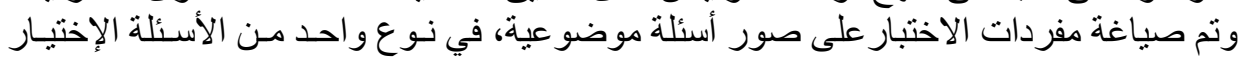

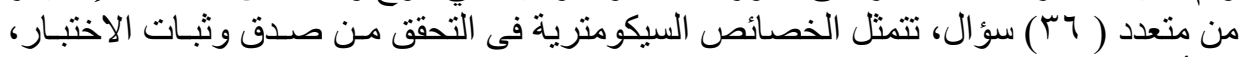

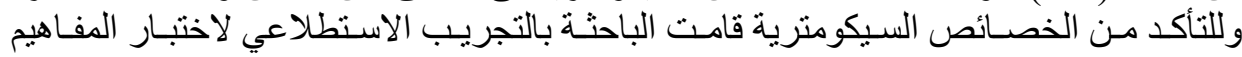

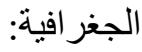

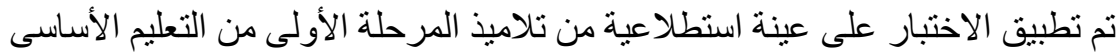

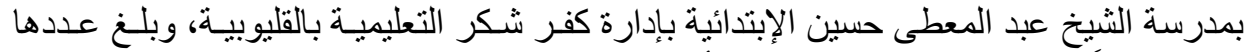

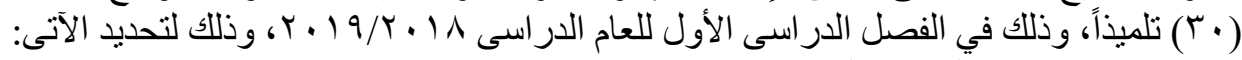

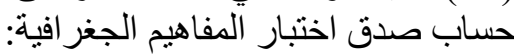

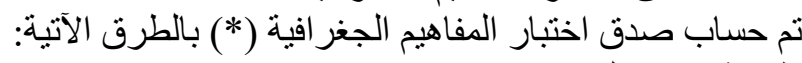

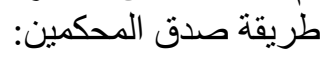




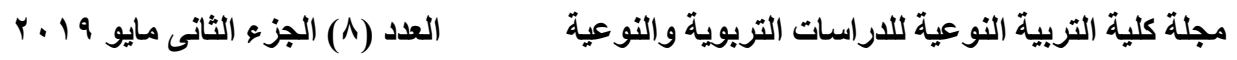

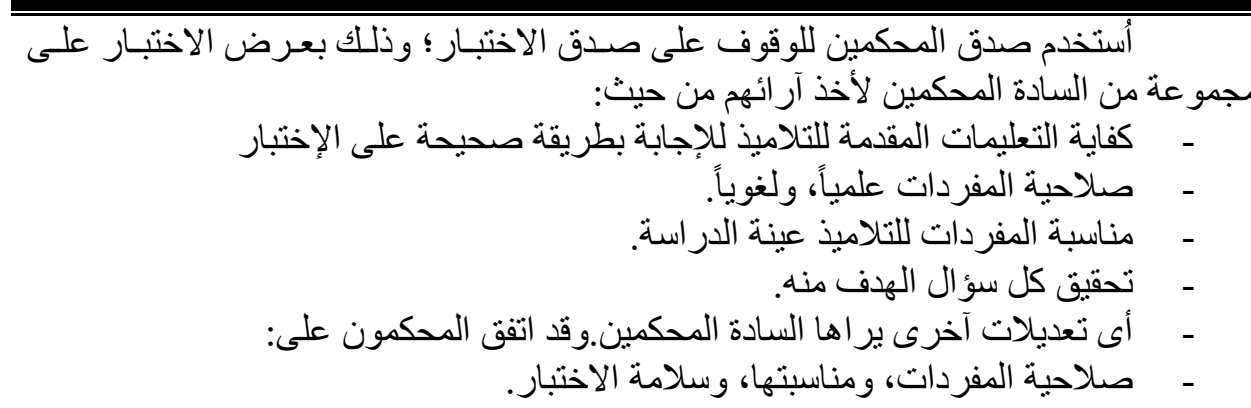

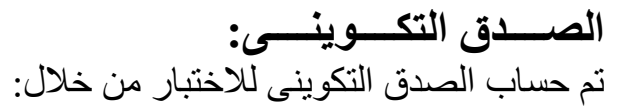

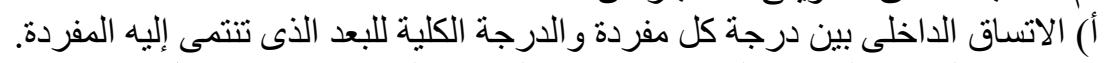

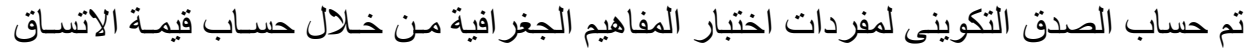

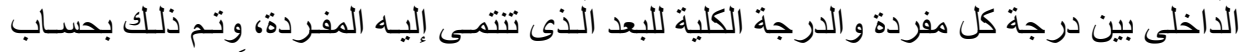

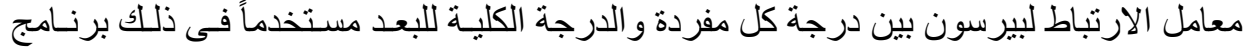

.SPSS V.18

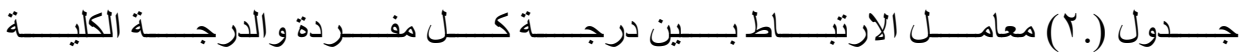

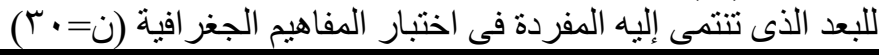

\begin{tabular}{|c|c|c|c|c|c|c|c|c|}
\hline البعد & الإرتباط & مفيــرد & البعد & الإرتباط & الاختبار & البعد & الإرتباط & الاختبار \\
\hline فهر & **, , Тד & ro & تطبيق & $* *,, 0 \wedge \wedge$ & $\pi$ & تذكر & $* * ., 7 r \leqslant$ & 1 \\
\hline تذكر & **., 707 & דצ & تذكر & $* * ., 790$ & $1 \varepsilon$ & تذكر & **., TrT & r \\
\hline تذكر & **., 707 & TV & تذكر & $* *, 0 \leqslant 0$ & 10 & فهر & $* * ., 791$ & r \\
\hline تذكر & $* *,, 741$ & rᄉ & تذكر & $* *$. , $\vee 9$ & 17 & تذكر & $* *, 0 \leqslant r$ & $\varepsilon$ \\
\hline فهز & $* *,, 1 \leqslant$. & rq & فهر & $*,, r \wedge \varepsilon$ & IV & تذكر & $* * ., 01 Y$ & 。 \\
\hline تطبيق & $* *, \quad \vee T_{0}$ & r. & تذكر & $* \cdot, \varepsilon Y T$ & 11 & فهم & $*_{.},\{07$ & 4 \\
\hline فهز & $* *, \quad V \vee \varepsilon$ & M & تذكر & $* *,, \vee, q$ & 19 & فهز & $* *, V, V I$ & v \\
\hline تذكر & $* *, 09 \leqslant$ & r & تذكر & $* * ., 7 \leqslant 7$ & r. & تطبيق & $* *, 01 \leqslant$ & $\wedge$ \\
\hline تذكر & **., OY Y & זr & تذكر & **., & r) & تذكر & $* *,, \leq 9 \wedge$ & $q$ \\
\hline تطبيق & $* \cdot, \leqslant r q$ & r & تطبيق & **.,07r & rT & فهز & $* * .$, AV & 1. \\
\hline تذكر & $* * ., 09 \leqslant$ & ro & تذكر & $* * ., \leqslant 9 १$ & Tr & تذكر & $* *, 011$ & 11 \\
\hline فهم & $*_{0}, \varepsilon \Gamma \leqslant$ & די & تذكر & $* * \cdot, \leqslant \wedge q$ & $r \varepsilon$ & فهم & $* *,, \uparrow \wedge$ & ir \\
\hline
\end{tabular}

ب) الاتساق الداخلى بين درجة كل بعد والارجة الكلية للاختبار. 


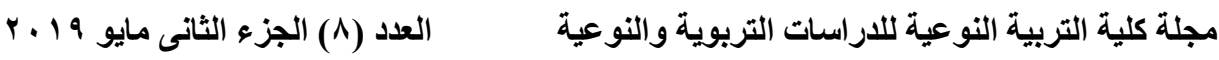
تم حساب الصدق التكوينى لأبعاد الاختبار من خلال حساب قيمة الاتساق الداخلى بين

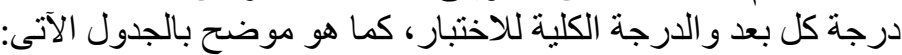

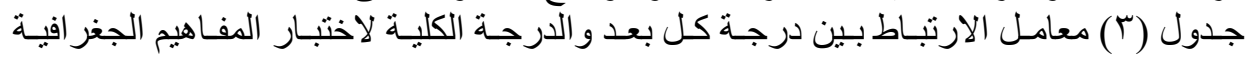

\begin{tabular}{|c|c|c|c|}
\hline التطبيق & الفهم & التذكر & البعد \\
\hline 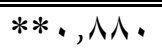 & (**,,907 & 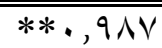 & معامل الارتباط \\
\hline
\end{tabular}

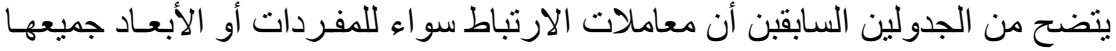

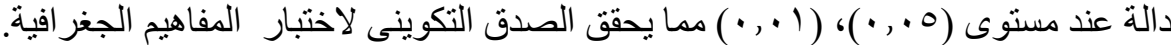

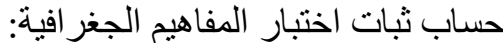

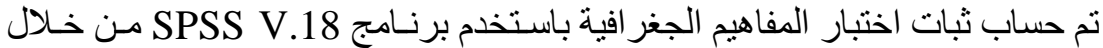

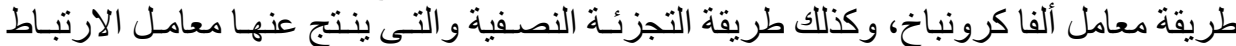

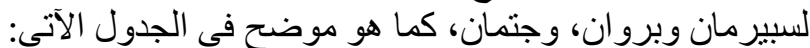

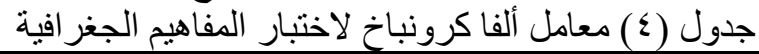

\begin{tabular}{|c|c|c|c|}
\hline & طربر اون & معامل ألفا كرونباخ & الاختبار \\
\hline$\cdot, 9 \leq 7$ & $\cdot, 9 \leq 1$ & $\cdot, 9 \leq r$ & قيمة معامل ثبات الاختبار \\
\hline
\end{tabular}

يتضح من الجدول السابق أن قيمة معامل الثبات لاختبار المفاهيم الجغر افية قيمة كبيرة ومرتفعة؛ مما يدل على ثبات الاختبار و الوثنوق فئ التئ نتائجة.

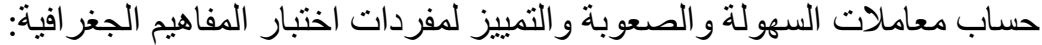

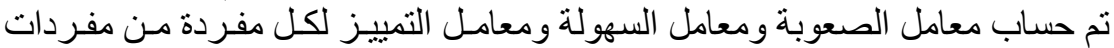
اختبار المفاهيم الجغر افية. 


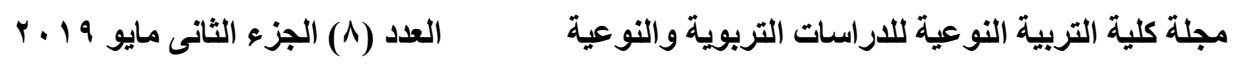

\begin{tabular}{|c|c|c|c|c|c|c|c|}
\hline التمبيزيـــاملات & السهولة & معــــاملات & المفردة & التمبيز & السـهولة & معاملغت & المفردة \\
\hline י & $\cdot, v \cdot$ & • & 19 & $\cdot, \wedge \wedge$ & $\cdot, \leqslant \mu$ &., $0 \mathrm{~V}$ & 1 \\
\hline$\cdot, \vee>0$ & חד, • & • TV & $r$. &,$- \vee 0$ & $\cdot, 0$. & $\cdot, 0$. & r \\
\hline$\cdot, \wedge \wedge$ & $\cdot, 7 V$ & سז, • & YI & $\cdot, \vee 0$ & $\cdot, V$. & • • & r \\
\hline$\cdot, \vee>0$ & س , & $\cdot, \leqslant V$ & Yr &,$- \vee 0$ & $\bullet, \varepsilon$. & $\cdot, 7$. & $\varepsilon$ \\
\hline זד, • &., $0 \mathrm{~V}$ & • & r & זד, • &., 0 . &., 0 . & 0 \\
\hline זד, י & r &., $0 \mathrm{~V}$ & $T \leq$ & זד, י & $\bullet, \Sigma$. & $\cdot, 7$. & 7 \\
\hline חד, & חד, • & • , V & ro & - , $\vee 0$ &., $0 \mathrm{~V}$ & - & V \\
\hline חצ, . & $\cdot, \vee \vee$ & سY, & ד r &, 0 . & س & $\cdot, r V$ & $\Lambda$ \\
\hline$\cdot, 0$ & • , & $\cdot, r V$ & TV & $\cdot, \vee_{0}$ & $\cdot, \varepsilon$. & $\cdot, 7$. & 9 \\
\hline זד, י & $\cdot, 7$. & $\cdot, \varepsilon$. & rᄉ & $\cdot, \wedge \wedge$ & $\cdot, 7 V$ & سז, • & 1. \\
\hline$\cdot, \wedge \wedge$ & r &., $0 \mathrm{~V}$ & $r q$ & $\cdot, \vee>0$ & r, & $\cdot, \leqslant V$ & 11 \\
\hline$\cdot,>0$ & $\cdot, 0$. & $\cdot, 0$ & r. & "ד, י & $\cdot, 7$. & $\cdot, \varepsilon$. & IT \\
\hline$\cdot, \wedge \wedge$ & $\cdot, 7$. & $\cdot, \varepsilon$. & ו &., 0 . & $\cdot, 0$. & $\cdot, 0$. & Tr \\
\hline$\cdot, \vee 0$ & $\cdot, \leqslant V$ & •, or & r & $\cdot, \vee 0$ & $\cdot, 7$. & $\bullet, \varepsilon$. & $1 \varepsilon$ \\
\hline$\cdot, \vee 0$ & $\cdot, \leqslant V$ & •, & rr & $\cdot, \vee 0$ & $\cdot, \leq \Gamma$ & $\cdot, 0 \mathrm{~V}$ & 10 \\
\hline • , & $\cdot, r V$ & $\cdot, V T$ & r & - , \o & $\cdot, \leqslant \Gamma$ & $\cdot, 0 \mathrm{~V}$ & 17 \\
\hline$\cdot, \vee 0$ & $\cdot, \leqslant V$ & •, Or & ro & $\cdot, 0$. & $\cdot, \leqslant V$ & •, & IV \\
\hline ש & $\bullet, \Sigma$. & $\cdot, 7$ & דr & $\cdot, \pi \wedge$ & • & $\cdot, \leqslant V$ & 11 \\
\hline
\end{tabular}

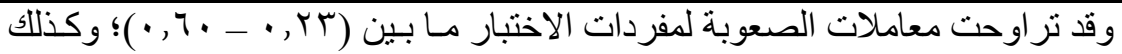

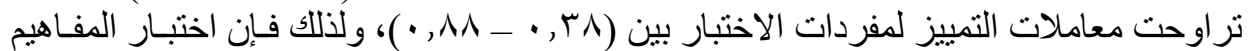
الجغر افية له القدرة على التهين التمييز بين أفرداد الاد العينة.

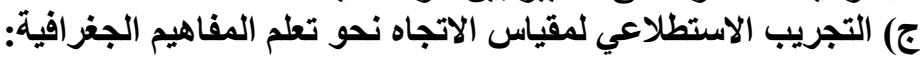

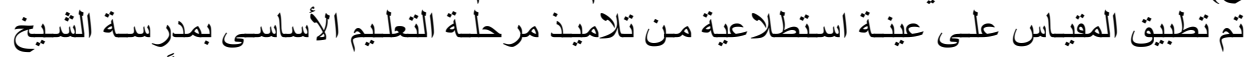

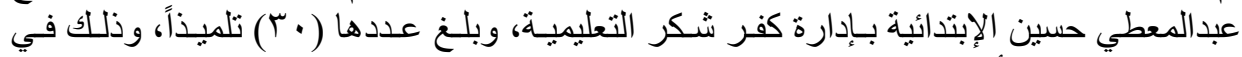

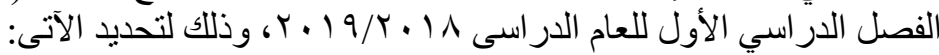

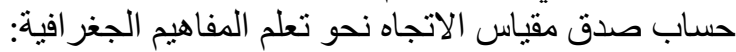
تم حساب صدق مقياس الاتجاه (*) نحو تعلم المفاهيم الجغر افية بالطرق الآتية:

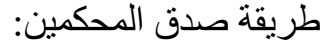




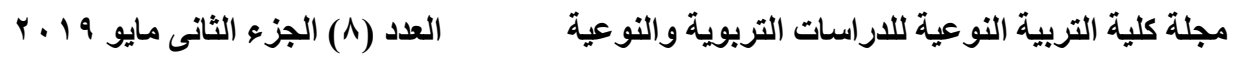
أُستخدم صدق المحكمين للوقوف على صدق المقياس؛ وذلك بعرض المقياس على مجموعـة مـن

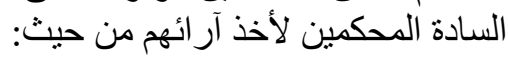

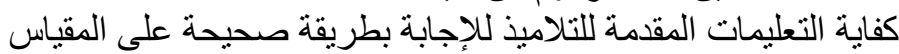
صلاحية المفردات علمياً، ولغوياً. مناسبة المفردات للتناميذ عينة الدراسئة ولغياً تحقيق كل سؤ ال الهدف منه. أى تعديلات آخرى ير اها الهادئة الهادة المحكمين.وقد اتفق المحكمون على: صلاحية المفردات، ومناسبتها، وسلامة المقياس.

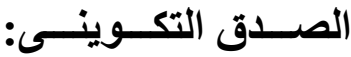

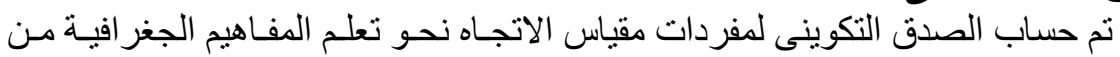

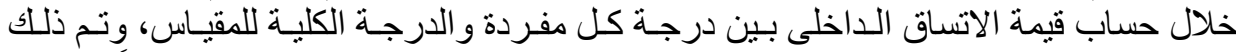
بحساب معامل الارتباط لبيرسون بين درجة كل مفردة و الدرجة الكلية للمقياس مستخدماً في ذلك للك

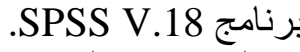
جدول (7) معامل الارنباط بين درجة كل مفردة و الدرجة الكلية لمقياس الاتجاه نحو تعلم المفاهيم

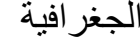

\begin{tabular}{|c|c|c|c|c|c|c|c|}
\hline معامـال & الاختبار & الإرتباط معامــــل & الاختبار & الإرتباطـــــل & الاختبار & 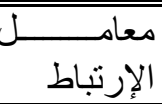 & مفـــردات \\
\hline$* *, 0 \wedge 0$ & 17 & $* *$,,$\leqslant \vee \uparrow$ & 11 & $\left.*_{\bullet}, \S\right)$ & 7 & $* *, \wedge$, & 1 \\
\hline$*_{0}, \varepsilon r V$ & IV & **, Trธ & ir & $* *, \vee \backslash \backslash 7$ & V & $* *,, 799$ & r \\
\hline$\left.*_{*}, \varepsilon\right)$. & 11 & $* *, 71$. & سו & *., $\leqslant Y V$ & $\Lambda$ & $* *,, \vee \vee \Gamma$ & r \\
\hline$* *_{0}, 0 \vee 1$ & 19 & $* *,, T \leqslant 0$ & $1 \leqslant$ & *, r rqr & 9 & $* *,, \vee \vee 9$ & $\varepsilon$ \\
\hline$* *_{.}, 0 \mathrm{~V}$. & $r$. & $* *,, 000$ & 10 & $* *,, \vee \circ \wedge$ & 1. & $* *,, \vee \backslash 7$ & 0 \\
\hline
\end{tabular}

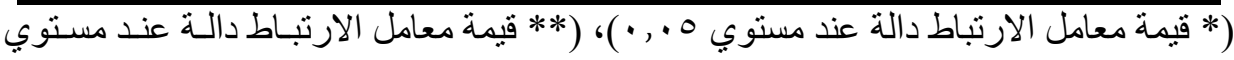

يتضح من الجدول السـابق أن معـاملات الارتبـاط لمفردات المقيـاس جميعهـا دالـة عند مسـتوى

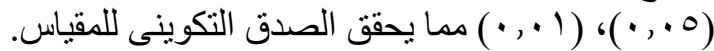

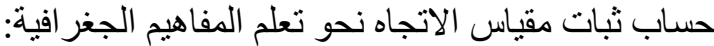

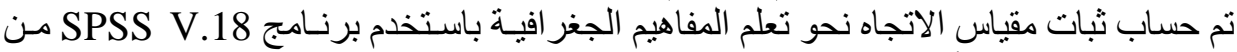

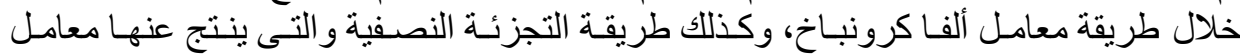

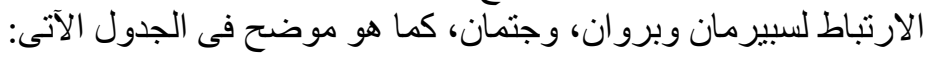




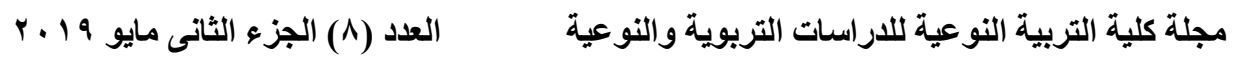

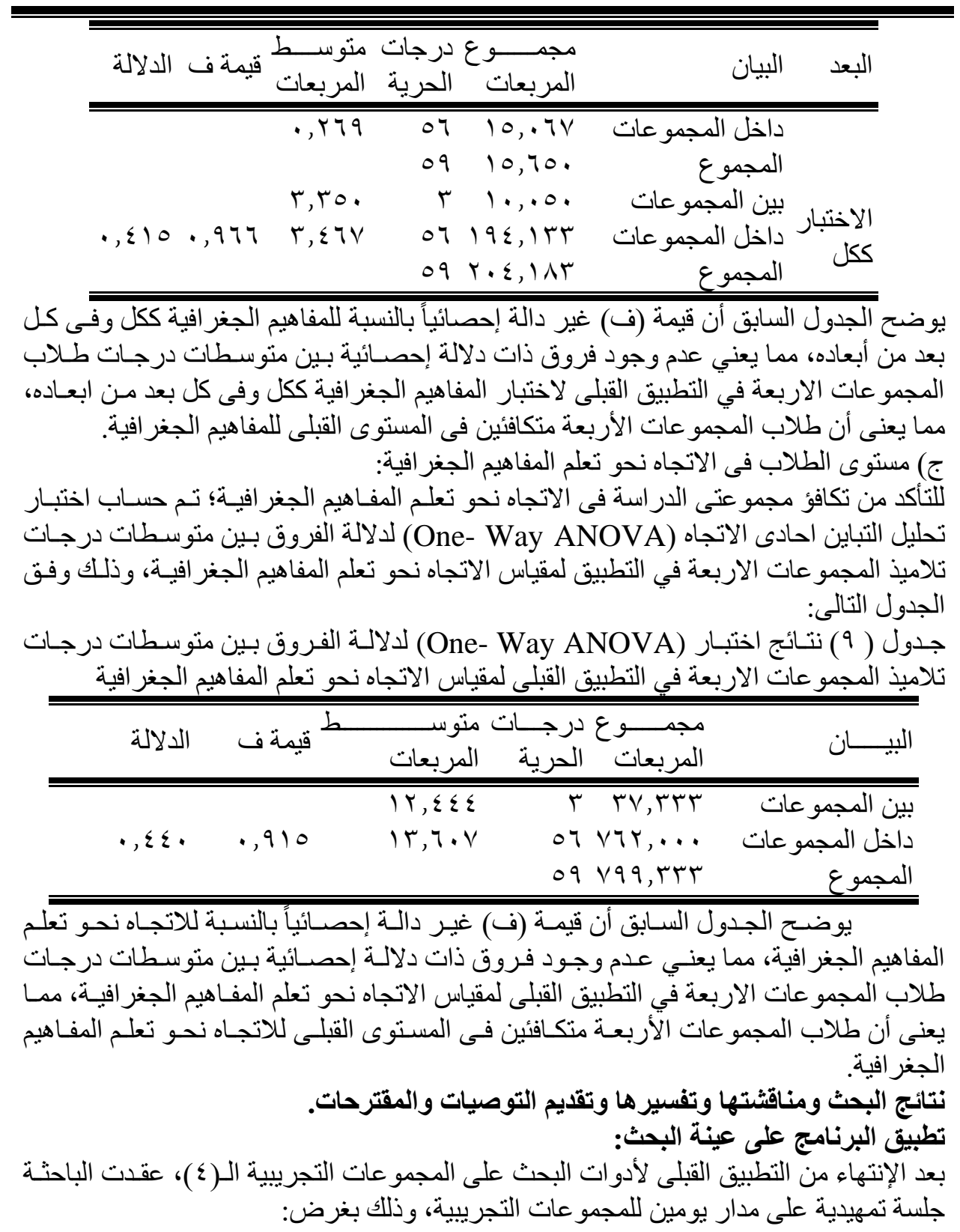




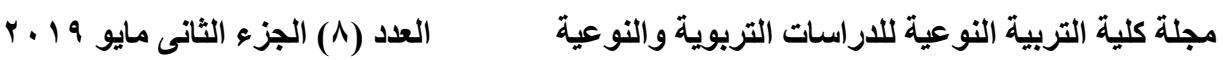

تعريف التلاميذ بأهداف المنظمات الرسومية المتقدمة وطبيعة المحتوى التعليمى وما يتضمنه من

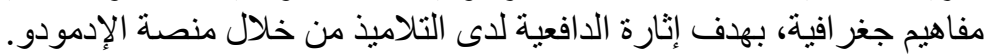

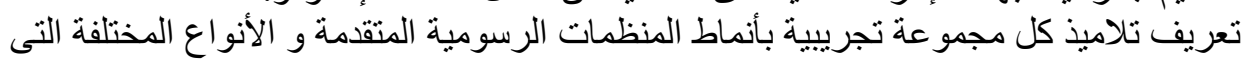

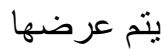

التطبيق البعدى لأدوات البحث التبات

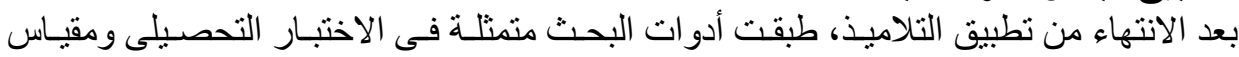

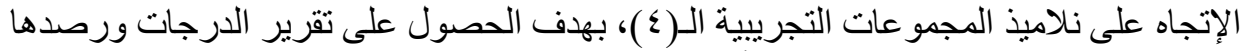

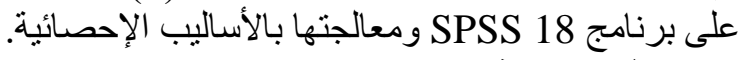

نتائج البحث ونفير

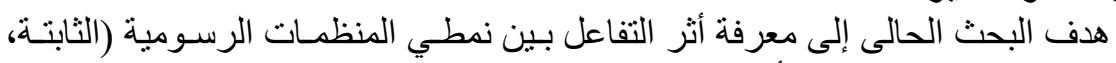

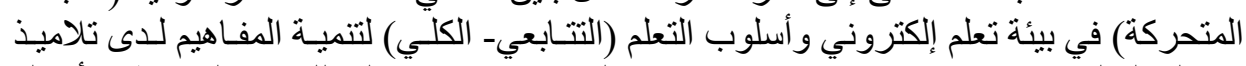

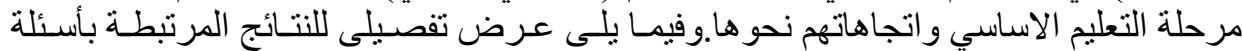

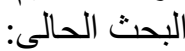

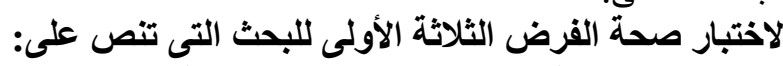

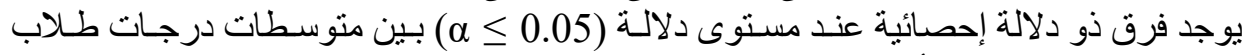

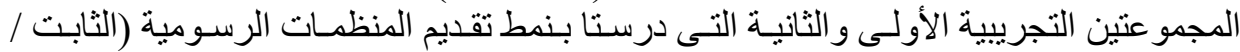

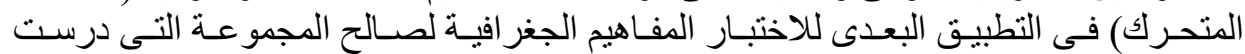

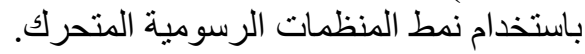

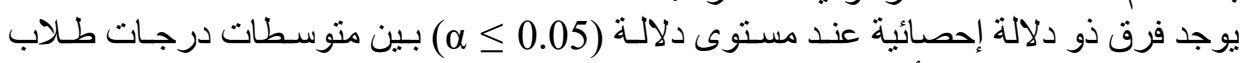

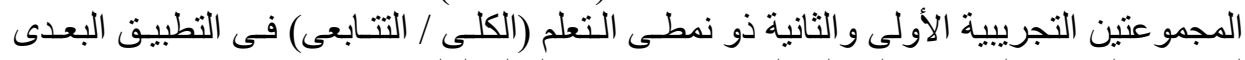

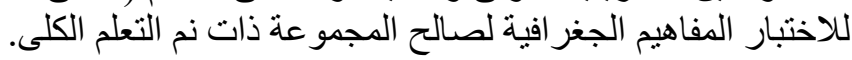

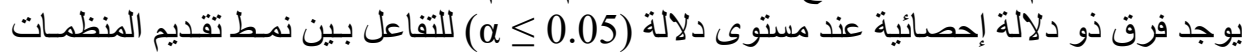

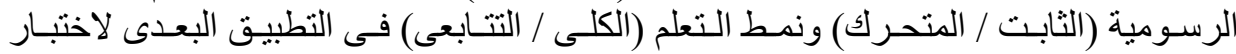

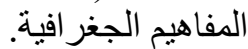

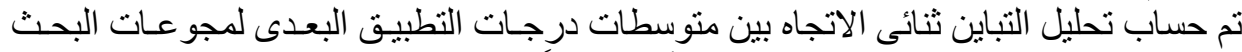

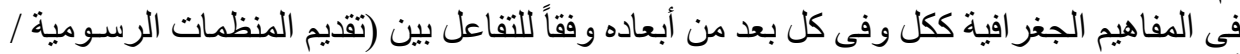

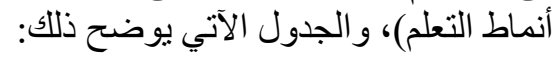




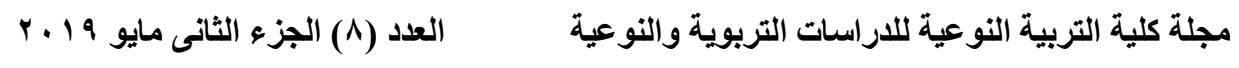

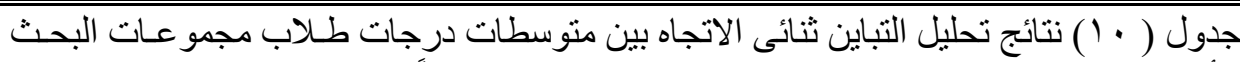

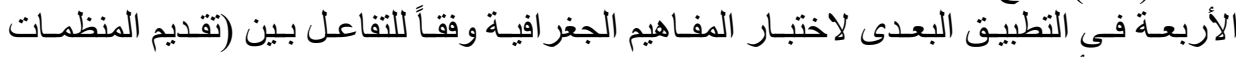

الرسومية / أنماط التعلم)

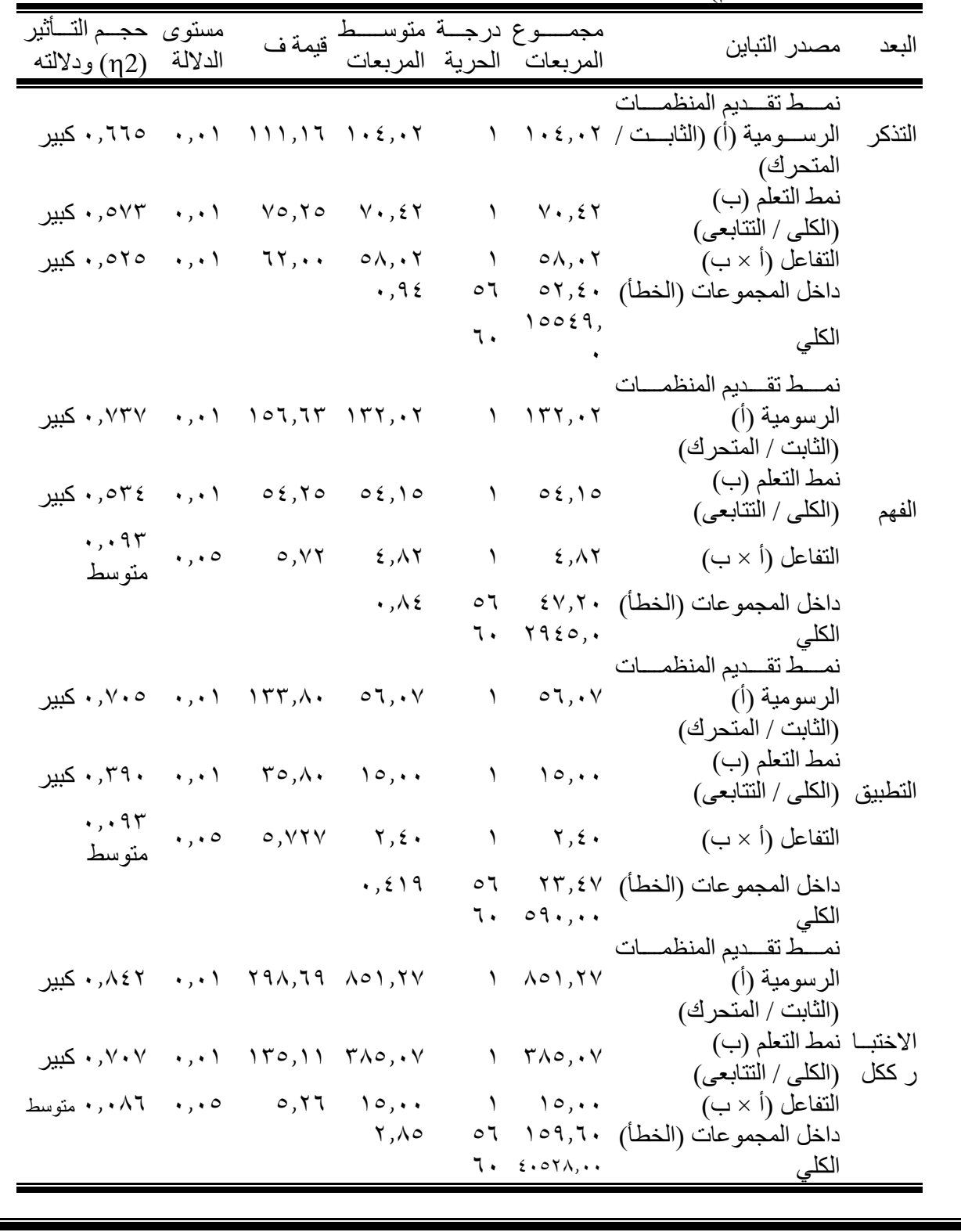




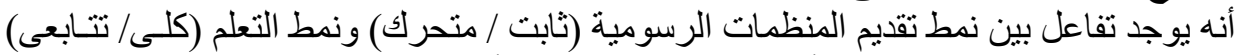

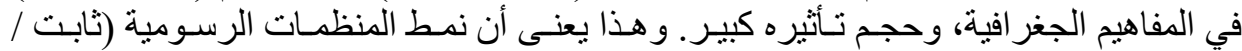

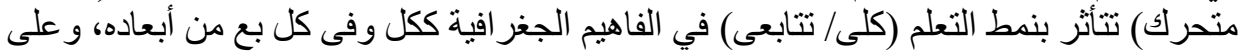

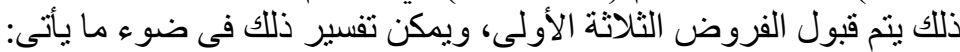

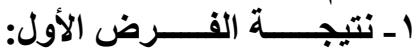

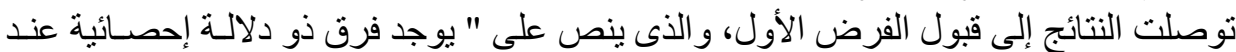

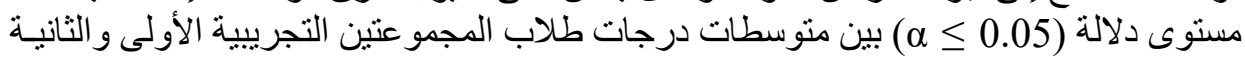

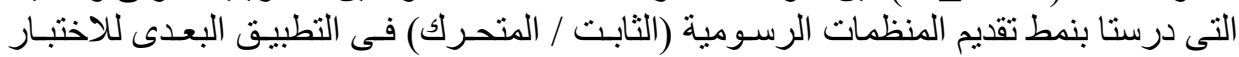

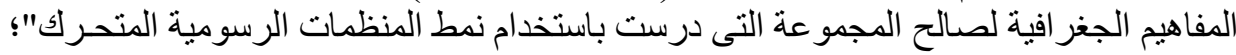

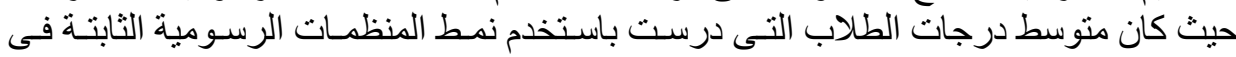

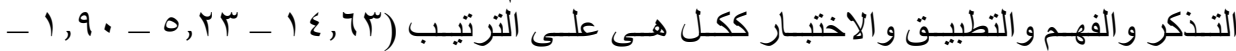
الرسو , , VV

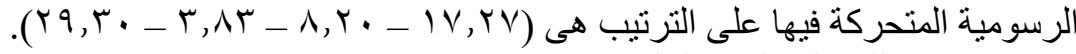
ويمكن تفسير ذلك علي النحو التالي :

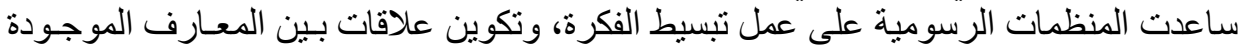

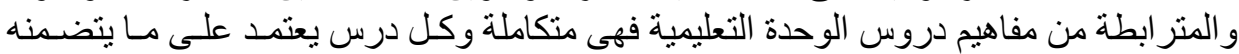
الدرس السابق من المفاهيم الجغر افية.

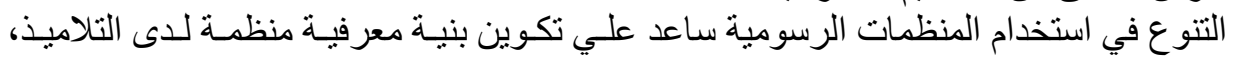

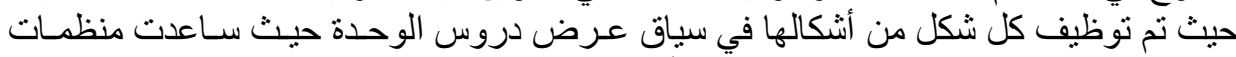

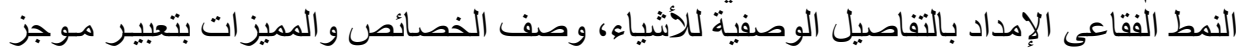

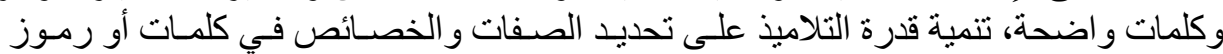

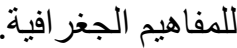

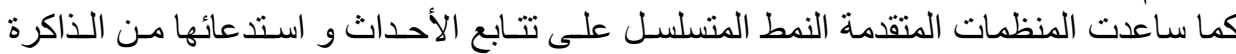

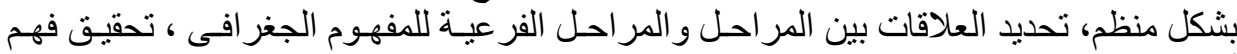
أفضل للمفاهيم الجغر افية المعقدة.

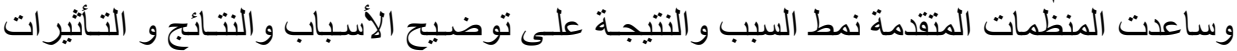
وتحليل المفاهيم الجغر افية بالنظر إلى الأسباب والنتائج الجيدة أو السيئة، التنبؤ بالنتائج في ضو النو

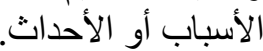

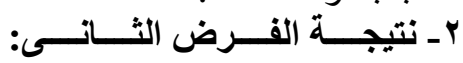

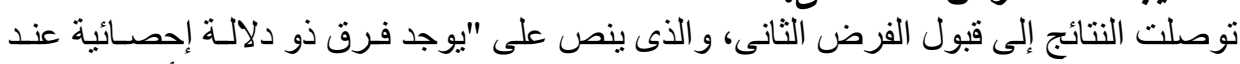

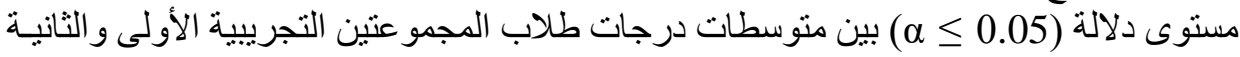

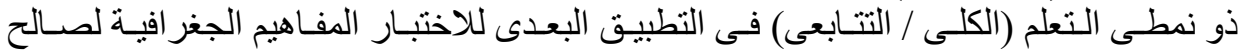

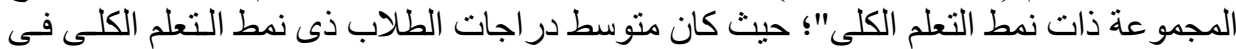

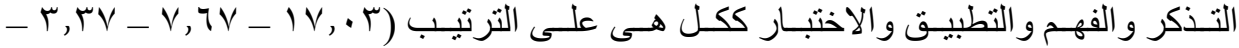




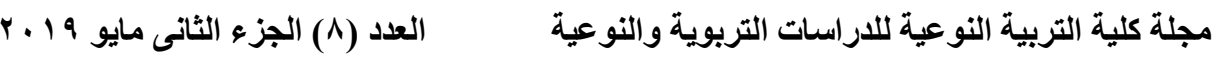

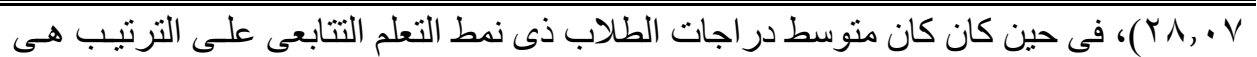
. (Yr, . - Y, r $r V-0, V V-l \varepsilon, \Lambda V)$

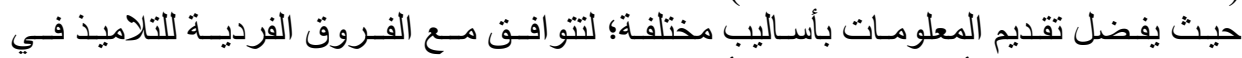

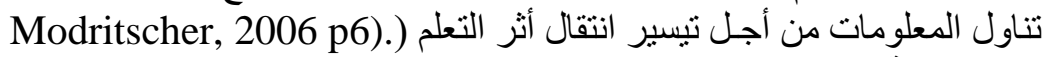

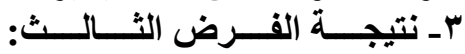

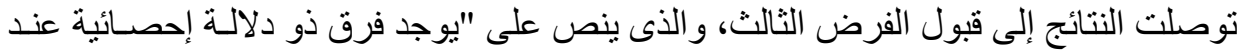

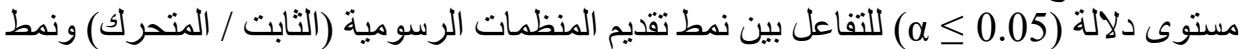
التعلم (الكلى / التتابعى) فى التطبيق البعدى لإنى لاختبار المفاهيم الجغر افية".

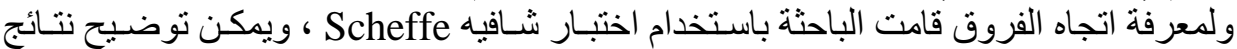

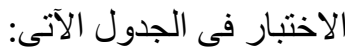

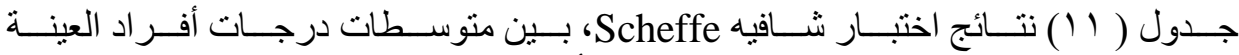
فى اختبار المفاهيم الجغر افية ككل وفى كل بعد من أبعاده

\begin{tabular}{|c|c|c|c|c|c|}
\hline ثابت تتابعى & 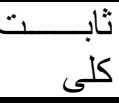 & تتابعى متحــر & المتوسط & المجمو عات & البعد \\
\hline $\begin{array}{c}* \varepsilon, \Lambda . \\
\cdot, T V \\
\cdot, r .\end{array}$ & $\begin{array}{l}* \varepsilon, 7 . \\
\cdot, \leqslant \vee\end{array}$ & $* \varepsilon, 1 T$ & $\begin{array}{l}19, \pi T \\
10, r . \\
1 \varepsilon, V T \\
1 \varepsilon, O T\end{array}$ & ثنابت ثترك تلى تتابعى كلى & التذكر \\
\hline$* \varepsilon, \wedge \vee$ & $* Y, \varepsilon$. & سז, ו * & $\Lambda, \wedge \vee$ & متحرك/ كلى & \\
\hline $\begin{array}{l}* r, \text { or } \\
* r, \leqslant V\end{array}$ & $* 1, \cdot v$ & & $\begin{array}{l}V, O r \\
T, \leqslant V \\
\varepsilon, \ldots\end{array}$ & ثنابت كترك تتابعى & الفهم \\
\hline $\begin{array}{l}* r, q u \\
* r, r r \\
* 1, \varepsilon .\end{array}$ & $\begin{array}{l}* 1, \text { or } \\
* ., 94\end{array}$ & $\cdot, 7$. & $\begin{array}{l}\varepsilon, 1 r \\
r, O r \\
r, T . \\
1, r .\end{array}$ & ثنابت ثترك تلى تلابعى كلى & التطبيق \\
\hline$* \mid r, 7$. & $* \lambda$, or & $* 7, \cdot V$ & rr, & متحرك/ كلى & \\
\hline *4, Or & $* Y, \leqslant V$ & & $r \tau, r V$ & متحرك تتابعى & الاختبــــار \\
\hline$* \varepsilon, \cdot V$ & & & $\begin{array}{l}r \mu, \Lambda . \\
19, V r\end{array}$ & ثابت تنابعى كلى & ككل \\
\hline
\end{tabular}

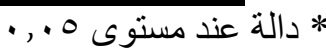
يتضح من الجدول السابق انه:

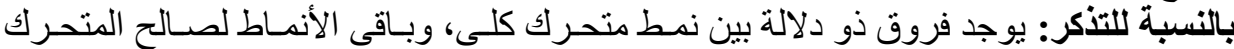

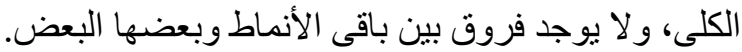




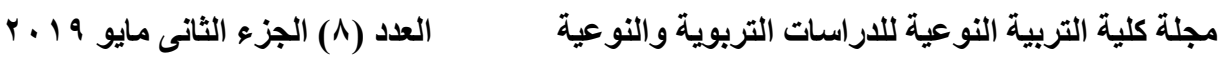

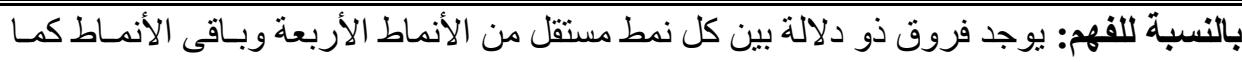

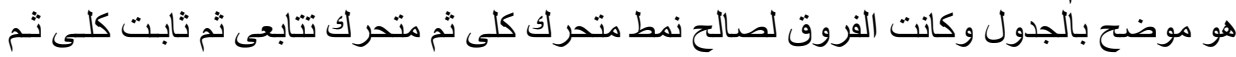

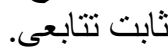

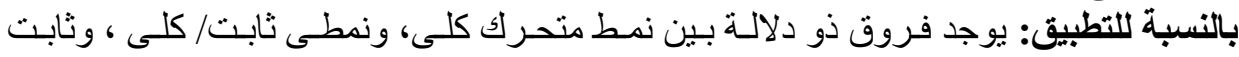

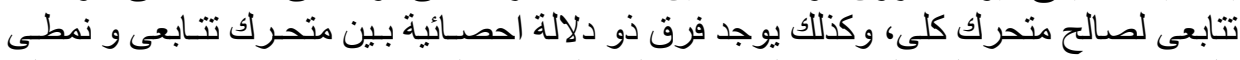

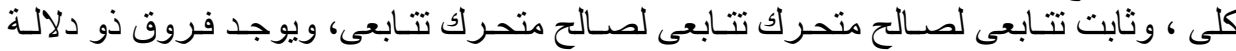

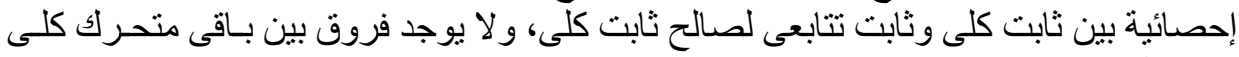

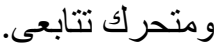

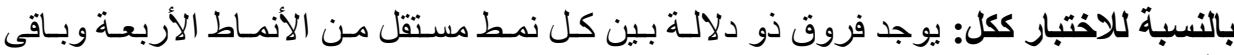

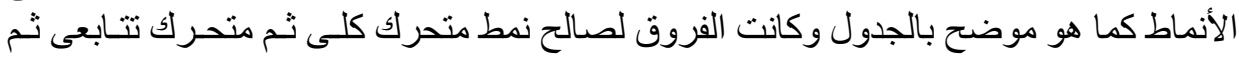

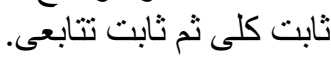

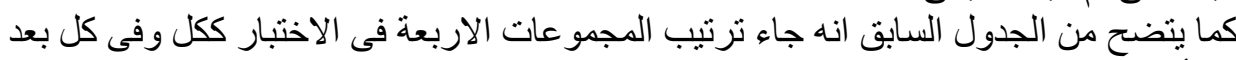

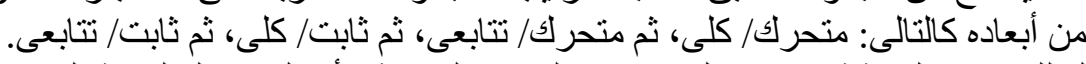

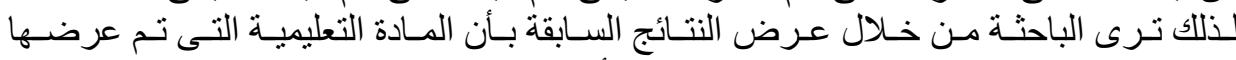

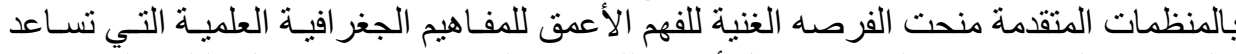

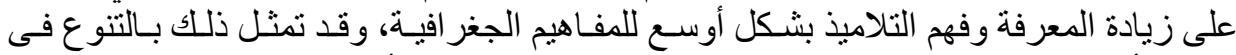

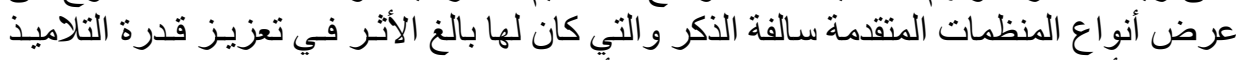

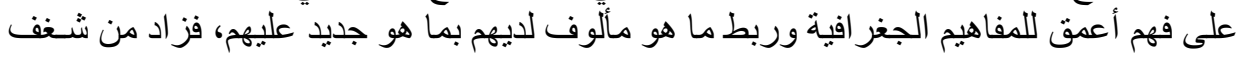

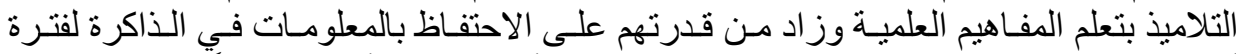

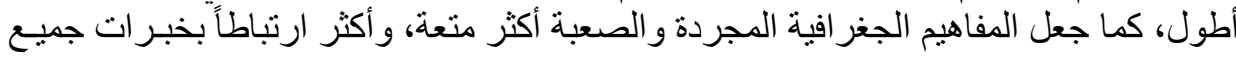

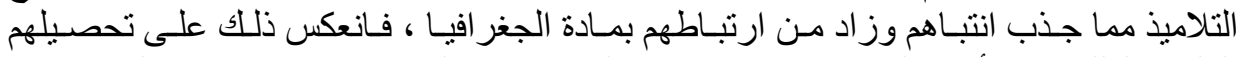

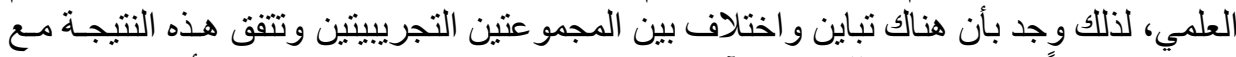

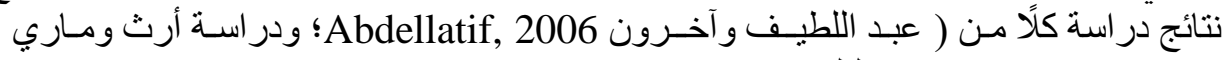
Blake, 2004 Mary\& Arth, 2002

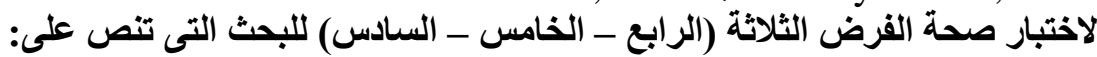

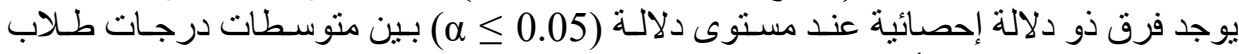

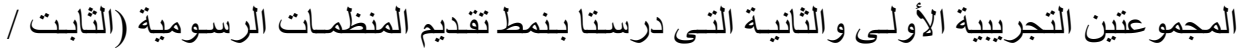

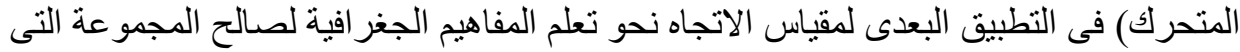

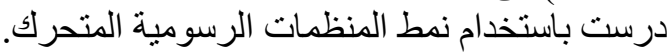

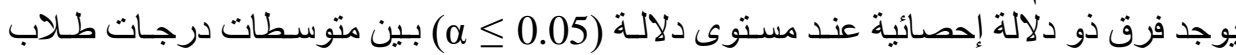

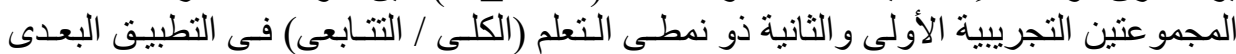

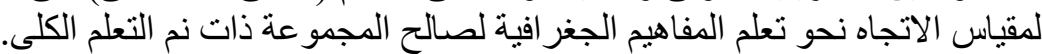

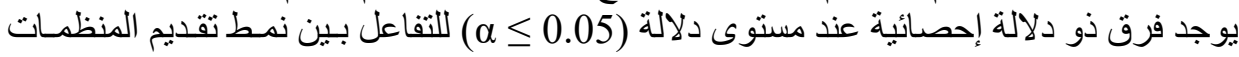

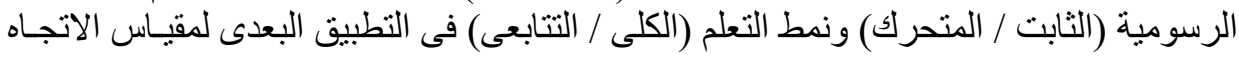
نحو تعلم المفاهيم الجغر افية. 


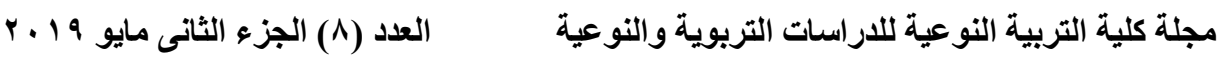

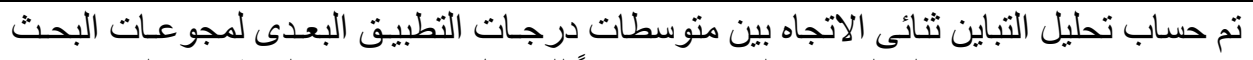

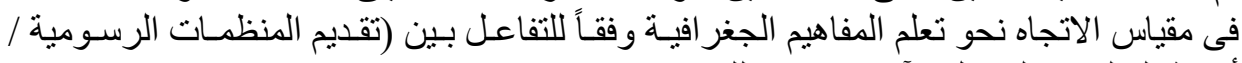

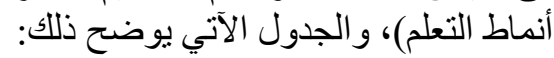

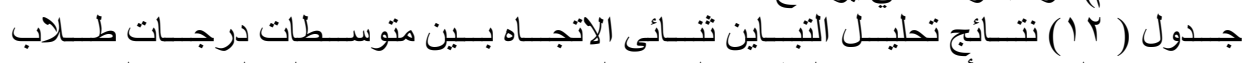

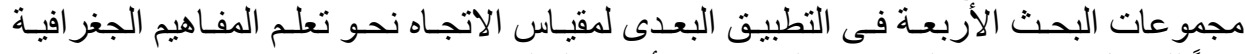

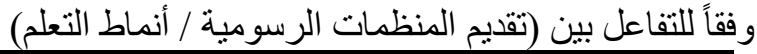

\begin{tabular}{|c|c|c|c|c|c|c|}
\hline $\begin{array}{r}\text { ودجم التأثير } \\
\text { ودلالته }\end{array}$ & مسـتوى & قيمة ف & متو ســـــــــ & الحرية & المربعات & 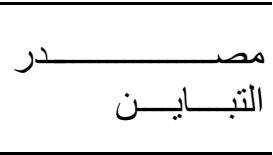 \\
\hline كبير 79 , • & $\cdot, \cdot 1$ & IYT,OV & $1.0 \Lambda, \varepsilon$. & 1 & $1.01, \varepsilon$ & 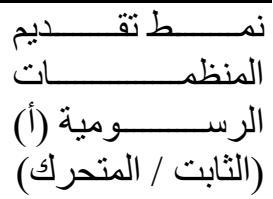 \\
\hline كبير & $\cdot, \cdot 1$ & q & $r \wedge 1, T V$ & 1 & rNI,TV & (الكلى / التتابعىى) \\
\hline 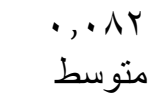 &., .0 & $\varepsilon, 9 \wedge$ & $\varepsilon 1,7 \vee$ & 1 & $\varepsilon 1,7 v$ & التفاعل (أ × ب) \\
\hline & & & ג & 07 & $\{\neg \Lambda, r \vee$ & داخلـل المجمو عـات \\
\hline & & & & 7. & $1 \leqslant 091 \ldots$ & الكغالـــي \\
\hline
\end{tabular}

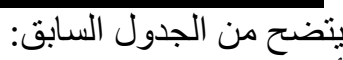

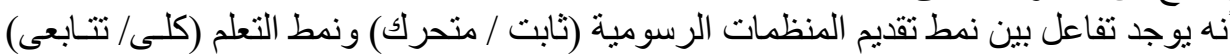

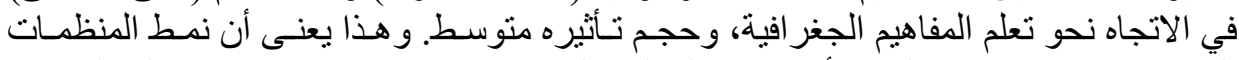

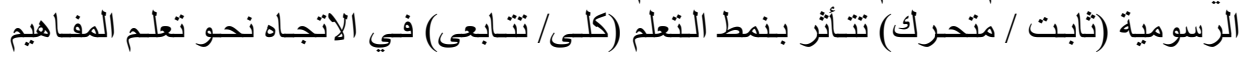

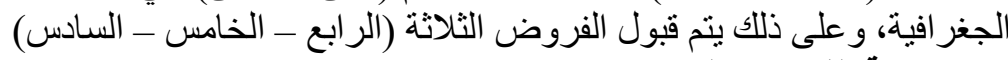

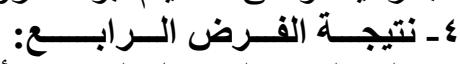

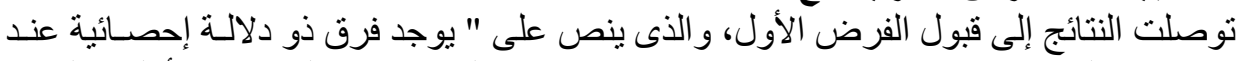

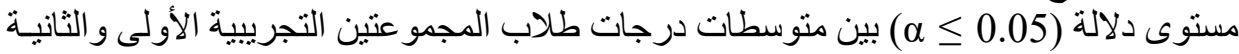

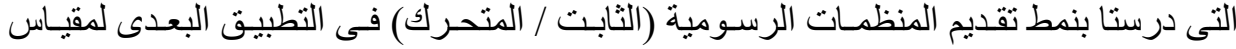

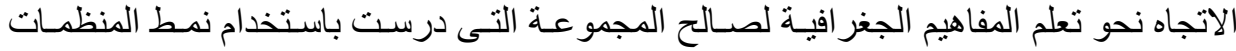

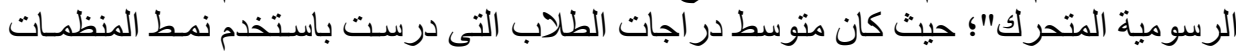

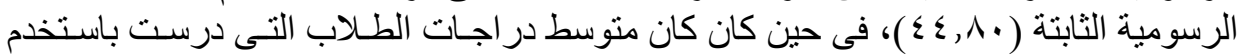

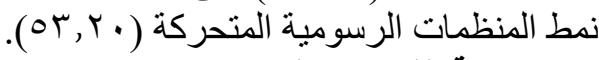

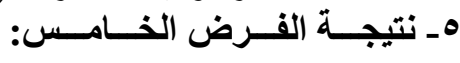




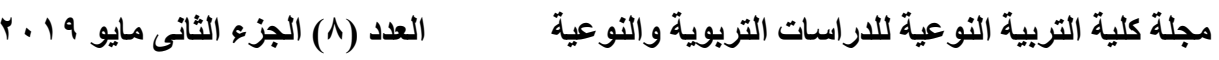

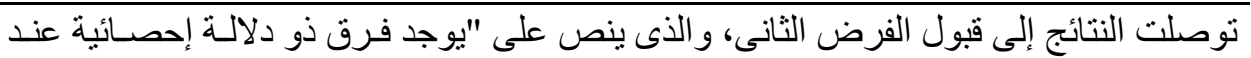

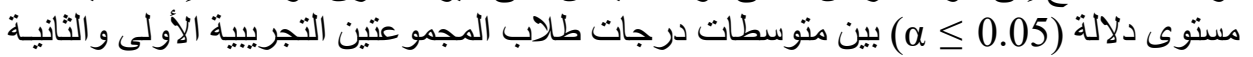

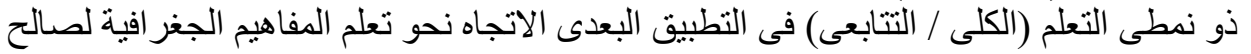

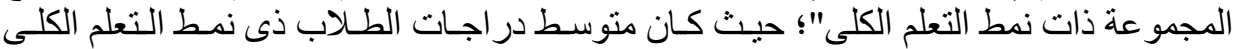

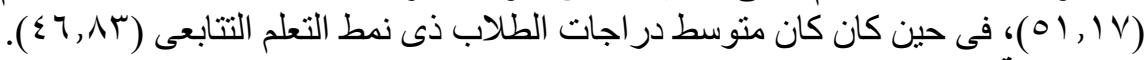

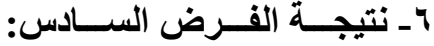

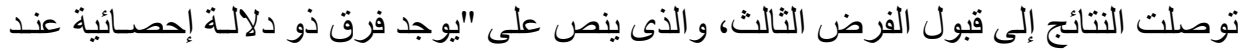

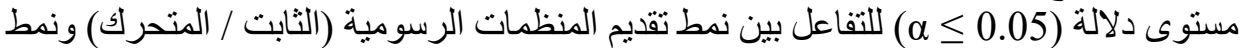

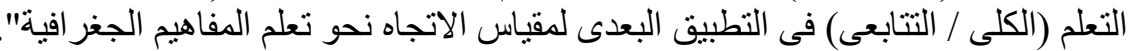

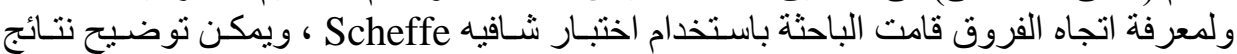

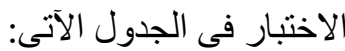

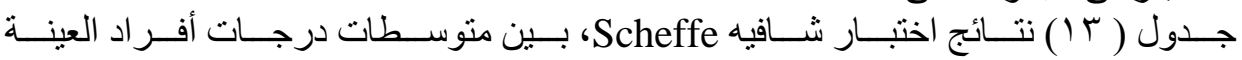
فى مقياس الاتجاه نحو تعلم المفاهيم الجغر افية

\begin{tabular}{|c|c|c|c|c|}
\hline ثابت تتابعى & ثابت كلى & متحرك تتابعى & المتوسط & المجمو عات \\
\hline$* \mid r, V \mu$ & $* 1 \cdot, \cdot V$ & $* 7, \ldots$ & $07, Y$. & متحرك/ كلى \\
\hline$* 4, V \mu$ & $* \varepsilon, \cdot V$ & & $0 ., Y$. & متحرك تتابعى \\
\hline$* Y, T V$ & & & $\varepsilon 7,1 \Gamma$ & ثابت كلى \\
\hline & & & $\varepsilon r, \varepsilon \nu$ & ثابت تتابعى \\
\hline
\end{tabular}

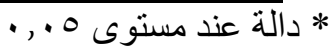

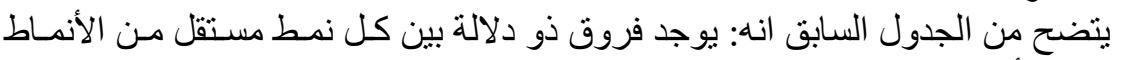

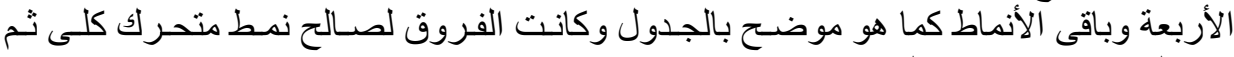

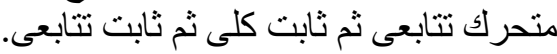

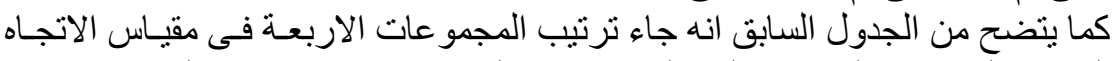

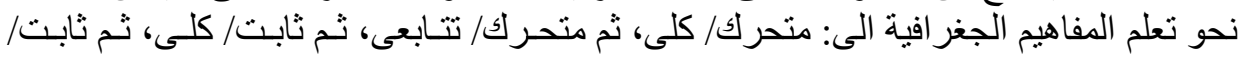

التفسير في ضوء نظريات التعلم، أنماط عرض المنظمات المتقدمة

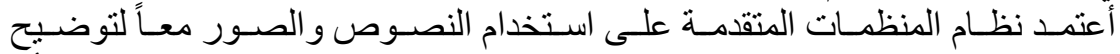

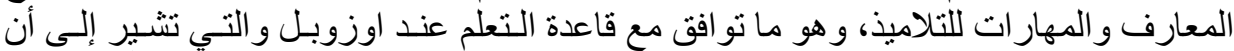

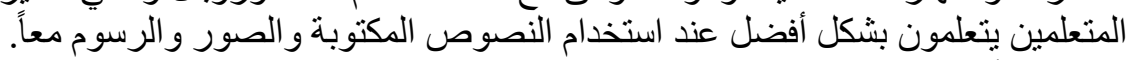

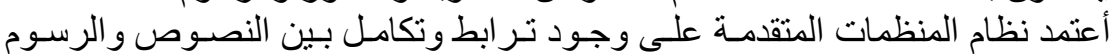

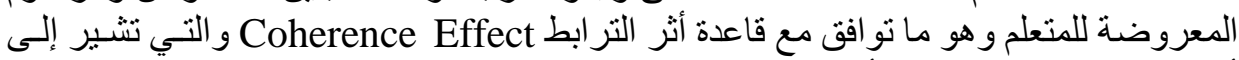

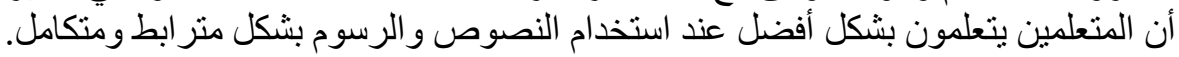




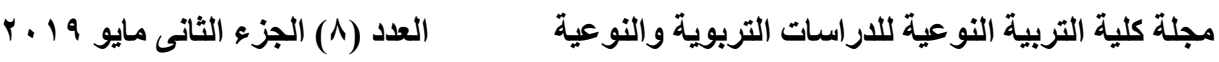

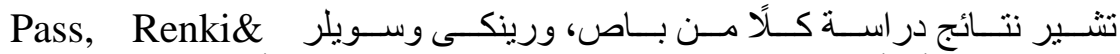

أن أساليب التعلم المفضلة لدى التلاميذ لها علاقة ونتأثير على التحصيل (Sweller,2003,p3)

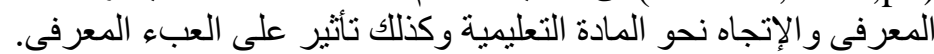

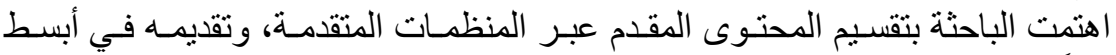

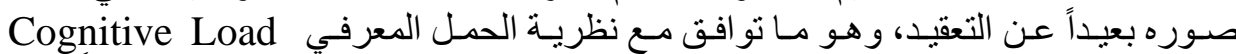

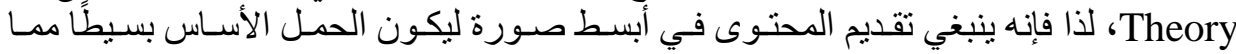

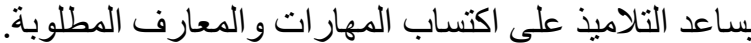

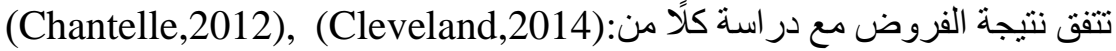

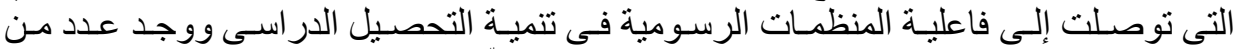

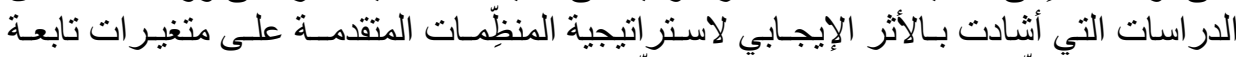

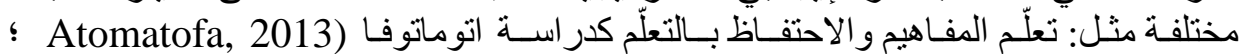

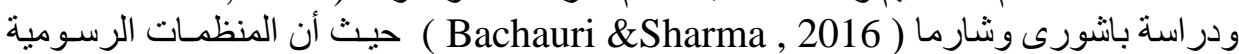

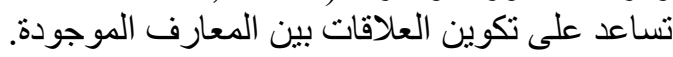

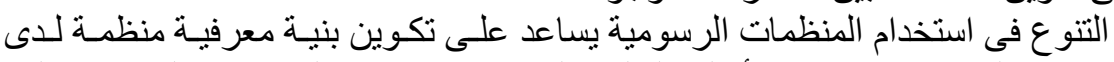

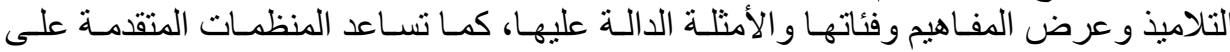

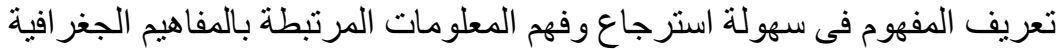

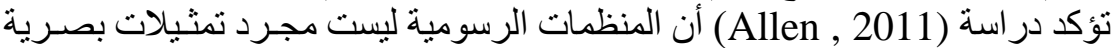

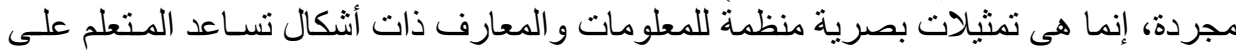

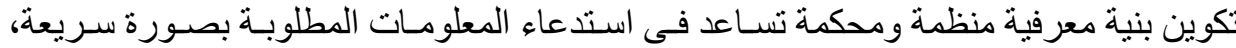

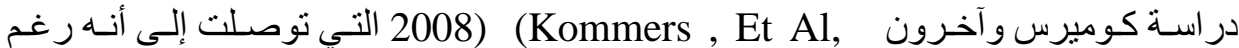

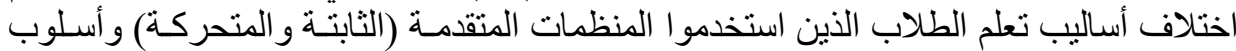

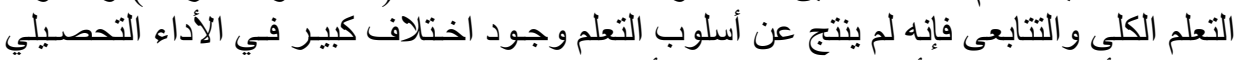

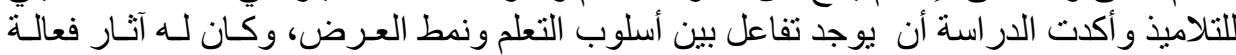
لتحسين أداء التلاميذ.

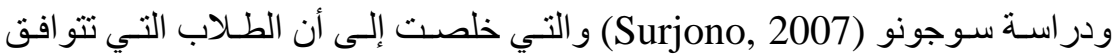

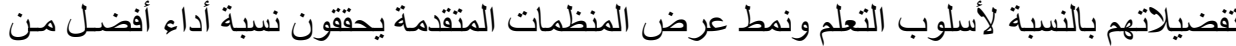

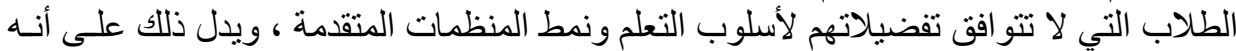

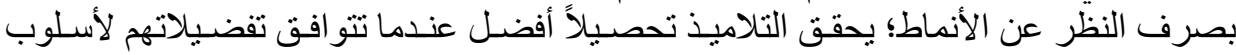
التعلم ونمط عرض المنظم الانمات المتقدمة.

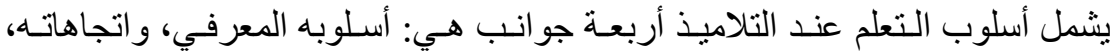

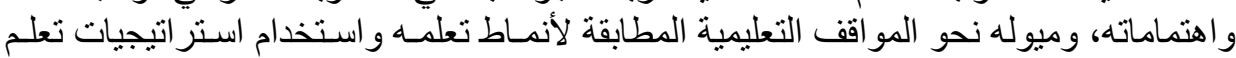

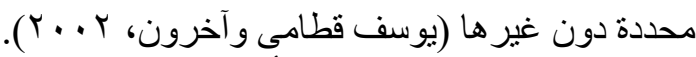

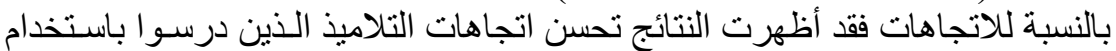

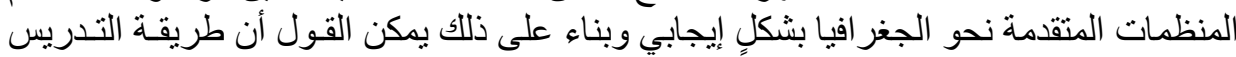

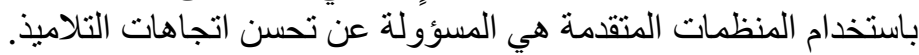




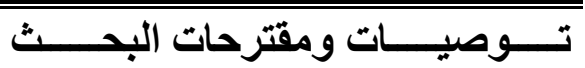

فى ضوء ما توصل إليه البحث من نتائج، يمكن تقديم مجمو عة من البح التوصيات:

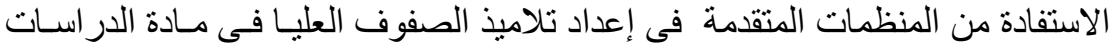

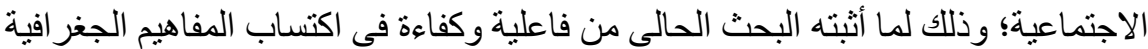

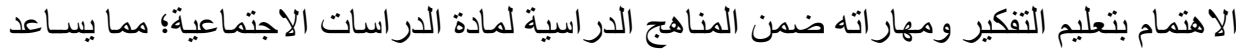

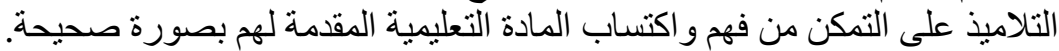

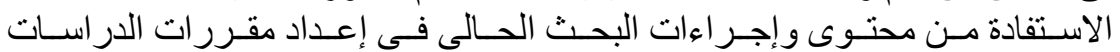

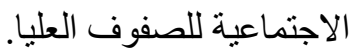

الاهتمام بالوسائل التكنولوجيا الحديثة، وتوظيفها لتدريب التلاميذ على تنميـة المفـاهيم

و واستخدامها.

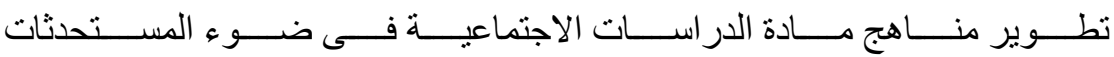

التكنولوجية Technological Advancements ذات العلاقة المبانشرة بالعملية التعليمية ومـن هذه المستحدثات المنظمات المتقدمة

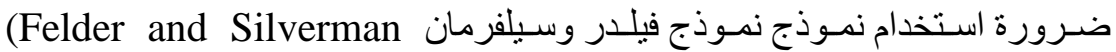

( model)

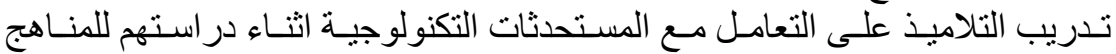

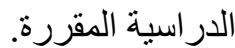

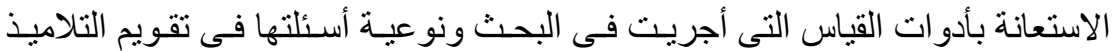

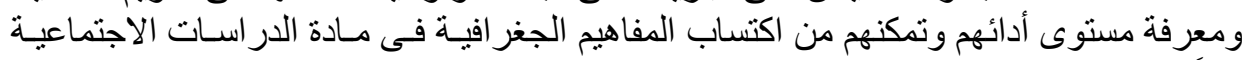

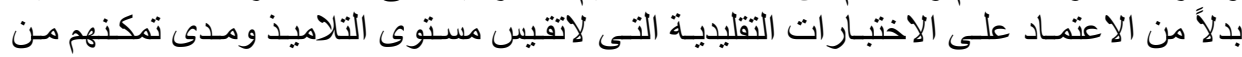
محتوى هذة المقررات الدر اسية.

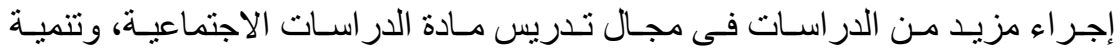
مهار ات اكتساب المفاهيم واتخاذ القرار في المرحلة الابتدائية بوجه عام.

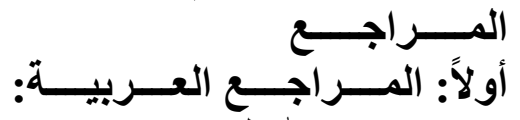

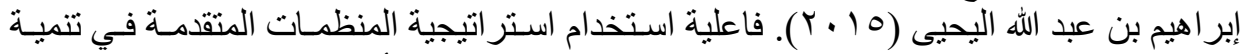

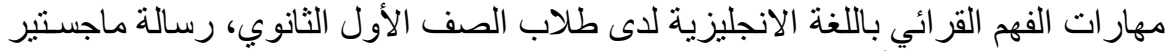
غير منشورة، جامعة أم القرى، السعة الإنهودية.

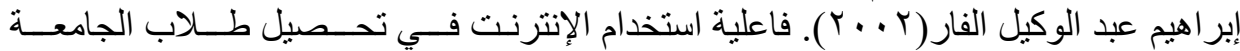

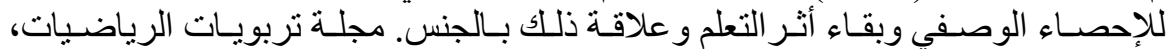

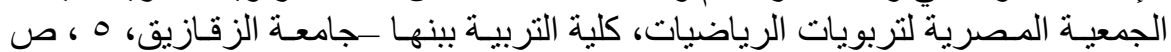

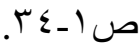

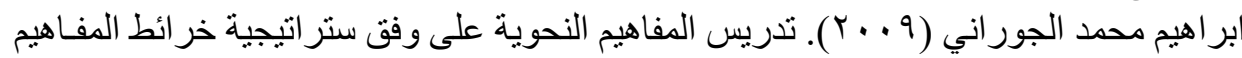
(بحث تجريبي)، دراسات تربوية، العدد السابع، تموز. 


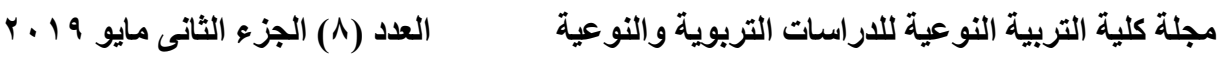

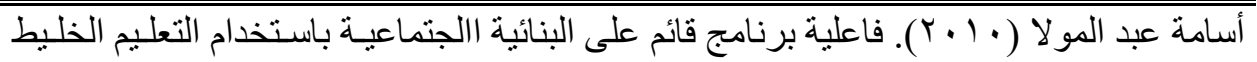

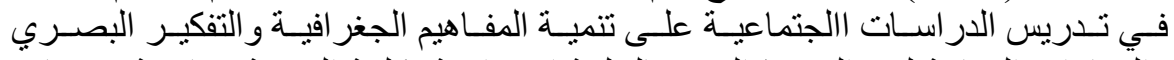

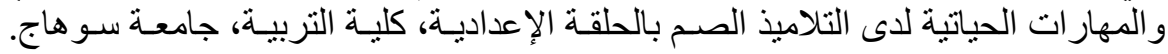
رسالة دكتور اه غير منشورة.

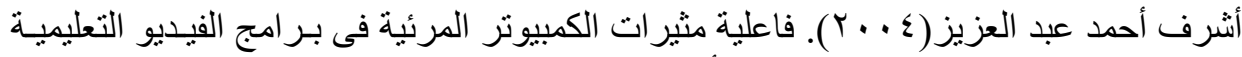

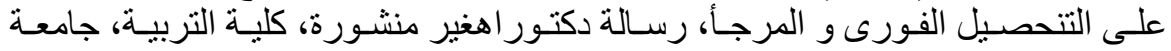

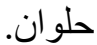

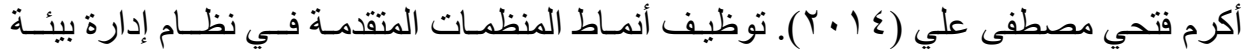

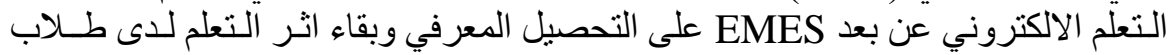

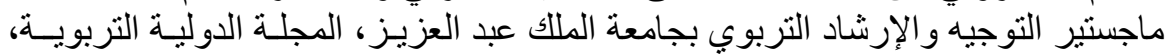

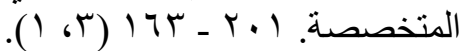

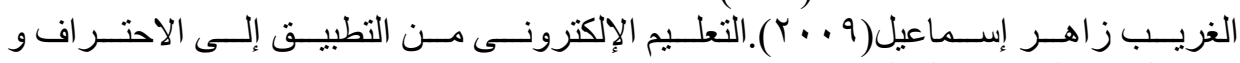

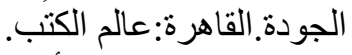

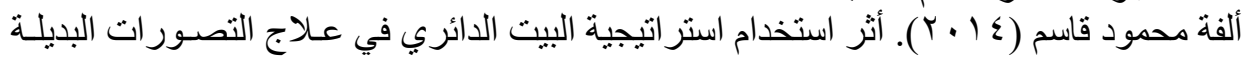

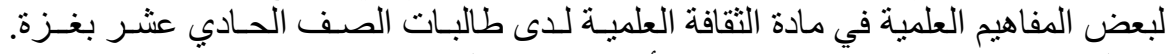

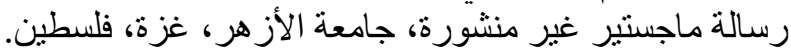

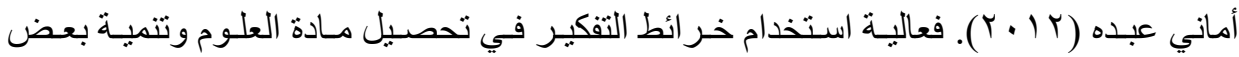

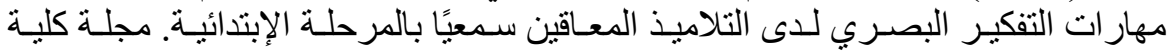

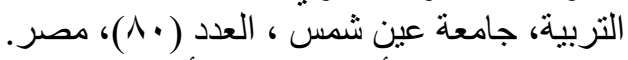

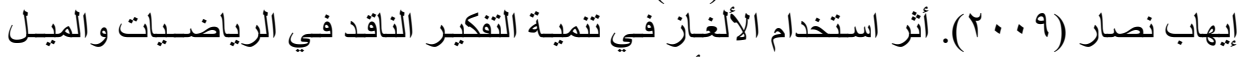

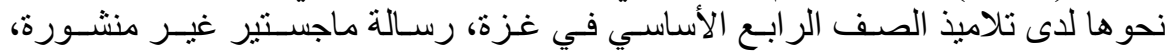
الجامعة الإسلامية، فلسطين. الجين.

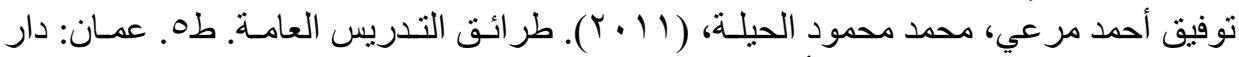
المسيرة للنشر و التوزيع، الأردن.

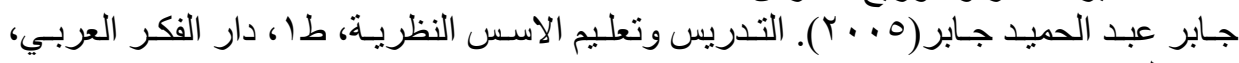

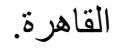

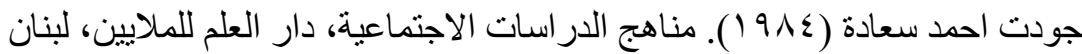

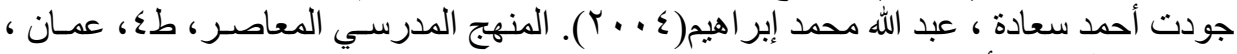

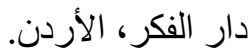

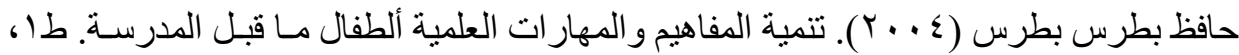

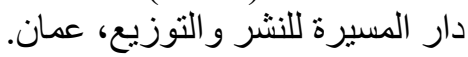

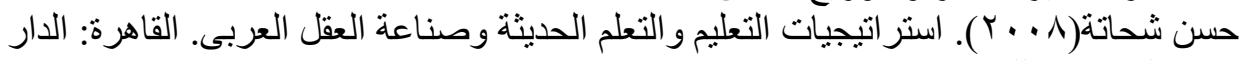
المصرية اللبنانية. 


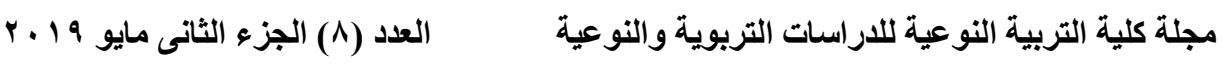

حمدى إسماعيل شعبان(10 ب ب).أثر اختلاف نمطى تصميم محتوى ملف الإنجـاز الإلكترونسى

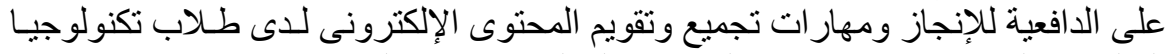

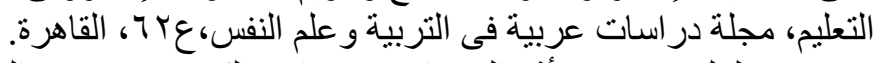

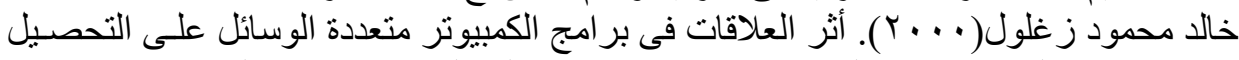

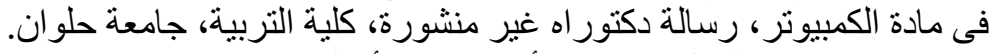

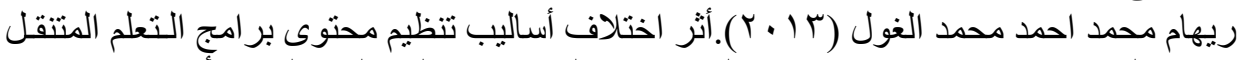

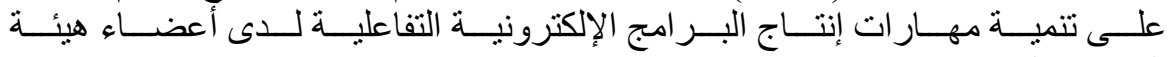

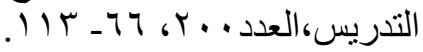

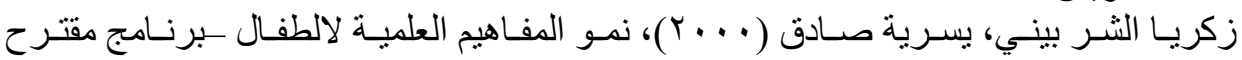

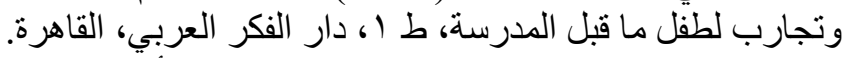

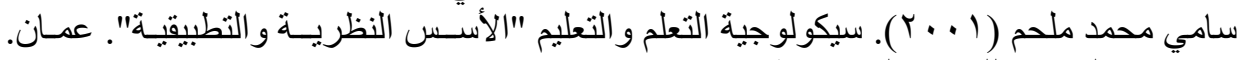

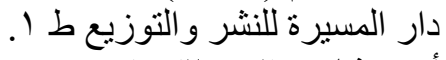

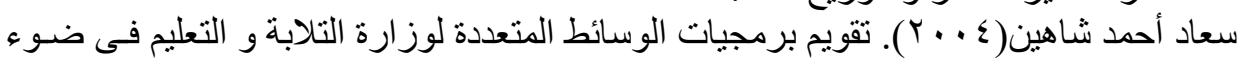

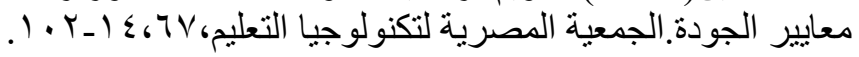

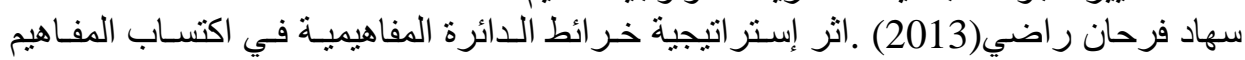

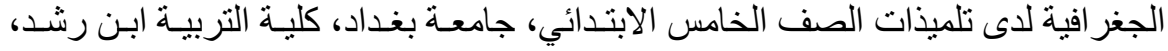

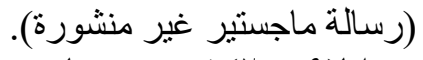

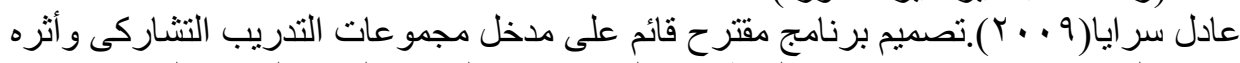

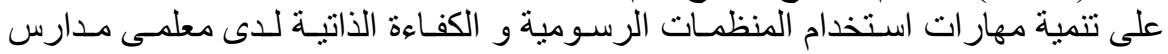

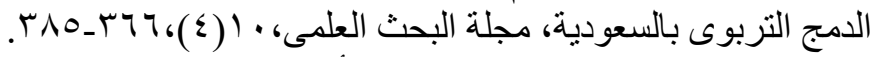

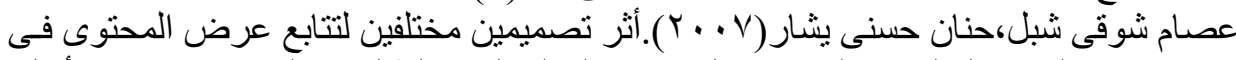

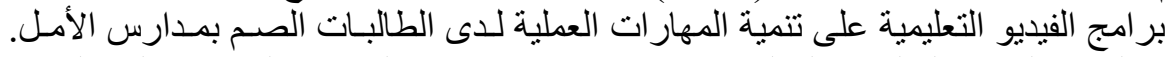

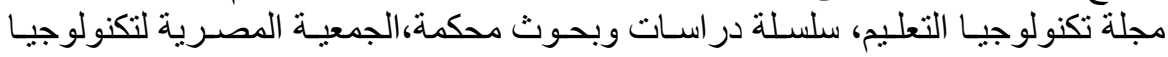

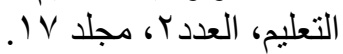

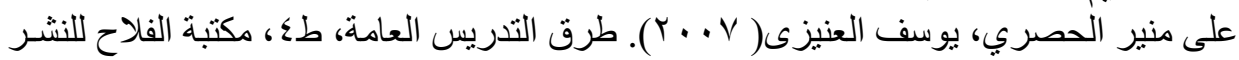

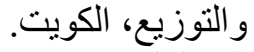

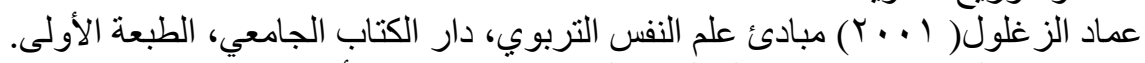

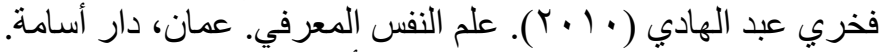

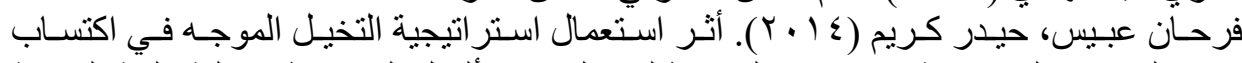

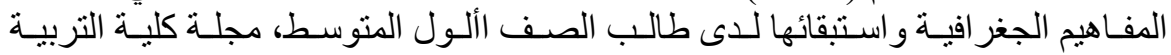

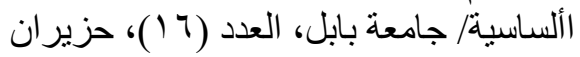

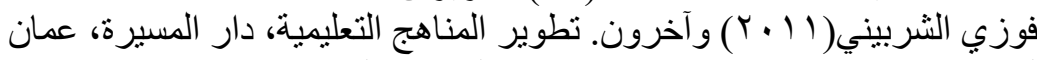

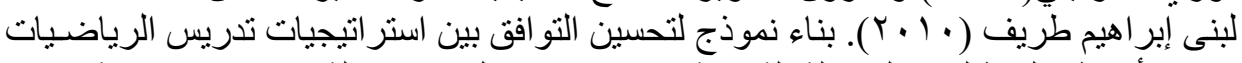

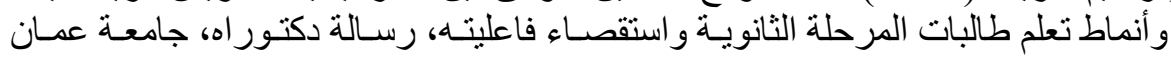

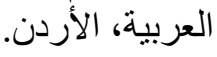




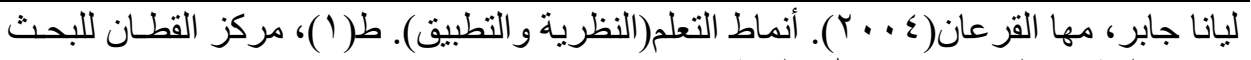

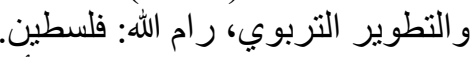

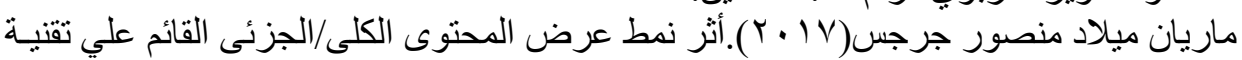

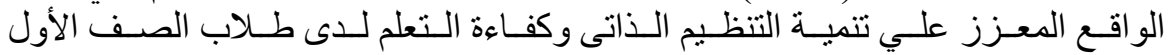

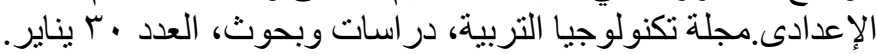

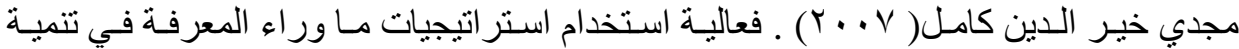

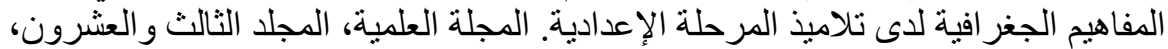

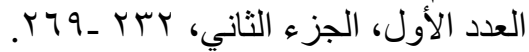

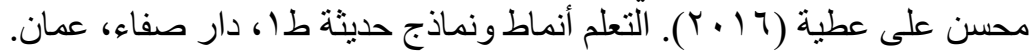

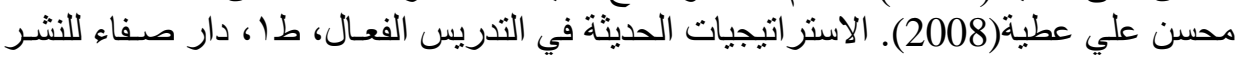
و التوزيع، عمان، الاردن.

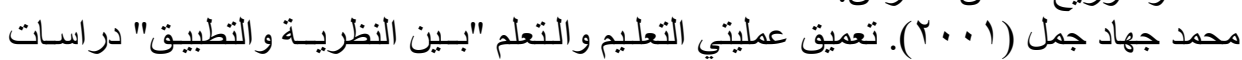

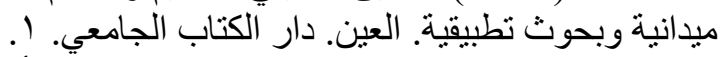

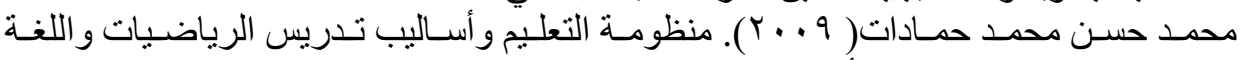

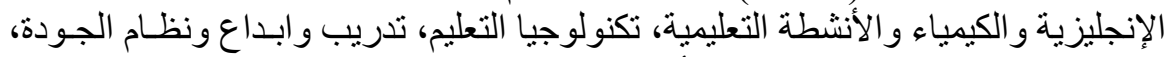

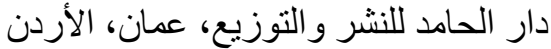

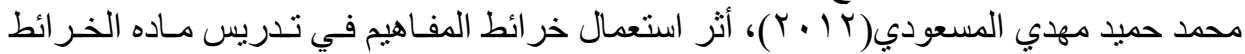

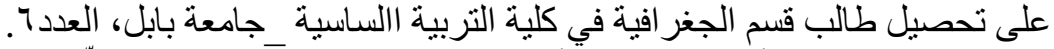

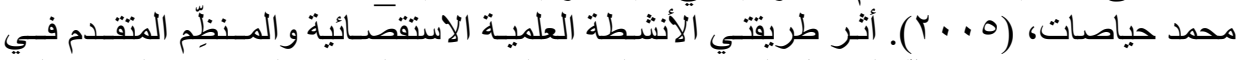

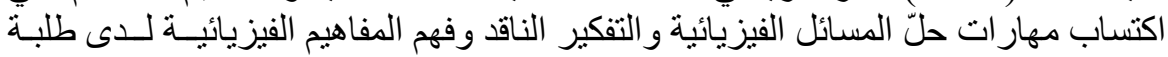

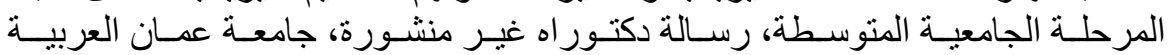

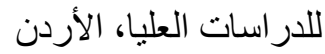

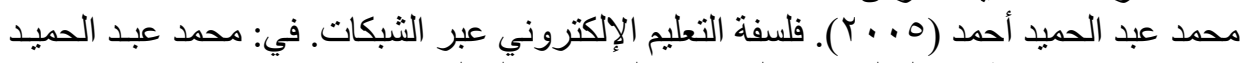

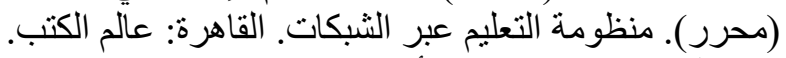

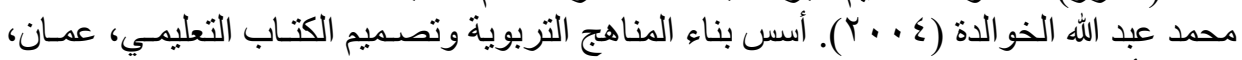

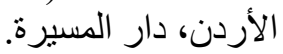

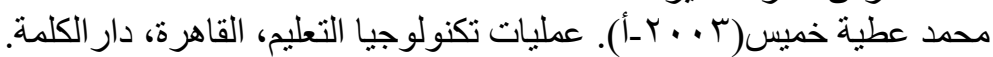

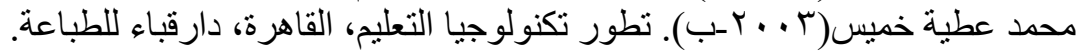

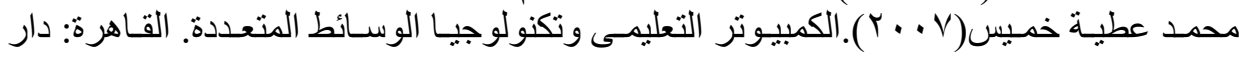

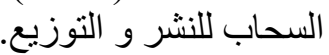
محمد عطية خميس(10 (ب).مصادر التعلم الإلكترونى الجزء الأول: الأفراد و الوسـائط،القاهرة، دار السحاب

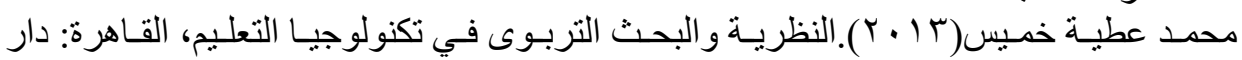

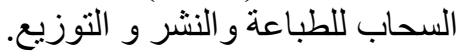

محمد عطية خميس(1) (ب).بيئات التعلم الإلكترونى(الجزء ع الأول).القاهرة، دار السحاب 


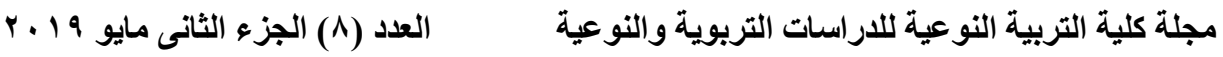

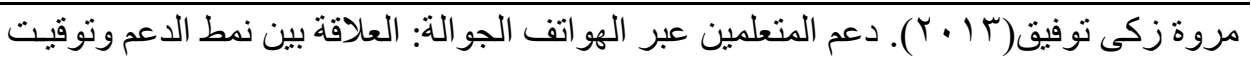

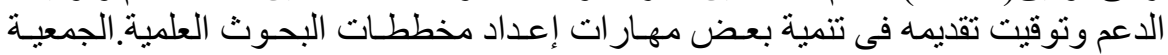

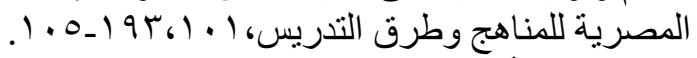

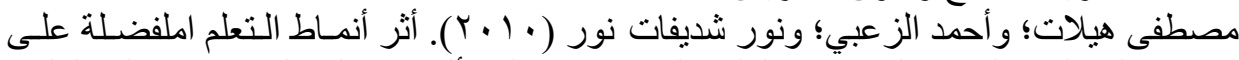

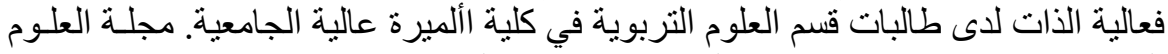

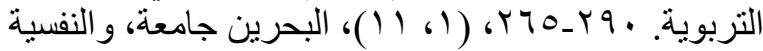

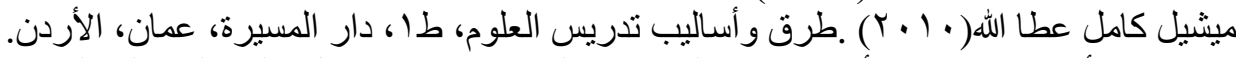

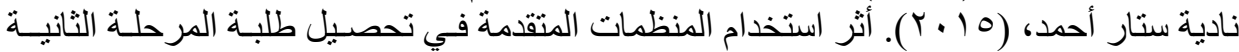

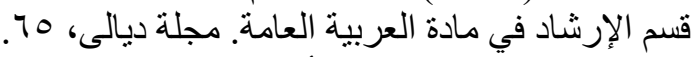

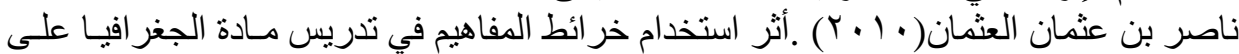

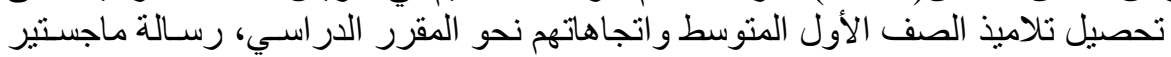

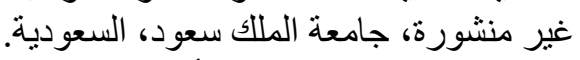

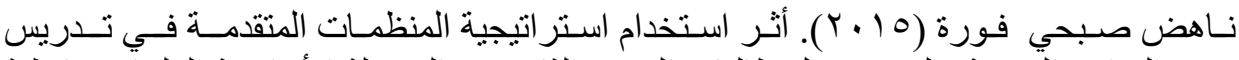

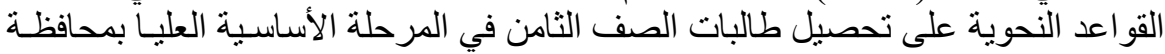

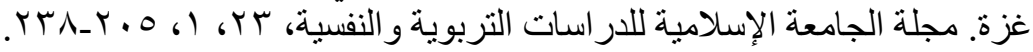

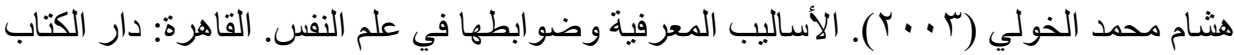
الحديث

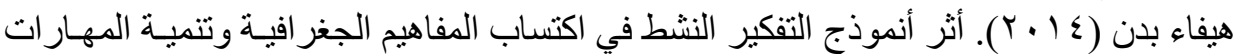

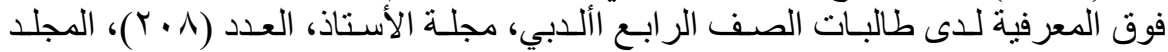
الثاني.

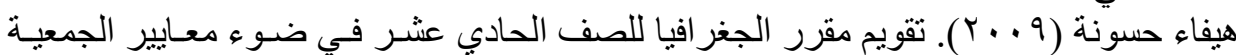

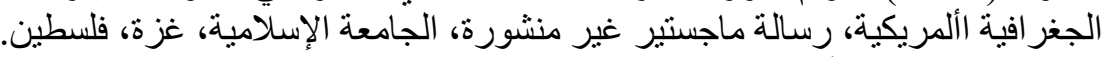

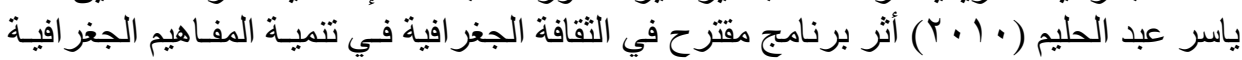

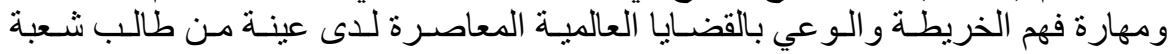

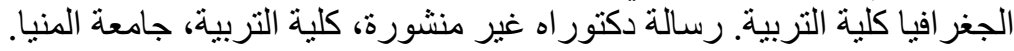

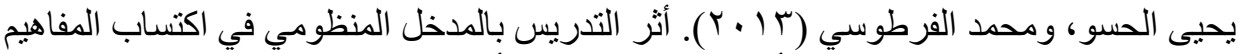

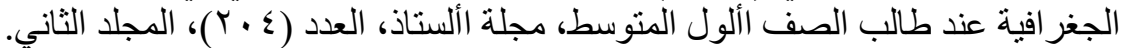

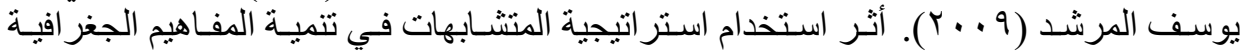

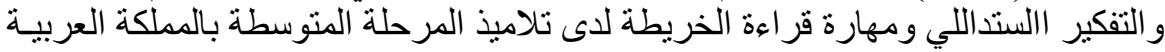

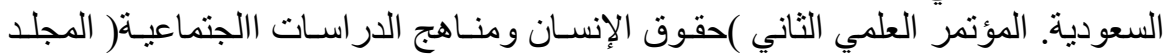

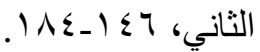

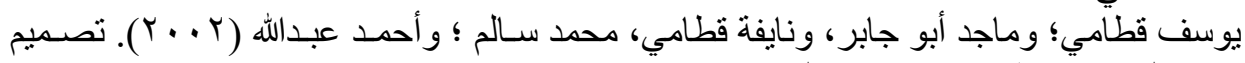
التدريس، طبك، عمان: دار الفكر. (• (1). 


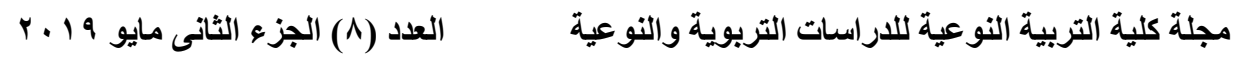

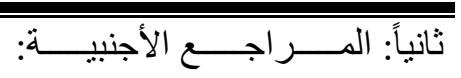

Abdellatif, H., Cummings, R. and Maddux, C.(2006 Factors affecting ) the development of analogical reasoning in young children: a review of literature .University of Nevada at Reno Education, 129 (2):pp 239-249.

Adapted from Adler, C.R. (Ed).( 2001). Put Reading First: The Research Building Blocks for Teaching Children to Read, pp. 49-54. National Institute for Literacy. Retrieved Nov. 1, 2007, fromhttp://www.nifl.gov/partnershipforreading/publications/reading_firs t1 text.html

Adjorlu, Hussain, Modekjaer \& Austed.(2018).Head-Mounted DisplayBased Virtual Reality Social Story as a Tool to teach Social Skills, Copenhagen, Aalborg University, PP.1-20.

Al Husseiny, F.I. (2014). Enhancing Critical Thinking through Cooperative Learning in Biology. Lebanese University, LB.

Allen, C.G.(2011). The effects of visual complexity on cognitive load as influenced by field dependency and spatial ability. A doctoral dissertation, New York University.

Atomatofa, R. (2013). Effects of advanced organizers on attainment and retention of students' concept of gravity in Nigeria, International Journal of Research Studies in Educational Technology, 2(1), 8190.

Ausubel, D. P. (2000). The Acquisition and Retention of Knowledge: A Cognitive View. Boston: Kluwer Academic Publishers. doi:10.1007/978-94-015-9454-7

Bayrak, B.K. (2013). Using Two-Tier Test to Identify Primary Students' Conceptual Understanding and Alternative Conceptions in Acid Base. Mevlana International Journal of Education, 3(2), 19-26.

Blake, A.(2004). Helping young children to see what is relevant and why: supporting cognitive change in earth science using analogy. International Journal of Science Education, 26 (15): 1855-1873.

Buchanan, E. (2015). Using graphic organizers to enhance students' science vocabulary and comprehension of nonfiction science text.Dissertation Abstracts International, 77 (6), 179 -190. 


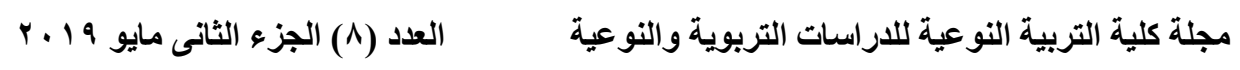

Carten, cood, dictionary of education, Mc Graw hill book company, Inc, New York, 1973, p; 124.

Chantelle, D. (2012).Ehancing learning through the use of graphic organizers to teach science to grade eleven students in Jamaica. Dissertations Publishing.

Chen, W., You, M. 2001. Internet mediated design course: the construction of the Internet to assist design course, Design Research, 2: 109-115.

Chen, B. (2007). Effects Of Advance Organizers On Learning And Retention From A Fully Web-Based Class, Unpublished Ph.D. disseration, University of Central Florida, FL.

Clark, A. (2004). E- Learning Skills. New York: Plagrave Macmilan.-

Cleveland, L. (2014). The effect of graphic organizers on students' attitudes and academic performance in undergraduate general biology. University of Northen Colorado.

Conceição-Runlee, S. \& Daley, B. (2003). Constructivist Learning Theory to Web-Based Course Design: an Instructional Design Approach. Retrieved Oct. 7, 2012, from: http://www.bsu.edu/teachers/ departments/edld/conf /constructionism.html

Dexter,DD., Park, Y.J. \&Hughes, C.A.(2011). A Meta-analytic review of graphic organizers and science instruction for adolescents with learning disabilities:Implications for the intermediate and secondary science classroom. Learning Disabilities Reasearch \& Practice, 26(4), 204-213.

Diamond, R.M (2000). Designing Assessing Courses Curricula .San Francisco, Jessey. Bass Publish hers.

Diana, T (2003). Online learning programs using mind-mapping techniques at Ninewells Medical Training \& Management Development Methods.

Elgazzar, A. (2014). Developing E-Learning Environments for Field Practitioners and Developmental Researchers: A Third Revision of an Isd Model to Meet E-Learning and Distance Learning Innovations. Open Journal Of Social Sciences. Vol. 2. Pp. 29-37.

Essik, A. (2008). Learning Styles and E-Learning, Master Thesis, Tampere University of Technology. 


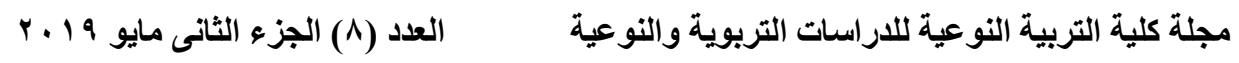

Fleming N. D. \& Bonwell C. C.(2002)."How to I learn best: A students guide instruction, Journal to psychology in school, 152-189. (2). (1).

Frazier, Cherly A. and Boehm, Richard G. (2012). Using Technology for Geography Teacher Education: Web-based Professional Development, Review of International Geography Education Online (C) RIGEO, Vol. 2, No. 1, March.

Fuad, N. Zubaidah, S. Mahanal, S. Suarsini, E. (2017). Improving Junior High Schools' Critical Thinking Skills Based on Test Three Different Models of Learning. International Journal of Instruction, 10(1), 101-116.

Furner, J. M., Yahya, N., \& Duffy, M. L. (2005). Teach mathematics: Strategies to reach all students. Intervention in school and clinic, 41(1), 16-23

Gallavan,Nancy\&Kottler,Ellen.(2010) .Visualizing the life and Legacy of Henry Vill:guiding Students with Eight Types of Graphic organizer" ,SOCIAL Studies, V101 n3 p93 May-June (E1881883)

Graf, S., Kinshuk, \& Liu, T.-C. (2009). Supporting Teachers In Identifying Students' Learning Styles In Learning Management Systems: An Automatic Student Modelling Approach. Educational Technology \& Society. Vol 12. No 4.pp 3-14.

Geraldi \& Kevin.(2008).Planned Programming Pays Dividends. Journal Articles; Opinion Papers; Reports,95(2),PP.75-79.

Goss, P. A. (2009). The influence of graphic organizers on students' ability to summarize and comprehend science content regarding the Earth's changing surface. University of Central Florida.

Honey \& Mumford. A.(2000)."The 23 learning styles helper's guide". Maidenhead, Berkshire, UK: Peter Honey publication limited.

Hu,Ml.\&Wu,M.H(2012): "The effect of concept mapping on student's cognitive load", World Transaction on Engineering and Technology Education, Vol. 10, No. 2, P.134-137.

John p. Dececco, The psychology of leavning and instruction: educational psychology, prentice - hall Inc, Englewood cliffs. New Jersey, 1968, p: 388. 


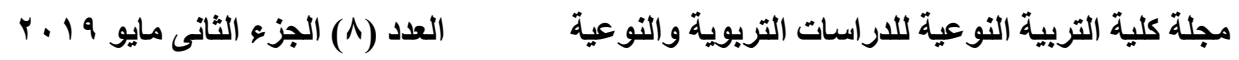

Jonassen, D. H. 2002. Designing constructivist leaning environment, available from: http:// www. coe. missouri.edu/ jonassen/ courses/ CLE.

Joyce, B. R., Weil, M., \& Calhoun, E. (2000). Models of teaching (6th ed.). Boston: Allyn and Bacon. Retrieved from https://www.amazon.com/Models-Teaching-6th-

BruceJoyce/dp/020531038

Kinshuk, T. (2004). Application of Learning Styles Adaptively In Mobil Learning Environments, Third Pan Commonwealth Forum on Open Learning.

Kommers, P., Stoyanov, S., Mileva, N. \& Martínezmediano, K. (2008). The Effect of Adaptive Performance Support System on Learning Achievements of Students. International Journal of Continuing Engineering Education and Lifelong Learning. Vol 18. No 3.pp 351365.

Kools, Marieke; Van De Wiel, Margaretha W. J; Ruiter, Robert A. C; Cruts. Anica \& KOK. Gerjo .(2006). The Effect of Graphic organizers on Subjecttive and Objective Comprehension of aHealth Text "Health Education \& Behavior, v33 n6 p760-772, (EJ813676)

Kowshik, M.C. (2015). A Study on the Relative Effectiveness between Advance Organizer Model and Traditional Method of Teaching in Biology, International Journal for Infonomics, 8(2), 1097-1101.

Lehman, M. E. (2011). Relationships of learning styles, grades, and instructional preferences, NACTA Journal, 55( 2), 40-45

Lewis, B. (2008). David Ausubel's "Advance Organizer" Available; http; //www.coe.ufl.edu /webtech /Greatldeas /pages /peoplepage /a usabel.htm.

Lupshenyuk, D. (2010). What is Web 2.0 Video? Pedagogical Strategy forInfusing Web 2.0 Video in Student Learning. In J. Herrington \& C. Montgomerie (Eds.), Proceedings of EdMedia: World Conference on Educational Media and Technology 2010 (pp. 1369-1373). Association for the Advancement of Computing in Education (AACE).

Magoulas, G., Chen, S., Papanikolaou, K. (2003). Integrating layered and heuristic evaluation for adaptive learning environments. In: 


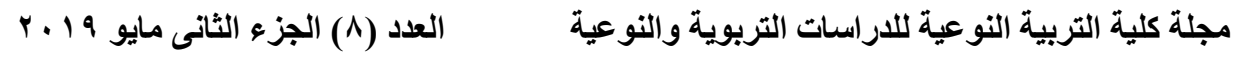

Weibelzahl, S. And Paramythis, A. (Eds.). Proceedings Of The Second Workshop On Empirical Evaluation Of Adaptive Systems, Held At The 9th International Conference On User Modeling Um2003, Pittsburgh, pp. 5-14.

Mary, Arth, A.(2002):Teacher questioning in the elementary mathematics class room :Engaging students in an on -task dialogue. Doctoral Dissertation, University of Wyoming.

Mayer, R . (2003). Learning and Instruction, NJ.

Mayer, R. E., \& Alexander, P. A. (2010). hanbook of research on learning and instruction. england: Routledge.

Mc-Daniel, S. C., \& Flower, A. (2015). Use of a behavioral graphic organizer to reduce disruptive behavior. Education and Treatment of Children, 38(4), 505- 522.

Modritscher, F. (2006). E-Learning theories in practice: a comparison of three methods. Journal of Universal Science and Technology of Learning.5(4), 3- 18.

Muiruri, M. Wambugu, P. Wamukuru, K. (2016). Using Advance Organizers to Enhance Pupils' Achievement in Learning Poetry in English Language, Journal of Education \& Practice, 7(31), 113-117.

Nesbit, J., Belfer, K., \& Vargo, J. (2002). A Convergent Participation Model for Evaluation of Learning Objects. Canadian Journal of Learning and Technology, 38(3), 1-28. Retrieved from https://www.cjlt.ca/index.php/cjlt/article/view/26569/19751

Nor, B. \& Siti, M. (2006). Modeling Learning Styles Based On The Student Behavior In Hypermedia Learning System Using Neural Network. Proceedings of the Postgraduate Annual Research Seminar 2006.

Paik, Susan J, Ten Strategies That Improve Learning.( 2003). educational HORIZONS, (www.pilambda.oragnorizons/v81 2/paik.pdf).

Park \& Chai(2017).Virtual Reality Training System for Live-Line, International Journal of Human-Computer Interaction, Vol.20(3), PP .285-303.

Pedro, P. \& Pilar, R. (2004). A Mixed Approach to Modelling Learning Styles in Adaptive Educational Hypermedia. Proceedings Of The Iasted International Conference Web- Based Education. Austria 


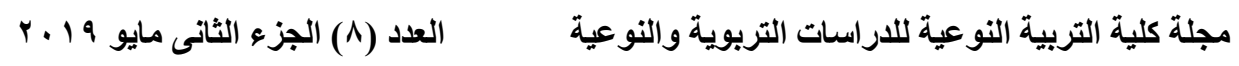

Perez, W. (2011). Integration of Instructional design Principle's to online courses and faculty training in three Puerto Rican institution of higher education . Doctoral Dissertation, capella University. Pro Quest Dissertation and theses.

Piskurich, G. (2010.net). Rapid instructional design

Powell G. (2001). The ABCs of Online Course Design. Educational Technology, 41(4), 43-47.

Puzziferro, M. \& Shelton, K. (2008). A Model for developing highquality online courses: Integrating a systems approach with learning theory. Journal of Asynchronous Learning Networks, 12(3-4), 119-136.

Reigeluth, C.M. (2000). The elaboration theory: Guidance for scope and sequence decisions. In C.M. Reigeluth (Ed.), Instructional-Design Theories and Models: A New Paradigm of Instructional Theory. (Volume II). Hillsdale, N.T: Lawrence Erlbaum Assoc.

Rock, Marcia L,.( 2004).“Graphic organizers: Tools to build behavioral literacy and foster emotional competency, intervention in school and clinic, v40, n1, p10-37 sep. (E693695)

Richard, S. (2002). Web - Based Distance Education: Pedagogy, Epistemology, and Instructional Design. University Of Saskatchewan.

Rihards, Hoffman \& Sharar .(2016).Virtual Environment Display Quality, Australia, University of Newastle, PP.1-30.

Ropič, M., \& Aberšek, M. (2012). Web graphic organizers as an advanced strategy for teaching science textbook reading comprehension. Problems of Education in the 21st Century, 45, 87-99

Ruffini, M. (2000). Systematic Planning in the Design of an Educational Web Site. Educational Technology, 40(2) ،58-64.

Sharma, A. Pachauri, D. (2016). Comparison of Advance Organizer Model and Concept Attainment Model for Teaching Concepts of Science to Slandered IX. International Journal of Educational Research and Technology, 7(1), 23-26 .

Shihusa, H., \& Keraro, F. N. (2009). Using Advance Organizers to Enhance Students' Motivation in Learning Biology. EURASIA Journal of Mathematics, Science \& Technology Education, 5(4), 413420. Retrieved from https://eric.ed.gov/?id=EJ905690 


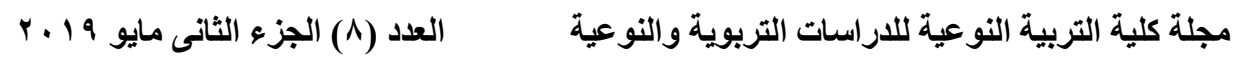

Singleton, S. \& Filce,H (2015).Graphic organizers for secondary students with learning disabilites. Teaching Exceptional Children, 48( 2), $110-117$.

Smith,j .(2002), the use of graphic organizers in vocabulary instruction,ERIC No. ED463556.

Smith(2015).Immersive Virtual Environment Technology to Supplement Environmental Perception, Preference and Beavior Research, A Review with Appliations, International Journal of Environmental Research and Public Health, Vol.12(9), PP.11486-11505.

Stuart, K.(2011). Gestalt principles in the control of motor action . Journal Articles; Opinion Papers, 137(3), PP.443-462.

Surjono, H. (2007). Empirical Evaluation of an Adaptive E-Learning System and the Effects of Knowledge, Learning Styles and Multimedia Mode on Student Achievement. In Proceeding of the Uitm International Conference on ELearning (Uicel). Universities knologi Mara, Shah Alam, Malaysia 12 - 14 December.

Sweller, J. (2003). Evolution of human cognitive architecture. The psychology of learning and motivation, 43, 215-266.

Taber \& Susan . (2009). Capitalizing on the Unexpected . Journal Articles; Reports - Descriptive , 15(3) , pp.155-148.

Technology Education conference and workshop (2003). Orlando, Fl. December (11-14) available at http://acctoline.org/about/ division/dir.tech.work.

Technology Education conferences and workshope (2002).asvegas, NV. December (12-15) available at http://www.acteoline -org/about division/dir-tech-work). 22/5/2012.

Tseng, Ch. Wang, W. Lin, Y. Hung, P. (2002). Effects of Computerized Advanced Organizers on Elementary School Mathematics Learning, paper presented at the International Conference On Computers In Education (ICCE’02)

UzZaman, T. Choudhary, F.R. Qamar, A.M. (2015). Advance Organizers Help to Enhance Learning and Retention. International Journal of Humanities Social Sciences and Education, 2(3), 45-53. 


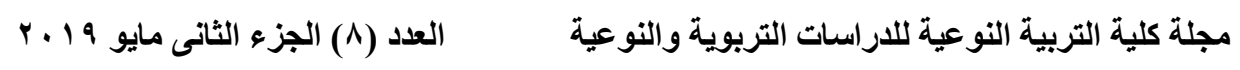

Vitharana, P.R . (2015). Students Misconceptions about plant transport- a Sri Lankan example, European Journal of Science and Mathematics Education, 3(3), 275-288.

Walberg, Herbert J., Paik,Susan, (2000). Effective educational practices, Educational Practices Series, no 3, unesco

Wann, Krueger \& Slater.(2018).Methodologies and Technologies for Designing Virtual Environment, Army Researh Institute for the Behavioural and Social Sciences, PP.44-69

Widyarto \& Shafie.(2016).Virtual Environment for Training and Tour Purposes, Malay Sia, Technology University, PP.1-52

William cood win and Herbert, J Klausmeier faciliting.(2004). student learning an intvoduction to educational psychology, Harper and row pulishers.

William, C. (2015). A correlational study of graphic organizers and science achievement of English language learners. ProQuest Dissertations Publishing.

Yasmín, H. \& Guillermo, R. (2011). Learning Styles Theory For Intelligent Learning Environments - Adapting The Instruction, In Proceeding Of: Csedu 2011 - Proceedings Of The 3rd International Conference On Computer Supported Education. Vol 1. Noordwijkerhout. Netherlands, 6-8 May.

Zampetakis, A. \& Tsironis, L. (2007). Creativity development in engineering education:the case of mind mapping, journal of Management Development 26(4), pp.370-380.

Zhang, Nunamaker.c. (2006). Instructional video in e-learning; Assessing the impact of, Journal of Information \& Management, (43) 15-27.

Zolman, Alan .(2009). "Mathematical Graphic organizers", Teaching children mathematics, v16, n4, p222-230, Nov. (E862804). 